\title{
Vasculogenic mimicry in malignant tumors : tumor cells in disguise
}

Citation for published version (APA):

Paulis, Y. W. J. (2013). Vasculogenic mimicry in malignant tumors : tumor cells in disguise. [Doctoral Thesis, Maastricht University]. Maastricht University. https://doi.org/10.26481/dis.20130426yp

Document status and date:

Published: 01/01/2013

DOI:

10.26481/dis.20130426yp

Document Version:

Publisher's PDF, also known as Version of record

\section{Please check the document version of this publication:}

- A submitted manuscript is the version of the article upon submission and before peer-review. There can be important differences between the submitted version and the official published version of record.

People interested in the research are advised to contact the author for the final version of the publication, or visit the DOI to the publisher's website.

- The final author version and the galley proof are versions of the publication after peer review.

- The final published version features the final layout of the paper including the volume, issue and page numbers.

Link to publication

\footnotetext{
General rights rights.

- You may freely distribute the URL identifying the publication in the public portal. please follow below link for the End User Agreement:

www.umlib.nl/taverne-license

Take down policy

If you believe that this document breaches copyright please contact us at:

repository@maastrichtuniversity.nl

providing details and we will investigate your claim.
}

Copyright and moral rights for the publications made accessible in the public portal are retained by the authors and/or other copyright owners and it is a condition of accessing publications that users recognise and abide by the legal requirements associated with these

- Users may download and print one copy of any publication from the public portal for the purpose of private study or research.

- You may not further distribute the material or use it for any profit-making activity or commercial gain

If the publication is distributed under the terms of Article $25 \mathrm{fa}$ of the Dutch Copyright Act, indicated by the "Taverne" license above, 


\section{Vasculogenic mimicry in malignant tumors}

Tumor cells in disguise 
(C) Copyright Yvette Paulis, Maastricht 2013

The research described in this thesis was funded by the Maastricht University Medical Center Profileringsfonds and by the department of Medical Oncology of the Maastricht UMC+.

ISBN: 978-94-6191-657-0

Layout: Tiny Wouters

Printed by: Ipskamp Drukkers, the Netherlands

Financial support by Amgen BV, Becton Dickinson BV, GlaxoSmithKline BV, Greiner BioOne BV, MSD BV, Novartis Oncology, Pfizer Oncology, and Roche Nederland BV for the publication of this thesis is gratefully acknowledged. 


\title{
Vasculogenic mimicry in malignant tumors
}

\section{Tumor cells in disguise}

\author{
PROEFSCHRIFT
}

ter verkrijging van de graad van doctor

aan de Universiteit Maastricht,

op gezag van de Rector Magnificus, Prof. dr. L.L.G. Soete

volgens het besluit van het College van Decanen,

in het openbaar te verdedigen

op vrijdag 26 april 2013 om 10.00 uur

door

Yvette Wilhelmina Joanna Paulis 


\section{Promotores}

Prof. dr. V.C.G. Tjan-Heijnen

Prof. dr. A.W. Griffioen (VU medisch centrum)

\section{Copromotor}

Dr. P.M.M.B. Soetekouw

\section{Beoordelingscommissie}

Prof. dr. A. zur Hausen (voorzitter)

Prof. dr. E. Boven (VU medisch centrum)

Prof. dr. M.A.G.G. Vooijs 


\section{Contents}

$\begin{array}{lll}\text { Chapter } 1 & \text { General introduction } & 7\end{array}$

Chapter 2 Aim and outline of the thesis 25

Chapter $3 \quad$ Signaling pathways in vasculogenic mimicry 29

Chapter $4 \quad$ Imatinib reduces the vasculogenic potential of plastic 57 tumor cells

Chapter $5 \quad$ Intratumoral perivascular cell invasion predicts increased 75 aggressiveness by tumor cell plasticity

Chapter $6 \quad$ CD44 enhances tumor aggressiveness by promoting 99 tumor cell plasticity

$\begin{array}{lll}\text { Chapter } 7 & \text { General discussion and future perspectives } & 119\end{array}$

$\begin{array}{ll}\text { Summary } & 133\end{array}$

$\begin{array}{ll}\text { Samenvatting } & 137\end{array}$

$\begin{array}{ll}\text { Dankwoord } & 141\end{array}$

$\begin{array}{ll}\text { Curriculum Vitae } & 147\end{array}$ 



\section{Chapter 1}

General introduction 


\section{Introduction}

Oxygen and nutrients are of critical importance for living cells within the human body. These components are required for proper cell function and growth. Although tumor cells can hardly be classified as proper functioning cells, they also depend on oxygen and nutrient supply by nearby blood vessels to grow. Consequently, when the tumor volume increases, the oxygen diffusion capacity becomes insufficient, which brings tumor progression to a halt. In order to overcome this growth-limiting step, tumor cells switch to an angiogenic phenotype and stimulate nearby blood vessels to sprout towards them, a process called tumor angiogenesis.

Over the years, inhibition of tumor angiogenesis as anticancer therapy has gained a lot of attention ${ }^{1,2}$. The rational behind this treatment strategy is that tumor growth can be stabilized and progression inhibited when the outgrowth of new blood vessels towards the tumor is prevented. Though the initial results were promising, antiangiogenesis treatment has not been able to improve the lifespan of patients with more than a few months. This suggests that tumors have mechanisms to evade the effects of angiogenesis inhibition. Indeed, several modes of resistance to antiangiogenesis treatment have been described. Among these are alternative routes for tumor vascularization, like the formation of tubular structures by tumor cells themselves, a process called vasculogenic mimicry. The term vasculogenic mimicry refers to the process by which aggressive tumor cells acquire the capacity to transdifferentiate and adopt an endothelial-like phenotype. Like normal endothelial cells, these plastic tumor cells are able to form vasculogenic networks, which are speculated to contribute to circulation. By their ability to mimic endothelial cells, tumor cells are proposed to acquire a secondary vascularization mechanism, making them independent of normal blood vessel development.

\section{Blood vessel development}

Blood vessels form a highly organized and complex structure. By regulating the blood flow throughout the body, blood vessels are important for providing tissues with oxygen and nutrients and for an efficient removal of waste products. Due to the limited diffusion capacity of oxygen, cells must be in close proximity of vessels to ensure proper oxygen supply. Therefore, the formation of new blood vessels is critical during tissue growth.

Vascular endothelial cells line the luminal surface of blood vessels. These cells function as a barrier between the bloodstream and tissues. During embryonic development, the vascular system is the first organ system to develop. The formation of the embryonic vasculature is initiated by the appearance of blood islands, which are formed by a close association of endothelial progenitor cells, known as 
angioblasts, and hematopoietic precursor cells ${ }^{3}$. To indicate the close relationship between blood cell precursors and endothelial cell precursors, these islands are also referred to as hemangioblasts. Within the blood islands, the hematopoietic cells are found at the center, while the angioblasts are located at the periphery. Angioblasts differentiate towards an endothelial phenotype and assemble into de novo endothelial-lined tubular structures ${ }^{4-6}$. These structures then form the basis for the circulation system. The process by which embryonic vascular structures are formed is called vasculogenesis. Subsequently, the vascular system can be expanded by the formation of novel blood vessels through angiogenesis ${ }^{7}$. This process is defined as the formation of novel blood vessels by active endothelial sprouting from pre-existing vessels. During angiogenesis, endothelial cells migrate and proliferate in response to various stimuli, assembling into tubes containing tight cell-to-cell junctions characteristic of endothelium.

Vascular structures formed by endothelial cells alone are referred to as immature blood vessels, which are leaky and highly instable. Mature blood vessels are composed of two distinct cell types namely endothelial cells and perivascular cells (pericytes or vascular smooth muscle cells) ${ }^{8}$. Whereas endothelial cells form the inner lining of the blood vessel, perivascular cells associate to the endothelial cells and encircle the endothelial cell tube. Both cell types communicate by direct physical contact through a jointly synthesized basement membrane ${ }^{9,10}$. The association of perivascular cells to a developing blood vessel contributes to its stabilization and to homeostatic regulation of the mature blood vesse ${ }^{11}$. Perivascular cells also contribute to the persistence of flow due to their contractile properties ${ }^{12}$ and they secrete endothelial survival factors thereby keeping endothelial cells in a non-proliferative, quiescent state ${ }^{13}$. As these cells coat the endothelial tube, perivascular cells have an important function in guarding cell transit across the vascular wall.

Specific signaling pathways activated by endothelial cells are implicated in perivascular cell differentiation, recruitment, and their attachment to endothelial cells ${ }^{14,15}$. Platelet-derived growth factor-B (PDGF-B), the main factor for vessel maturation, is secreted as a homodimer from the endothelium of the angiogenic sprout. Its expression stimulates proliferation of vascular smooth muscle cells and induces perivascular cell differentiation in undifferentiated mesenchymal cells ${ }^{16-18}$. Absence of PDGF-B results in perivascular cell deficiency, which causes vessel leakage, tortuosity, microaneurysm formation, severe bleeding and perinatal lethality ${ }^{19}$.

Within the healthy human body, blood vessel formation through angiogenesis is highly balanced by the presence of both positive and negative angiogenesis stimuli. By these means, angiogenesis is suppressed in normal blood vessels by endogenous angiogenesis inhibitors, causing endothelial cells to remain in a non-proliferative, quiescent, state. This angiostatic balance may be shifted towards a pro-angiogenic response during physiological processes like embryogenesis, tissue repair or wound healing, and during the female reproductive cycle $^{20}$. These are all examples of 
physiological angiogenesis. On the other hand, angiogenesis is also well recognized for its impact in pathological conditions such as arthritis, diabetes mellitus, and cancer ${ }^{21}$.

\section{Tumor vascularization}

\section{Tumor angiogenesis}

Like most cells in the human body, tumor cells require oxygen and nutrients for proper cell function and growth. When the tumor volume exceeds $1-2 \mathrm{~mm}^{3}$ in size, the oxygen diffusion capacity becomes insufficient and the tumor cells become hypoxic. The lack of oxygen and nutrient supply puts tumor progression to a stop. In order to overcome this growth-limiting step, hypoxic tumor cells can switch to an angiogenic phenotype and stimulate nearby blood vessels to grow towards them, a process called tumor angiogenesis (Figure 1.1) . $^{22}$. Although angiogenesis is a critical event for primary tumor growth, it is also involved in metastasis formation and further outgrowth of metastases ${ }^{23}$.

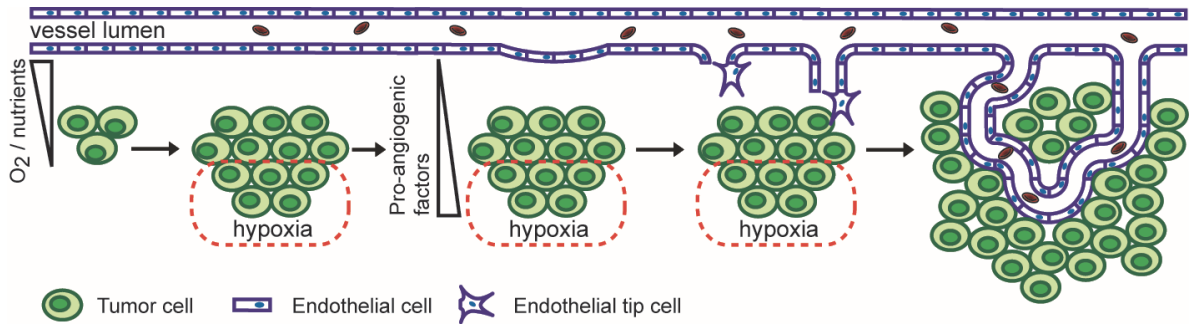

Figure 1.1 Tumor angiogenesis. As the oxygen diffusion capacity is limited, continuous tumor growth results in the presence of hypoxic tumor areas (red-dotted circle). Hypoxic tumor cells produce and release angiogenic growth factors that diffuse into the tissue and activate the nearby blood vessels. Activated endothelial cells subsequently produce factors to degrade the extracellular matrix. One endothelial cell, called the tip cell, is selected to guide the tube formation. Endothelial cells following the tip cell form an endothelial sprout by proliferation and migration. Finally, a lumen is formed to enable blood flow. Extracellular matrix deposition and perivascular cell recruitment stabilize the new blood vessel. The formation of new blood vessels within a tumor mass allows tumor cells to continue their growth.

The most frequently described pro-angiogenic factors secreted by tumor cells are vascular endothelial growth factor-A (VEGF-A) ${ }^{24}$ and basic fibroblast growth factor $(\mathrm{bFGF})^{25}$. The binding of pro-angiogenic proteins to their receptors on endothelial cells promotes tumor angiogenesis via a series of processes. First, perivascular cells detach from the vessel wall. To allow endothelial cells to migrate towards the hypoxic tumor region, matrix metalloproteinases (MMPs) are activated to degrade the basement membrane surrounding the pre-existing blood vessel and the extracellular matrix. 
Next, an endothelial sprout is formed by endothelial cell proliferation, migration and invasion of the degraded matrix. To prevent massive endothelial movement towards the angiogenic signal, one endothelial cell is selected to lead the tip. The adjacent endothelial cells assume positions as stalk cells, which divide to elongate the angiogenic sprout. An immature blood vessel is formed by the polarization of the migrating endothelial cells to form a lumen and an abluminal surface ${ }^{26}$. The recruitment of perivascular cells and the generation of extracellular matrix subsequently stabilize immature blood vessels. Although angiogenesis is tightly balanced during physiological angiogenesis, tumor angiogenesis is characterized by continuous angiogenic stimulation. This causes the tumor vasculature to be disorganized and abnormal.

\section{Tumor vessel characteristics}

As mentioned before, pathological angiogenesis is different from physiological angiogenesis. Although the principle of new blood vessel formation is similar, the resulting vascular system is often distinct from that of normal tissues. Comparison of tumor vessels with vessels formed after trauma, i.e. physiological angiogenesis, revealed some clear differences.

The tumor vasculature is characterized by a disorganized nature, structure, and function ${ }^{27-29}$. Tumor vessels are heterogeneous, tortuous, branch chaotically, and have an uneven vessel lumen. Tumor cells themselves have been identified as part of the vessel wall, in cooperation with endothelial cells. Such vessels are referred to as 'mosaic vessels' ${ }^{30}$. In addition to the endothelial abnormalities, perivascular cells and the basement membrane are also atypical. Importantly, tumor vessels are characterized by an increased permeability and are therefore often referred to as 'leaky vessels'. Due to this leakiness, escaping fluid increases the interstitial fluid pressure within the tumor. As a result, blood flow is heterogeneous, and oxygen, nutrients, immune cells, and drugs are unevenly distributed throughout the tumor. The abnormalities in tumor vessels create a hostile microenvironment characterized by hypoxia, acidity, and high fluid pressure. These factors select for more malignant tumor cells with the capacity to survive. Furthermore, the defective barrier functions of the tumor vessels facilitate the intravasation, and therefore metastasis, of tumor cells. Since both radiotherapy and chemotherapy are highly dependent on proper tissue perfusion for their mode of action, the presence of tumor hypoxia reduces the efficacy of these treatment strategies.

\section{Tumor hypoxia and - progression}

Due to their abnormal structure, tumor vessels function poorly as they are incapable of delivering sufficient oxygen and nutrients to support the growing tumor mass ${ }^{31}$. As the available oxygen is consumed rapidly by proliferating tumor cells within 70 to $150 \mu \mathrm{m}$ of the tumor vasculature, the amount of oxygen available to diffuse further into the tumor is limited. This causes the majority of solid tumors to be characterized 
by fluctuations in oxygen tension, thereby creating poorly oxygenated (hypoxic) tumor regions (ranging from $<1 \%$ to $>50 \%$ of the tumor volume). Within these hypoxic areas, the oxygen tension is less than $10 \mathrm{mmHg}$, being equivalent to $1.3 \% \mathrm{O}_{2}$ in vitro ${ }^{32}$.

Although poor tumor oxygenation would suggest poor tumor growth, tumor hypoxia is associated with a poor clinical outcome. This is partly due to the fact that the efficacy of tumor irradiation and cytotoxic drugs depends on an adequate tissue perfusion. In addition, hypoxic tumor cells promote tumor progression and metastasis through a variety of direct and indirect mechanisms. Patients with primary tumors containing high proportions of hypoxic cells have been shown to have decreased overall survival rates due to increased development of metastatic disease ${ }^{33,34}$. The close association between tumor hypoxia and tumor cell metastasis suggests that hypoxia promotes a more aggressive and metastatic tumor phenotype.

In conditions of low oxygen, tumor cells activate hypoxia-induced responses that are aimed at cellular adaptation in a hostile environment and thus allow survival. Cellular adaptation is due to alterations in gene expression. The best-described cellular hypoxic response is mediated through the transcriptional activity of the heterodimeric transcription factors hypoxia-inducible factor (HIF)-1 and HIF-2. These key transcriptional regulators promote hypoxic tolerance by activating genes involved in glycolysis and angiogenesis ${ }^{35,36}$. Importantly, the expression of HIF-1 and HIF-2 also promotes tumor cell transitions towards a more malignant phenotype by inducing the expression of genes implicated in increased cell motility and invasion ${ }^{37-41}$. These changes facilitate the metastasis of malignant tumor cells to distant sites where oxygen supplies are sufficient for continuous growth.

In addition to cells adapting to hypoxia, there is also a subpopulation of cells that actually depend on a hypoxic microenvironment. Hypoxia has been shown to be critical for the maintenance of undifferentiated states in embryonic, hematopoietic, mesenchymal, and neural stem cell phenotypes and also to influence cell-fate commitment $^{42}$. Stem cells hold the ability to self-renew while maintaining their multipotency. Research has identified the existence of a subset of tumor-initiating cells called cancer stem cells (CSCs). CSCs are stem-like tumor cells displaying a high degree of dedifferentiation and expressing various stem cell markers such as CD133 and $\mathrm{CD} 44^{43,44}$. As CSCs are able to initiate tumor growth at distant sites, unlike 'normal' tumor cells, these stem-like tumor cells are thought of as extremely malignant. As is the case for normal stem cells, CSCs are assumed to prefer a hypoxic niche. Thus, it appears that the presence of hypoxia selects for the most malignant tumor cells with the capacity to re-establish tumor growth. This hypothesis questions the clinical benefits of angiogenesis inhibitors. Indeed, it has been shown that although angiogenesis inhibition results in reduced tumor growth, it may increase the rate of distant metastasis at the same time ${ }^{45,46}$. 


\section{Anti-angiogenesis treatment and resistance}

In 1971, Judah Folkman introduced the concept of tumor angiogenesis inhibition. He proposed that as tumor cells rely heavily on a constant growth of novel blood vessels, the repression of this process would halt tumor growth and inhibit progression resulting in a dormant state ${ }^{47}$. By restoring the balance between pro- and antiangiogenesis factors, the tumor vasculature may be normalized ${ }^{48}$. In the past two decades, various angiogenesis inhibitors have been developed, and several have shown to be effective in inhibiting tumor growth in vivo. However, results of early clinical trials with these inhibitors have not paralleled the success achieved in animal models.

The most notable angiogenesis inhibitors target the VEGF signaling pathway. VEGF-A, a major mediator of tumor angiogenesis, exerts its signal by binding to VEGFR-2 that is expressed by endothelial cells. This signaling cascade results in endothelial cell proliferation and migration. In 2005, bevacizumab (Avastin ${ }^{\circledR}$, Genentech/Roche) was the first US Food and Drug Administration (FDA) approved angiostatic drug. This monoclonal antibody binds VEGF-A, thereby preventing the interaction with its receptor and thus endothelial sprouting ${ }^{24,49}$. Subsequently, the FDA approved the clinical use of the small-molecule tyrosine kinases sorafenib (BAY43-9006, Nexavar ${ }^{\circledR}$, Bayer $^{50}$ and sunitinib (SU11248, Sutent ${ }^{\circledR}$, Pfizer) ${ }^{51}$. By targeting the ATP-binding site of the VEGFR-2, downstream signaling is hampered in response to VEGF-A binding ${ }^{52}$. The first developed tyrosine kinase inhibitors are called multi-targeted kinase inhibitors, as they are unable to inhibit the activity of one specific kinase. As multiple signaling cascades are affected by their presence, the risk for treatment-induced toxicity may increase ${ }^{53,54}$.

Although angiogenesis inhibitors showed promising results initially, these treatment strategies have so far not been able to prolong the lifespan of patients with more than a few months. The majority of patients show a transient benefit from antiangiogenesis treatment, before the tumor recovers and starts to regrow and metastasize. This demonstrates that the current treatment strategies, which are mainly aiming to target VEGF signaling, are not effective enough. Due to the broad targeting of tyrosine kinase inhibitors, it was expected that these drugs possess a broader clinical efficacy compared to a single-targeting inhibitor. However, as for single-targeting drugs, tumors have been shown to continue to grow and even progress during the course of tyrosine kinase inhibitor anti-angiogenesis treatment. This indicates that treatment-induced vascular normalization is only temporal and that tumors are able to become resistant during the treatment.

Since many different regulatory factors and signaling pathways are involved in angiogenesis, therapies targeting angiogenesis are quite susceptible for drug resistance. Two modes underlying anti-angiogenesis therapy resistance have been 
proposed: an adaptation to evade the angiogenic blockage and an intrinsic or preexisting indifference ${ }^{55}$. Adaptation resistance, or evasive resistance, is largely indirect. It implies that alternative ways to sustain tumor growth are activated, while the specific therapeutic target of the angiostatic compound remains inhibited ${ }^{56-58}$. Current evidence has suggested various mechanisms that contribute to adaptation resistance to anti-angiogenesis therapies. Among these is the induction or upregulation of alternative pro-angiogenic signaling pathways within the tumor ${ }^{59}$. For example, it has been suggested that the Notch-signaling may be involved in the resistance to antiVEGF treatment ${ }^{60}$. In addition, tumor cells can adapt to angiogenesis inhibition by the recruitment of bone marrow-derived pro-angiogenic cells that reinitiate or continue the angiogenesis ${ }^{61,62}$. Also, increased perivascular cell coverage of tumor blood vessels is proposed to protect these vessels against anti-angiogenesis treatment ${ }^{63,64}$. Perivascular cell-covered blood vessels may survive angiogenesis inhibition because these cells mediate endothelial cell quiescence, thereby rendering endothelial cells less responsive to angiostatic compounds. Another proposed adaptive resistance mechanism is the elimination of the requirement for tumor neovascularization. Through the activation and enhancement of tumor cell invasion and metastasis tumor cells gain access to the normal vasculature ${ }^{65,66}$. This abolishes the need for tumor angiogenesis. In addition, a novel resistance mechanism was identified recently. Besides its anti-angiogenic effects, sunitinib also inhibits tumor cell proliferation. Sunitinib-resistant tumor cells were shown to sequester sunitinib from their cytoplasmic compartment into acidic lysosomes. This increased lysosomal capacity contributed to a decreased growth inhibitory effect of this tyrosine kinase inhibitor ${ }^{67}$.

The second mode of resistance, i.e. intrinsic resistance, is less well defined. It implies that tumor cells may already have activated evasive resistance mechanisms prior to treatment. These resistance mechanisms are most likely the result of selective pressure from the microenvironment during tumor development and malignant progression $^{55}$. It is well known that the cells within a cancerous growth hold a high degree of cellular heterogeneity. This diversity causes tumor cell sensitivity towards a given treatment to be variable. Intrinsic resistance has been proposed to include preexisting diversity of redundant pro-angiogenic signals, which enables continuous tumor growth when one of the signals is inhibited ${ }^{68}$. Also, it may result from preexisting inflammatory cell-mediated vascular protection by expression of proangiogenic factors. It was demonstrated that tumor responsiveness to anti-VEGF treatment was irreversibly correlated to the presence of inflammatory cells ${ }^{69}$. Furthermore, this form of resistance may be caused by tumor-characteristic hypovascularity. Some tumors are intrinsically poorly vascularized and thus adapted to survive and prosper in a harsh microenvironment ${ }^{70,71}$. Such conditions render these tumors intrinsically indifferent to angiogenesis inhibition. Also, intrinsic resistance may result from previously gained invasive and metastatic capacities early in their ontology and not as an adaptive response to treatment. These characteristics enable tumor cells to grow along quiescent normal blood vessels to sustain diffusive growth 
without evoking an angiogenic response ${ }^{72-74}$. This process, called vessel co-option, is often observed in highly vascularized tissue.

Importantly, tumor cells that have the ability to survive treatment will have a growth advantage over tumor cells that are responsive to treatment. As the resistant cells will expand and progress over time novel treatment strategies are required to eliminate these highly aggressive cells. Future drug discovery efforts aimed at increasing patient survival will not only have to consider the above mentioned modes of resistance, but also the plasticity of cancer cells. Tumor cell plasticity is associated with increased malignancy and includes phenomena like epithelial-to-mesenchymal transition, the emergence of cancer stem cells and vasculogenic mimicry. Although it remains to be elucidated whether tumor cell plasticity is an adaptive or an intrinsic response, its presence is related to poor treatment response.

\section{Vasculogenic mimicry}

The ability of solid tumors to induce and sustain blood vessel formation is considered as a hallmark of cancer. For years, tumor vasculature formation was considered to largely follow physiological neovascularization, with endothelial cell sprouting and proliferation being considered as the main routes to accomplish this. However, it has become accepted over the years that tumors may have unexpected mechanisms of neovascularization at their disposal ${ }^{75}$.

The term vasculogenic mimicry was introduced in 1999 to describe the unique ability of highly aggressive melanoma cells to adopt an endothelial-like phenotype and to form vasculogenic matrix-embedded tubular networks (Figure 1.2) ${ }^{76}$. In tissue sections from both cutaneous and uveal melanoma, patterned networks of interconnected loops of extracellular matrix were observed. The presence of these matrix networks, which can be identified by periodic acid-Schiff (PAS) staining, was correlated to poor clinical outcome ${ }^{77,78}$. Although these vasculogenic patterned networks contained erythrocytes, endothelial cells were not identified at the border of these tubular structures. Morphological characterization of the PAS loops demonstrated that these matrix networks were lined by tumor cells (Figure 1.3 , in vivo $)^{76,79}$. In vitro analysis of aggressive and poorly aggressive melanoma cell lines demonstrated the ability of the aggressive cell lines to form vasculogenic networks on both Matrigel and collagen matrix, while poorly aggressive melanoma cell lines lacked this capacity (Figure 1.3, in vitro $^{76,80}$. 
a

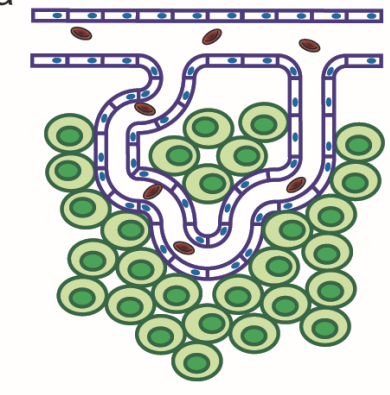

Tumor cell Endothelial cell b

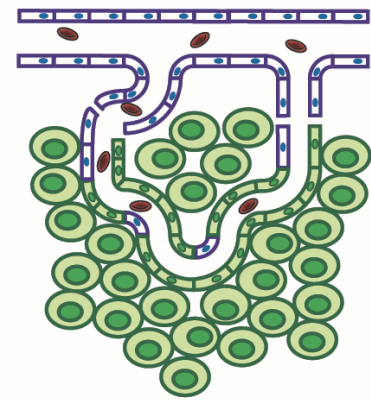

Transdifferentiated tumor cell

Figure 1.2 Tumor angiogenesis versus vasculogenic mimicry. (a) In response to tumor cell hypoxia, tumor angiogenesis is induced. This results in the formation of an endothelial cell-lined vasculature within a tumor mass. (b) Differentiation plasticity enables aggressive tumor cells to adopt endothelial characteristics. Vasculogenic mimicry is displayed by the presence of tumor cell-lined vascular structures. Vasculogenic tumor cells (green squares) mimic endothelial cells (blue-lined squares) and gain the ability to conduct blood components. Although it has been established that there is a physiological connection between the endothelial vasculature and vasculogenic mimicry channels, the precise method for their assembly is unknown (indicated by a gap). It is speculated that as the tumor remodels the vasculature, the blood vessels become leaky resulting in the extravasation of blood cells.

Microarray analysis of poorly aggressive melanoma cells and highly aggressive melanoma cells isolated from the same metastasis demonstrated that the ability of aggressive tumor cells to engage in vasculogenic mimicry was dependent on differentiation plasticity ${ }^{80-82}$. Aggressive melanoma cells engaged in vasculogenic mimicry displayed a reduced expression of genes associated with a melanocytespecific phenotype. This was demonstrated by decreased expression of genes encoding for melan-A and tyrosinase (Table 1.1). In contrast, aggressive melanoma cells displayed an increased expression of genes associated with a vascular phenotype. Among these were the genes encoding for vascular endothelial (VE)cadherin, Tie1, CD34, and Ephrin receptor A2 (EphA2) (Table 1.1). In addition to the expression of endothelial markers, vasculogenic mimicry positive tumor cells, but not their poorly aggressive counterparts, expressed proteins involved in the coagulation cascade. A major function of endothelial cells is to prevent blood coagulation by the expression of anticoagulant proteins at the luminal surface. In the absence of anticlotting factors, blood will coagulate immediately when in contact with tumor cells ${ }^{83}$. Tumor cells engaged in vasculogenic mimicry and directly lining the vasculogenic networks expressed tissue factor pathway inhibitor-1 (TFPI-1) and TFPI- $2^{84}$. These data clearly demonstrated the transdifferentiation capacity of aggressive melanoma cells toward an endothelial lineage and their role in fluid transportation. Furthermore, highly aggressive tumor cells also showed an increased expression of genes encoding for matrix-associated proteins like laminin-5 $\gamma 2$ and metalloproteinases ${ }^{85}$. 
In vivo

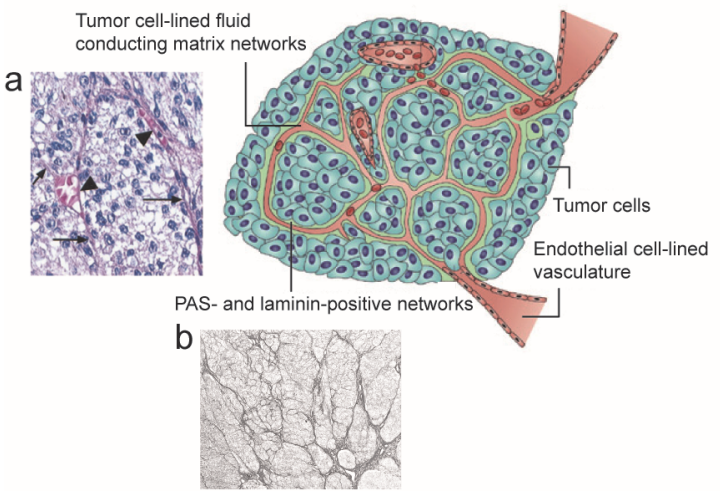

In vitro
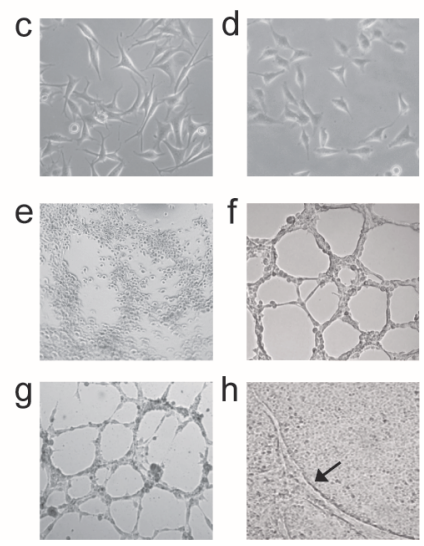

Figure 1.3 Analysis of vasculogenic mimicry. Schematic representation of vasculogenic mimicry in a tumor cross-section $^{103}$. Vasculogenic mimicry is displayed by the presence of tumor cell-lined fluid conducting networks. The endothelial-lined vasculature (pink) is expected to be closely apposed to the matrix-rich (green) vasculogenic networks formed by tumor cells (blue). The ability of tumor cells to mimic endothelial cells can be examined both in vivo (a-b) and in vitro (c-h). In tumor tissues, vasculogenic mimicry can be visualized by hematoxylin and eosin staining, which visualizes matrix networks consisting of solid cords (arrows) that connect to round channels or tubes containing red blood cells (arrowheads) ${ }^{76}$ (a). By PAS staining the presence of matrix-rich vasculogenic networks organized in a honeycomb-like manner is demonstrated (b). In vitro, tumor cell lines can be characterized for vasculogenic mimicry by several methods, including cell morphology and vasculogenic network formation. Non-vasculogenic tumor cells display a spindle-shaped phenotype (c), while vasculogenic tumor cells are cobble-shaped (d). When grown on 3-dimensional matrices, vasculogenic tumor cells have the ability to form vasculogenic networks. On Matrigel, non-vasculogenic tumor cells attach to the matrix, but do not show any other phenotypical activity (e). Tumor cells that have gained endothelial characteristics form patterned vasculogenic networks (f). These networks closely resemble the networks formed by vascular endothelial cells (g). In addition to vasculogenic network formation on Matrigel, tumor cells that have gained endothelial characteristics are able to form tubes when cultured on collagen matrix (h). In addition to the displayed features, vasculogenic mimicry can also be assessed by quantitative PCR analysis for genes displayed in Table 1.1.

Following the initial discovery in melanoma, vasculogenic mimicry has now been described for breast ${ }^{86}$, lung $^{87}$, prostate $^{88}$, ovarian ${ }^{89,90}$, and hepatocellular carcinoma ${ }^{91}$, but also in Ewing sarcoma ${ }^{92}$, hemangiopericytoma ${ }^{93}$, astrocytoma $^{94}$, and glioblastoma ${ }^{95}$. This demonstrates that the presence of vasculogenic mimicry is independent of the germ layer origin of the tumor and thus suggests a selective pressure for vasculogenic mimicry of malignant cells independent of cell ontogeny. 
Table 1.1 Altered expression of angiogenesis/vasculogenesis-related genes by melanoma cells ${ }^{103}$. Aggressive tumor cells and poorly aggressive tumor cells were isolated from the same metastasis. Ratio of expression is displayed as VM-positive uveal melanoma cells versus VM-negative uveal melanoma cells.

\begin{tabular}{|c|c|c|c|}
\hline Gene & Unigene & Function & $\begin{array}{l}\text { Ratio of } \\
\text { expression }\end{array}$ \\
\hline \multicolumn{4}{|l|}{ Melanocyte-specific markers } \\
\hline Melan-A (MLANA) & Hs.154069 & Melanoma surface antigen & $0.044(\downarrow 22)$ \\
\hline $\begin{array}{l}\text { Microphtalmia-associated } \\
\text { transcription factor (MITF) }\end{array}$ & Hs.166017 & $\begin{array}{l}\text { Melanocyte-development transcription } \\
\text { factor }\end{array}$ & $0.028(\downarrow 34)$ \\
\hline Tyrosinase (TYR) & Hs.2053 & $\begin{array}{l}\text { Catalyzes the conversion of tyrosine to } \\
\text { melanin }\end{array}$ & $0.027(\downarrow 37)$ \\
\hline \multicolumn{4}{|l|}{ Vascular markers } \\
\hline Tyrosine kinase 1 (TIE1) & HS.78824 & Endothelial tyrosine kinase & 25 \\
\hline Epithelial-cell kinase (EphA2) & Hs.171596 & Receptor tyrosine kinase & 13 \\
\hline Neuropilin 1 (NRP1) & Hs. 69285 & VEGF receptor & 5.3 \\
\hline Vascular endothelial (VE)-cadherin & Hs.76206 & Cell-cell endothelial adhesion molecule & 11 \\
\hline CD34 & Hs.85289 & Stem-cell marker & 2.5 \\
\hline $\begin{array}{l}\text { Tissue factor pathway inhibitor } 1 \\
\text { (TFPI1) }\end{array}$ & Hs.170279 & Coagulation inhibitor & 4.0 \\
\hline Laminin-5 52 & Hs. 54451 & Extracellular matrix & 50 \\
\hline Fibronectin (FN1) & Hs.118162 & Extracellular matrix & 27 \\
\hline Collagen IV $\alpha 2$ (COL4A2) & Hs.75617 & Extracellular matrix & 3.6 \\
\hline $\begin{array}{l}\text { Endothelial differentiation-related } \\
\text { factor } 1 \text { (EDF1) }\end{array}$ & Hs.174050 & Endothelial cell differentiation regulator & 4.8 \\
\hline $\begin{array}{l}\text { Endothelial cell-specific molecule } 1 \\
\text { (ESM1) }\end{array}$ & Hs.41716 & $\begin{array}{l}\text { Endothelial cell-specific signaling } \\
\text { molecule }\end{array}$ & 41 \\
\hline
\end{tabular}

Although the function of vasculogenic mimicry networks in tumor tissues remains to be elucidated, the presence of erythrocytes within the patterned networks indicates that there is a connection of the vasculogenic networks to regular blood vessels. By means of advanced imaging techniques such as magnetic resonance imaging (MRI) and fluorescent dyes, the connection between vasculogenic mimicry networks and the vasculature has been confirmed ${ }^{96-99}$. Additionally, the injection of micro bubbles revealed a functional connection between the two distinct vessel types ${ }^{84}$. Based on these results, two main functions for vasculogenic mimicry networks have been proposed. First of all, vasculogenic mimicry has been assumed to function as a secondary circulatory system that may be of high importance when tumor angiogenesis is impaired. This function would imply that vasculogenic mimicry is induced as a survival or resistance mechanism when regular blood vessel formation is insufficient. Likely, malignant tumor cells with a high degree of differentiation plasticity and the ability to form vasculogenic networks have a survival advantage, as oxygen deficiency is characteristic for the tumor microenvironment. Consistent with this assumption, hypoxic conditioning of tumor cells promoted the alignment of tumor cells into vasculogenic structures and increased the expression of endothelialrelated genes ${ }^{100}$. In Ewing sarcoma tissues, HIF-1 expression was identified in transdifferentiated tumor cells surrounding vasculogenic mimicry-characteristic blood lakes $^{92}$. However, the fact that vasculogenic mimicry positive tumor areas are hypoxic 
suggests that vasculogenic mimicry does not functionally contribute to overcome oxygen depletion. Indeed, the blood flow through vasculogenic mimicry networks has been shown to be rather ineffective. Therefore, vasculogenic networks have also been proposed to serve as a route for tumor cell metastasis. As these networks have been shown to contain a physiological connection to the endothelial-lined vasculature, these tumor-lined tubes may facilitate the intravasation of malignant tumor cells. This assumption would be in line with the fact that hypoxia is strongly associated with enhanced tumor cell malignancy and increased tumor cells metastasis, and supports the hypothesis of vasculogenic mimicry as a process related to increased tumor cell malignancy.

The resemblance of aggressive tumor cells to vascular endothelial cells suggests that vasculogenic mimicry may be targeted by angiogenesis inhibitor treatment. However, despite the overlap of several endothelial features, angiostatic compounds have not been able to inhibit vascular network formation by aggressive melanoma cells ${ }^{101}$. This knowledge implies that vasculogenic mimicry positive tumor vessels do not share essential features with endothelial-covered vessels and might suggest that plastic tumor cells are highly selective on which endothelial-characteristics to adopt. Although most anti-angiogenesis therapies are targeting the VEGF signaling cascade, it was shown that VEGF stimulation or inhibition has no effect on vasculogenic mimicry tube formation in vitro and in vivo ${ }^{76,100}$. Therefore, tumor cell vessels are unaffected when angiogenesis is inhibited by current treatment strategies ${ }^{102}$. By detailed comparison of vasculogenic mimicry vessels to regular tumor blood vessels, treatment strategies targeting both vessel types could be developed. This would enable dual targeting of both tumor angiogenesis and vasculogenic mimicry. A better understanding of the molecular mechanisms underlying vasculogenic mimicry may thus circumvent treatment-induced resistance leading to improved clinical benefit. 


\section{References}

1. Griffioen AW, Molema G. Angiogenesis: potentials for pharmacologic intervention in the treatment of cancer, cardiovascular diseases, and chronic inflammation. Pharmacological reviews, 2000; 52: 237-68.

2. Molema G, Griffioen AW. Rocking the foundations of solid tumor growth by attacking the tumor's blood supply. Immunology today, 1998; 19:392-4.

3. Risau W, Sariola H, Zerwes HG, et al. Vasculogenesis and angiogenesis in embryonic-stem-cell-derived embryoid bodies. Development, 1988; 102:471-8.

4. Ferguson JE, 3rd, Kelley RW, Patterson C. Mechanisms of endothelial differentiation in embryonic vasculogenesis. Arteriosclerosis, thrombosis, and vascular biology, 2005; 25:2246-54.

5. Risau W, Flamme I. Vasculogenesis. Annual review of cell and developmental biology, 1995; 11:73-91.

6. Risau W. Differentiation of endothelium. FASEB journal : official publication of the Federation of American Societies for Experimental Biology, 1995; 9:926-33.

7. Carmeliet P. Mechanisms of angiogenesis and arteriogenesis. Nat Med, 2000; 6:389-95.

8. Jain RK. Molecular regulation of vessel maturation. Nature medicine, 2003; 9:685-93.

9. Darland DC, D'Amore PA. Cell-cell interactions in vascular development. Current topics in developmental biology, 2001; 52:107-49.

10. Armulik A, Abramsson A, Betsholtz C. Endothelial/pericyte interactions. Circulation research, 2005; 97:512-23.

11. von Tell D, Armulik A, Betsholtz C. Pericytes and vascular stability. Experimental cell research, 2006; 312:623-9.

12. Kutcher ME, Kolyada AY, Surks HK, et al. Pericyte Rho GTPase mediates both pericyte contractile phenotype and capillary endothelial growth state. The American journal of pathology, 2007; 171: 693-701.

13. Hellstrom $M$, Gerhardt $H$, Kalen $M$, et al. Lack of pericytes leads to endothelial hyperplasia and abnormal vascular morphogenesis. The Journal of cell biology, 2001; 153:543-53.

14. Gaengel K, Genove G, Armulik A, et al. Endothelial-mural cell signaling in vascular development and angiogenesis. Arteriosclerosis, thrombosis, and vascular biology, 2009; 29:630-8.

15. Hellberg C, Ostman A, Heldin CH. PDGF and vessel maturation. Recent results in cancer research. Fortschritte der Krebsforschung. Progres dans les recherches sur le cancer, 2010; 180:103-14.

16. Hellstrom M, Kalen M, Lindahl P, et al. Role of PDGF-B and PDGFR-beta in recruitment of vascular smooth muscle cells and pericytes during embryonic blood vessel formation in the mouse. Development, 1999; 126:3047-55.

17. Abramsson A, Lindblom P, Betsholtz C. Endothelial and nonendothelial sources of PDGF-B regulate pericyte recruitment and influence vascular pattern formation in tumors. The Journal of clinical investigation, 2003; 112:1142-51.

18. Hirschi KK, Rohovsky SA, Beck LH, et al. Endothelial cells modulate the proliferation of mural cell precursors via platelet-derived growth factor-BB and heterotypic cell contact. Circulation research, 1999; 84:298-305.

19. Bjarnegard M, Enge M, Norlin J, et al. Endothelium-specific ablation of PDGFB leads to pericyte loss and glomerular, cardiac and placental abnormalities. Development, 2004; 131:1847-57.

20. Chung AS, Lee J, Ferrara N. Targeting the tumour vasculature: insights from physiological angiogenesis. Nature reviews. Cancer, 2010; 10:505-14.

21. Folkman J. Angiogenesis in cancer, vascular, rheumatoid and other disease. Nature medicine, 1995; 1:27-31.

22. Bergers G, Benjamin LE. Tumorigenesis and the angiogenic switch. Nature reviews. Cancer, 2003; 3:401-10.

23. Hanahan D, Weinberg RA. The hallmarks of cancer. Cell, 2000; 100:57-70.

24. Ferrara N. VEGF as a therapeutic target in cancer. Oncology, 2005; 69 Suppl 3:11-6.

25. Presta M, Dell'Era P, Mitola S, et al. Fibroblast growth factor/fibroblast growth factor receptor system in angiogenesis. Cytokine \& growth factor reviews, 2005; 16:159-78.

26. Ferrara N, Gerber HP, LeCouter J. The biology of VEGF and its receptors. Nature medicine, 2003; 9:669-76. 
27. Jain RK. Normalization of tumor vasculature: an emerging concept in antiangiogenic therapy. Science, 2005; 307:58-62.

28. Carmeliet P, Jain RK. Molecular mechanisms and clinical applications of angiogenesis. Nature, 2011; 473:298-307.

29. Baluk P, Hashizume H, McDonald DM. Cellular abnormalities of blood vessels as targets in cancer. Current opinion in genetics \& development, 2005; 15:102-11

30. Chang YS, di Tomaso E, McDonald DM, et al. Mosaic blood vessels in tumors: frequency of cancer cells in contact with flowing blood. Proceedings of the National Academy of Sciences of the United States of America, 2000; 97:14608-13.

31. Brown JM, Giaccia AJ. The unique physiology of solid tumors: opportunities (and problems) for cancer therapy. Cancer research, 1998; 58:1408-16.

32. Bennewith KL, Dedhar S. Targeting hypoxic tumour cells to overcome metastasis. BMC cancer, 2011; 11:504.

33. Hockel M, Schlenger K, Aral B, et al. Association between tumor hypoxia and malignant progression in advanced cancer of the uterine cervix. Cancer research, 1996; 56:4509-15.

34. Vergis R, Corbishley CM, Norman AR, et al. Intrinsic markers of tumour hypoxia and angiogenesis in localised prostate cancer and outcome of radical treatment: a retrospective analysis of two randomised radiotherapy trials and one surgical cohort study. The lancet oncology, 2008; 9:342-51.

35. Semenza GL. Targeting HIF-1 for cancer therapy. Nature reviews. Cancer, 2003; 3:721-32.

36. Wenger RH, Stiehl DP, Camenisch G. Integration of oxygen signaling at the consensus HRE. Science's STKE : signal transduction knowledge environment, 2005; 2005:re12.

37. Sullivan R, Graham CH. Hypoxia-driven selection of the metastatic phenotype. Cancer metastasis reviews, 2007; 26:319-31.

38. Cairns RA, Khokha R, Hill RP. Molecular mechanisms of tumor invasion and metastasis: an integrated view. Current molecular medicine, 2003; 3:659-71.

39. Chaudary N, Hill RP. Increased expression of metastasis-related genes in hypoxic cells sorted from cervical and lymph nodal xenograft tumors. Laboratory investigation; a journal of technical methods and pathology, 2009; 89:587-96.

40. Rofstad EK, Gaustad JV, Egeland TA, et al. Tumors exposed to acute cyclic hypoxic stress show enhanced angiogenesis, perfusion and metastatic dissemination. International journal of cancer. Journal international du cancer, 2010; 127:1535-46.

41. Rankin EB, Giaccia AJ. The role of hypoxia-inducible factors in tumorigenesis. Cell death and differentiation, 2008; 15:678-85.

42. Mohyeldin A, Garzon-Muvdi T, Quinones-Hinojosa A. Oxygen in stem cell biology: a critical component of the stem cell niche. Cell stem cell, 2010; 7:150-61.

43. Mimeault M, Batra SK. Frequent gene products and molecular pathways altered in prostate cancerand metastasis-initiating cells and their progenies and novel promising multitargeted therapies. Molecular medicine, 2011; 17:949-64.

44. Tu LC, Foltz G, Lin E, et al. Targeting stem cells-clinical implications for cancer therapy. Current stem cell research \& therapy, 2009; 4:147-53.

45. Ebos JM, Lee CR, Cruz-Munoz W, et al. Accelerated metastasis after short-term treatment with a potent inhibitor of tumor angiogenesis. Cancer Cell, 2009; 15:232-9.

46. Paez-Ribes M, Allen E, Hudock J, et al. Antiangiogenic therapy elicits malignant progression of tumors to increased local invasion and distant metastasis. Cancer Cell, 2009; 15:220-31.

47. Folkman J. Tumor angiogenesis: therapeutic implications. The New England journal of medicine, 1971; 285:1182-6.

48. Jain RK. Normalizing tumor vasculature with anti-angiogenic therapy: a new paradigm for combination therapy. Nature medicine, 2001; 7:987-9.

49. Ferrara N, Kerbel RS. Angiogenesis as a therapeutic target. Nature, 2005; 438:967-74.

50. Wilhelm S, Carter C, Lynch M, et al. Discovery and development of sorafenib: a multikinase inhibitor for treating cancer. Nature reviews. Drug discovery, 2006; 5:835-44.

51. Faivre S, Demetri G, Sargent W, et al. Molecular basis for sunitinib efficacy and future clinical development. Nature reviews. Drug discovery, 2007; 6:734-45.

52. Gotink KJ, Verheul HM. Anti-angiogenic tyrosine kinase inhibitors: what is their mechanism of action? Angiogenesis, 2010; 13:1-14. 
53. Eskens FA, Verweij J. The clinical toxicity profile of vascular endothelial growth factor (VEGF) and vascular endothelial growth factor receptor (VEGFR) targeting angiogenesis inhibitors; a review. European journal of cancer, 2006; 42:3127-39.

54. Verheul HM, Pinedo HM. Possible molecular mechanisms involved in the toxicity of angiogenesis inhibition. Nature reviews. Cancer, 2007; 7:475-85.

55. Bergers G, Hanahan D. Modes of resistance to anti-angiogenic therapy. Nature reviews. Cancer, 2008; 8:592-603.

56. Kerbel RS. Therapeutic implications of intrinsic or induced angiogenic growth factor redundancy in tumors revealed. Cancer cell, 2005; 8:269-71.

57. O'Connor R, Clynes $\mathrm{M}$, Dowling $\mathrm{P}$, et al. Drug resistance in cancer - searching for mechanisms, markers and therapeutic agents. Expert opinion on drug metabolism \& toxicology, 2007; 3:805-17.

58. Gorre ME, Sawyers CL. Molecular mechanisms of resistance to STI571 in chronic myeloid leukemia. Current opinion in hematology, 2002; 9:303-7.

59. Casanovas O, Hicklin DJ, Bergers G, et al. Drug resistance by evasion of antiangiogenic targeting of VEGF signaling in late-stage pancreatic islet tumors. Cancer cell, 2005; 8:299-309.

60. Ellis LM, Hicklin DJ. Pathways mediating resistance to vascular endothelial growth factor-targeted therapy. Clinical cancer research: an official journal of the American Association for Cancer Research, 2008; 14:6371-5.

61. Shaked $Y$, Ciarrocchi A, Franco $M$, et al. Therapy-induced acute recruitment of circulating endothelial progenitor cells to tumors. Science, 2006; 313:1785-7.

62. Asahara T, Murohara T, Sullivan A, et al. Isolation of putative progenitor endothelial cells for angiogenesis. Science, 1997; 275:964-7.

63. Darland DC, Massingham LJ, Smith SR, et al. Pericyte production of cell-associated VEGF is differentiation-dependent and is associated with endothelial survival. Developmental biology, 2003; 264:275-88.

64. Song S, Ewald AJ, Stallcup W, et al. PDGFRbeta+ perivascular progenitor cells in tumours regulate pericyte differentiation and vascular survival. Nature cell biology, 2005; 7:870-9.

65. Du R, Lu KV, Petritsch C, et al. HIF1alpha induces the recruitment of bone marrow-derived vascular modulatory cells to regulate tumor angiogenesis and invasion. Cancer cell, 2008; 13:206-20.

66. Rubenstein JL, Kim J, Ozawa T, et al. Anti-VEGF antibody treatment of glioblastoma prolongs survival but results in increased vascular cooption. Neoplasia, 2000; 2:306-14.

67. Gotink KJ, Broxterman HJ, Labots M, et al. Lysosomal sequestration of sunitinib: a novel mechanism of drug resistance. Clinical cancer research : an official journal of the American Association for Cancer Research, 2011; 17:7337-46.

68. Relf M, LeJeune S, Scott PA, et al. Expression of the angiogenic factors vascular endothelial cell growth factor, acidic and basic fibroblast growth factor, tumor growth factor beta-1, platelet-derived endothelial cell growth factor, placenta growth factor, and pleiotrophin in human primary breast cancer and its relation to angiogenesis. Cancer research, 1997; 57:963-9.

69. Shojaei $\mathrm{F}, \mathrm{Wu} \mathrm{X}, \mathrm{Malik} \mathrm{AK}$, et al. Tumor refractoriness to anti-VEGF treatment is mediated by CD11b+Gr1+ myeloid cells. Nature biotechnology, 2007; 25:911-20.

70. Yu JL, Rak JW, Carmeliet P, et al. Heterogeneous vascular dependence of tumor cell populations. The American journal of pathology, 2001; 158:1325-34.

71. Yu JL, Rak JW, Coomber BL, et al. Effect of p53 status on tumor response to antiangiogenic therapy. Science, 2002; 295:1526-8.

72. Kaur B, Tan C, Brat DJ, et al. Genetic and hypoxic regulation of angiogenesis in gliomas. Journal of neuro-oncology, 2004; 70:229-43.

73. Holash J, Maisonpierre PC, Compton D, et al. Vessel cooption, regression, and growth in tumors mediated by angiopoietins and VEGF. Science, 1999; 284:1994-8.

74. Dome B, Paku S, Somlai B, et al. Vascularization of cutaneous melanoma involves vessel co-option and has clinical significance. The Journal of pathology, 2002; 197:355-62.

75. Hillen F, Griffioen AW. Tumour vascularization: sprouting angiogenesis and beyond. Cancer metastasis reviews, 2007; 26:489-502.

76. Maniotis AJ, Folberg R, Hess A, et al. Vascular channel formation by human melanoma cells in vivo and in vitro: vasculogenic mimicry. Am J Pathol, 1999; 155:739-52.

77. Folberg R, Rummelt V, Parys-Van Ginderdeuren R, et al. The prognostic value of tumor blood vessel morphology in primary uveal melanoma. Ophthalmology, 1993; 100:1389-98. 
78. Sun B, Zhang S, Zhao X, et al. Vasculogenic mimicry is associated with poor survival in patients with mesothelial sarcomas and alveolar rhabdomyosarcomas. Int J Oncol, 2004; 25:1609-14.

79. Folberg R, Maniotis AJ. Vasculogenic mimicry. Apmis, 2004; 112:508-25.

80. Seftor EA, Meltzer PS, Kirschmann DA, et al. Molecular determinants of human uveal melanoma invasion and metastasis. Clin Exp Metastasis, 2002; 19:233-46.

81. Bittner $\mathrm{M}$, Meltzer $\mathrm{P}, \mathrm{Chen} \mathrm{Y}$, et al. Molecular classification of cutaneous malignant melanoma by gene expression profiling. Nature, 2000; 406:536-40.

82. Seftor EA, Meltzer PS, Schatteman GC, et al. Expression of multiple molecular phenotypes by aggressive melanoma tumor cells: role in vasculogenic mimicry. Crit Rev Oncol Hematol, 2002; 44: 17-27.

83. Shoji M, Hancock WW, Abe K, et al. Activation of coagulation and angiogenesis in cancer: immunohistochemical localization in situ of clotting proteins and vascular endothelial growth factor in human cancer. The American journal of pathology, 1998; 152:399-411.

84. Ruf W, Seftor EA, Petrovan RJ, et al. Differential role of tissue factor pathway inhibitors 1 and 2 in melanoma vasculogenic mimicry. Cancer Res, 2003; 63:5381-9.

85. Seftor RE, Seftor EA, Koshikawa N, et al. Cooperative interactions of laminin 5 gamma2 chain, matrix metalloproteinase-2, and membrane type-1-matrix/metalloproteinase are required for mimicry of embryonic vasculogenesis by aggressive melanoma. Cancer Res, 2001; 61:6322-7.

86. Shirakawa K, Wakasugi H, Heike $\mathrm{Y}$, et al. Vasculogenic mimicry and pseudo-comedo formation in breast cancer. International journal of cancer. Journal international du cancer, 2002; 99:821-8.

87. Passalidou E, Trivella M, Singh N, et al. Vascular phenotype in angiogenic and non-angiogenic lung non-small cell carcinomas. Br J Cancer, 2002; 86:244-9.

88. Sharma N, Seftor RE, Seftor EA, et al. Prostatic tumor cell plasticity involves cooperative interactions of distinct phenotypic subpopulations: role in vasculogenic mimicry. Prostate, 2002; 50:189-201.

89. Sood AK, Seftor EA, Fletcher MS, et al. Molecular determinants of ovarian cancer plasticity. Am J Pathol, 2001; 158:1279-88.

90. Sood AK, Fletcher MS, Zahn CM, et al. The clinical significance of tumor cell-lined vasculature in ovarian carcinoma: implications for anti-vasculogenic therapy. Cancer Biol Ther, 2002; 1:661-4.

91. Guzman G, Cotler SJ, Lin AY, et al. A pilot study of vasculogenic mimicry immunohistochemical expression in hepatocellular carcinoma. Archives of pathology \& laboratory medicine, 2007; 131:1776-81.

92. van der Schaft DW, Hillen F, Pauwels $\mathrm{P}$, et al. Tumor cell plasticity in Ewing sarcoma, an alternative circulatory system stimulated by hypoxia. Cancer Res, 2005; 65:11520-8.

93. Zhang $Z$, Han $Y$, Zhang $K$, et al. Investigation of vasculogenic mimicry in intracranial hemangiopericytoma. Molecular medicine reports, 2011; 4:1295-8.

94. Liu Z, Li Y, Zhao W, et al. Demonstration of vasculogenic mimicry in astrocytomas and effects of Endostar on U251 cells. Pathology, research and practice, 2011; 207:645-51.

95. El Hallani S, Boisselier B, Peglion F, et al. A new alternative mechanism in glioblastoma vascularization: tubular vasculogenic mimicry. Brain : a journal of neurology, 2010; 133:973-82.

96. Clarijs R, Otte-Holler I, Ruiter DJ, et al. Presence of a fluid-conducting meshwork in xenografted cutaneous and primary human uveal melanoma. Invest Ophthalmol Vis Sci, 2002; 43:912-8.

97. Kobayashi $\mathrm{H}$, Shirakawa K, Kawamoto S, et al. Rapid accumulation and internalization of radiolabeled herceptin in an inflammatory breast cancer xenograft with vasculogenic mimicry predicted by the contrast-enhanced dynamic MRI with the macromolecular contrast agent G6-(1B4M-Gd)(256). Cancer Res, 2002; 62:860-6.

98. Maniotis AJ, Chen X, Garcia C, et al. Control of melanoma morphogenesis, endothelial survival, and perfusion by extracellular matrix. Lab Invest, 2002; 82:1031-43.

99. Hillen F, Kaijzel EL, Castermans K, et al. A transgenic Tie2-GFP athymic mouse model; a tool for vascular biology in xenograft tumors. Biochemical and biophysical research communications, 2008; 368:364-7.

100. Soda Y, Marumoto T, Friedmann-Morvinski D, et al. Transdifferentiation of glioblastoma cells into vascular endothelial cells. Proceedings of the National Academy of Sciences of the United States of America, 2011; 108:4274-80.

101. van der Schaft DW, Seftor RE, Seftor EA, et al. Effects of angiogenesis inhibitors on vascular network formation by human endothelial and melanoma cells. J Natl Cancer Inst, 2004; 96:1473-7. 


\section{Chapter 1}

102. Dunleavey JM, Dudley AC. Vascular mimicry: concepts and implications for anti-angiogenic therapy. Current Angiogenesis, 2012; 1:133-38.

103. Hendrix MJ, Seftor EA, Hess AR, et al. Vasculogenic mimicry and tumour-cell plasticity: lessons from melanoma. Nat Rev Cancer, 2003; 3:411-21. 


\section{Chapter 2}

Aim and outline of the thesis 


\section{Aim of the thesis}

New vessel formation is a critical event during tumor expansion. Although cancer research is aiming to develop anti-angiogenesis treatment strategies to effectively inhibit tumor growth and progression, clinical results remain limited. Anti-angiogenic compounds have not been able to increase the lifespan of patients by more than a few months. This demonstrates that at least a fraction of the tumor cells is able to adapt to a more hostile microenvironment and thereby survive treatment. Importantly, anti-angiogenic compounds appear to select for tumor cells with a highly aggressive phenotype, as tumor relapse is often associated with a more malignant state and the formation of distant metastases.

In this thesis, the work has been focused on the process of vasculogenic mimicry, i.e. the ability of tumor cells to form a vascularization system independent of host regulation. Though the function of vasculogenic mimicry remains to be established it has been suggested that endothelial cell-independent vascularization provides an alternative route for metastasis. As vasculogenic mimicry is linked to tumor aggressiveness and possibly treatment resistance, we aimed to unravel the underlying mechanisms implicated in this process. The identification of novel key molecules and the analysis of the interaction of these plastic tumor cells with their microenvironment improves our understanding of vasculogenic mimicry. This knowledge may be exploited to circumvent treatment-induced resistance thereby leading to the development clinically more effective treatment strategies.

\section{Outline of the thesis}

Following the initial description of vasculogenic mimicry in 1999, research on this topic has focused on identifying novel molecules implicated in vasculogenic network formation by highly aggressive tumor cells. Based on their initial finding, Hendrix et al. suggested a key role for a signaling pathway involving VE-cadherin, EphA2, MMP-2, and laminin-5 $\gamma 2$ during vasculogenic mimicry. Continuous research has identified additional molecules that are critical for vasculogenic tube formation. Among these are various embryonic signaling molecules that have been described previously in relation to endothelial cell differentiation. In chapter $\mathbf{3}$, we review the signaling pathways and individual molecules that are currently described to be involved in vasculogenic mimicry network formation. Though research has focused on vasculogenic mimicry for more than a decade now, the ongoing identification of novel proteins indicates that vasculogenic mimicry is a highly complex mechanism. Furthermore, this chapter discusses the process of vasculogenic mimicry in relation to other tumor phenomena related to tumor cell plasticity and the implication of vasculogenic mimicry for anti-angiogenesis treatment. 
Since vasculogenic mimicry is associated with a poor clinical outcome, targeting of this process, i.e. preventing or reverting the acquired tumor cell plasticity, may inhibit malignant progression. Although molecules implicated in vasculogenic mimicry have been identified, and knockdown studies have proven their potential as a therapeutic target, specific treatment strategies aimed at targeting vasculogenic mimicry remain to be developed. Tyrosine kinase inhibitors are clinically applied to cancer patients to inhibit angiogenesis or tumor cell proliferation. Although tyrosine kinase inhibitors are described to bind their targets with high affinity, it has been shown that in fact these drugs often possess low specificity for specific tyrosine kinases. Interestingly, the importance of tyrosine kinases throughout the process of vasculogenic mimicry has been demonstrated before. In chapter 4 , we describe the ability of the tyrosine kinase inhibitor imatinib (Gleevec ${ }^{\circledR}$, Novartis) to reduce tumor cell plasticity. This demonstrates the use of non-specific targeting as an effective treatment approach to inhibit vasculogenic mimicry.

In regular blood vessel development, endothelial cells form the inner lining of a blood vessel. After the angiogenic sprout has been formed, endothelial cells produce factors to attract perivascular cells that encircle them and provide structural support. Together these two cell types form a mature blood vessel. Research on perivascular cells is currently an important topic of cancer research. Tumor cells engaged in vasculogenic mimicry adopt endothelial characteristics and form vasculogenic tubular structures resembling immature blood vessels. We found that perivascular cells are located within the vasculogenic mimicry-characteristic matrix-rich vascular networks lined by tumor cells. In addition, vasculogenic mimicry positive tumor cells were shown to produce significantly more platelet-derived growth factor (PDGF)-B, the main cytokine involved in the attraction of perivascular cells. We therefore hypothesized that perivascular cells are of high importance for vasculogenic tumor cells. To examine the functional contribution of perivascular cells, these cells were cocultured under various conditions with vasculogenic tumor cells in vitro. In chapter 5 we describe the important role of perivascular cells to the process of vasculogenic mimicry.

The ability of tumor cells to transdifferentiate and acquire an endothelial phenotype is a critical event during vasculogenic mimicry. This process requires a high cellular plasticity and the expression of genes involved in maintaining pluripotency and/or plasticity. Interestingly, these characteristics are also of high importance in cancer stem cells. By microarray analysis comparing the gene expression profile of vasculogenic mimicry positive Ewing sarcoma cells to non-vasculogenic Ewing sarcoma cells, we identified the increased expression of CD44 in vasculogenic Ewing sarcoma cells. In chapter $\mathbf{6}$, we link the expression of this well-known cancer stem cells marker to the vasculogenic potential of vasculogenic mimicry positive tumor cells. We hypothesized that CD44 is contributing to the process of vasculogenic mimicry, and 
that targeting of CD44 may be a means of attacking tumor cell plasticity. Using a knockdown approach, we examined the correlation of this molecule to the vasculogenic potential of plastic tumor cells. Furthermore, we examined the localization of CD44 expression in a series of human Ewing sarcoma tissues.

Finally, chapter $\mathbf{7}$ discusses the main findings of the research presented in this thesis and it provides the future perspectives for their clinical translation. 


\section{Chapter 3}

3

Signaling pathways in vasculogenic mimicry

Yvette WJ Paulis, Patricia MMB Soetekouw, Henk MW Verheul, Vivianne CG Tjan-Heijnen, Arjan W Griffioen

Biochim Biophys Acta. 2010;1806:18-28 


\section{Abstract}

Solid tumor growth is dependent on the development of an adequate blood supply. For years, sprouting angiogenesis has been considered an exclusive mechanism of tumor vascularization. However, over the last years, several other mechanisms have been identified, including vessel-co-option, intussusception, recruitment of endothelial precursor cells (EPCS) and even mechanisms that do not involve endothelial cells, a process called vasculogenic mimicry (VM). The latter describes a mechanism by which highly aggressive tumor cells can form vessel-like structures themselves, by virtue of their high plasticity. VM has been observed in several tumor types and its occurrence is strongly associated with a poor prognosis. This review will focus on signaling molecules and cascades involved in VM. In addition, we will discuss the presence of VM in relation to ongoing cancer research. Finally, we describe the clinical significance of $\mathrm{VM}$ regarding anti-angiogenesis treatment modalities. 


\section{Introduction}

Vasculogenic mimicry (VM) was introduced in 1999 and described the unique ability of highly aggressive melanoma cells to dedifferentiate into multiple cellular phenotypes, and obtain endothelial-like characteristics ${ }^{1}$. This process would then lead to the formation of de novo vasculogenic-like matrix-embedded networks, i.e. vascular-like structures, containing plasma and red blood cells ${ }^{1,2}$, and ultimately contributing to blood circulation. Morphological characterization revealed that VM networks are rich in laminin and lined by tumor cells ${ }^{1-3}$, thereby encircling spheroidal nests of tumor cells. Within the matrix-rich channels endothelial cells were not identified by light microscopy, transmission electron microscopy, or by immunohistochemistry ${ }^{1}$. Following the identification of VM in melanomas, VM was also reported in nonmelanoma malignant tumors including breast ${ }^{4}$, ovarian $^{5,6}$, prostate ${ }^{7}$, Ewing sarcoma ${ }^{8}$, lung $^{9}$, and recently in clear cell renal cell carcinoma ${ }^{10}$. The occurrence of VM is relatively rare within tumors, but the presence of VM-associated matrix-rich patterned networks in patients tumor tissues correlates to increased risk of metastasis and therefore poor clinical outcome $\mathrm{e}^{1,11,12}$.

The distinctive pattern of VM networks appears to recapitulate embryonic vasculogenesis networks ${ }^{1}$. The resemblance of VM networks with embryonic vasculogenic structures suggests that aggressive tumor cells convert to an undifferentiated, embryonic-like phenotype. Gene expression analysis demonstrated that aggressive melanomas capable of VM express genes associated with multiple cellular phenotypes, including characteristics of epithelial cells, endothelial cells and fibroblasts ${ }^{13-15}$. In addition, these studies showed upregulation of genes involved in angiogenesis and vasculogenesis, such as VE-cadherin, EphA2 and laminin5Y2 chain $^{3,16,17}$. These molecules and their ligands are important for the formation and maintenance of blood vessels ${ }^{18}$. Interestingly, in Ewing sarcoma tissue sections, VE-cadherin and EphA2 expression was present in tumor cells directly lining VM structures ${ }^{8}$. Although plastic tumor cells express molecules implicated in angiogenesis, VM network formation is independent of regular angiogenesis, as pro-angiogenic growth factors, such as basic fibroblast growth factor (bFGF) and vascular endothelial growth factor (VEGF), were found to be unable to induce the formation of VM characteristic vascular networks in poorly aggressive melanoma cell lines incapable of $\mathrm{VM}^{1}$. Although studies have been inconclusive, the expression of VEGFR2 has been described to be associated with malignant transformation of melanoma cells ${ }^{19,20}$. Additionally, aggressive VM-positive tumors have a higher expression of the basement membrane extracellular matrix (ECM) component laminin $5 \mathrm{\gamma} 2$, and metalloproteinase (MMP)-1, -2, -9, and -14 (membrane type (MT)1-MMP). Of these markers, laminin5 2 2, MMP-2 and MT1-MMP act in a cooperative manner and were shown to be required for the formation of the VM-characteristic tubular networks of tumor cells, without endothelial cells or fibroblasts, in three-dimensional culture in collagen 
type I. Also, laminin5y2, MMP-2, and MT1-MMP were demonstrated to co-localize with the tubular networks formed on collagen $\mathrm{I} \mathrm{gel}^{3}$. The increased expression and specific localization of these ECM components suggests that highly aggressive melanoma cells are able to modify their ECM in such a way to initiate or promote VM. This review will focus on the signaling pathways and signaling molecules described to be implicated in the potential molecular mechanism of VM and tumor cell plasticity. Furthermore we will discuss the presence of VM in relationship to other ongoing fields of cancer research, i.e. cancer stem cell - and anti-angiogenesis research.

\section{Functional relevance of vasculogenic mimicry}

The presence of VM-characteristic structures in patients' tumor tissues is associated with a poor clinical outcome suggestive of a functional contribution of these networks to tumor progression. An interesting finding possibly contributing to unraveling the importance of VM was that among vascular cell-associated genes upregulated by aggressive VM-positive tumors are tissue factor (TF), tissue factor pathway inhibitor (TFPI)-1 and TFPI- $2^{14,21}$. All are critical components for regulation of the coagulation pathway. TF is the initiating cell-surface receptor of the coagulation cascade. Although angiogenic endothelial cells express $\mathrm{TF}^{22}$, excessive fibrin deposition and occlusive thrombosis is prevented within tumor vasculature due to effective anticoagulant mechanisms regulated by the cell-associated inhibitor TFPI-1. Similarly to endothelial cell anticoagulant properties, tumor cells lining the extravascular channels prevent blood coagulation predominantly by increased expression of TFPI- $1^{21}$. This mechanism thereby provides aggressive tumor cells with a similar anticoagulation capacity as endothelial cells. In vivo analysis demonstrated that TF, TFPI-1 and TFPI-2 are increasingly expressed throughout aggressive uveal melanoma compared to poorly aggressive. Furthermore, the staining pattern for TFPI-1 and TFPI-2 was more prominent along the tumor cell-lined VM networks ${ }^{21}$. In Ewing sarcoma, similar results were obtained ${ }^{8}$. Although TFPI-2 only plays a marginal role in TF function inhibition in aggressive melanoma cells, it was shown that TFPI-2 was required for VM in vitro as tube formation was suppressed upon treatment with anti-TFPI-2 antibody (R1552). In contrast, expression of TF or TFPI-1 was not required for the formation of VM networks in vitro ${ }^{21}$. Additional studies showed that anti-TFPI-2 markedly reduced MMP-2 endogenous activity, an effect that was not observed when treated with antibodies that did not inhibit VM. These data suggest a positive role for TFPI-2 in the regulation of MMP- $2^{21}$, which was previously reported to be of critical importance to melanoma VM. However, TFPI-2 is secreted in the ECM where it functions as a potent inhibitor of serine proteases ${ }^{23}$, in particular plasmin, which activate MMPs. Therefore, the role of TFPI-2 in MMP-2 activation appears inconsistent and might suggest a cellular context-dependent role for TFPI-2. Transcriptional upregulation of MMP-2 in melanomas capable of VM may ensure excess of MMP-2 over TFPI-2, thus preventing 
inactivation. Also, the positive effect of TFPI-2 on MMP-2 activity could be an indirect result, as multiple pathways link MMP-2 activation to serine proteases.

The finding that aggressive VM-positive tumors exhibit endothelial-like anticoagulant mechanisms, together with the observation that the tubular networks contain plasma and (red) blood cells, may imply that the tumor cell-lined extravascular networks could contribute to blood flow in vivo. By these means, VM channels could provide tumors with an additional vascularization mechanism, either dependent or independent of conventional vascularization ways. Several studies have examined this potential function of VM networks. Using tracers and magnetic resonance imaging (MRI), a physiological connection between endothelial-lined vasculature and tumorlined networks was revealed ${ }^{24-26}$. Microinjections of a fluorescent dye into VM networks formed in type-I collagen showed their ability to become perfused in vitro, as aggressive melanoma cells contracted and remodeled floating hydrated gels ${ }^{1,27}$. In vivo studies using color Doppler imaging in human melanoma xenografts demonstrated that flow was visible in the tumor-lined channels during systole. Twodimensional imaging of these tumors following arterial injection of microbubbles also established that these matrix-rich networks are connected to mouse vasculature within the xenograft models ${ }^{21}$. These data suggest tumor cells might actually contribute to conducting blood in vasculogenic-like structures in a manner independent of host regulation.

As VM networks are (in)directly linked to the endothelial-lined vasculature, the structure of VM channels in aggressive tumors might facilitate metastasis of tumor cells. The tumor cells lining the inner surface of the channels are directly exposed to the blood flow. Therefore, detachment of these tumor cells enables them to reach the blood stream and metastasize to other organs. However, the functional contribution of VM networks to tumor metastasis has not been established so far. Nevertheless, in agreement with this hypothesis a study in 2000 showed the presence of putative nonangiogenic lung metastases ( 5 out of 26 ) from primary breast carcinoma ${ }^{28}$. Although the primary tumors were angiogenic, there was no evidence of new vessel formation in these lung metastases. From these results it was concluded that there are at least two metastatic pathways; one directed by angiogenesis and one that is not, although it does co-opt with the existing vasculature.

Except for its potential function in facilitating tumor cell metastasis to the blood stream and subsequently distant organs, the tubular networks formed by highly aggressive tumor cells could contribute to tumor circulation as they appear to be capable of blood flow. This may imply that the occurrence of VM is associated with reduced oxygen tension, which stimulates the tumor to activate rescue mechanisms. In Ewing sarcomas, the presence of VM structures coincided with high levels of VEGF, suggesting an inducing function for VEGF. However, VEGF stimulation or inhibition did not respectively enhance or inhibit VM network formation in vitro in plastic Ewing 
sarcoma or melanoma cells. Additionally, no increased expression of genes involved in tube formation was observed ${ }^{8}$. Besides VEGF, hypoxia-inducible factor (HIF)-1 $\alpha$ was shown to be found around VM blood lakes in Ewing sarcomas, while no expression was seen around CD31+ blood vessels. Although HIF-1 $\alpha$ is not solely activated by low oxygen levels, pimonidazole staining, specific for hypoxia, indicated that the regions around VM structures are indeed hypoxic ${ }^{8}$. Together with data suggesting a fluid/nutrient conducting function for VM networks, this implies highly inefficient blood flow through the tumor-lined structures. Hypoxic culturing of VM cell lines significantly increased the expression of the VM markers laminin $5 \gamma 2$ chain, Tie-1, TFPI1 and EphA2. However, it would be interestingly to examine whether the expression of VM-related genes also increases in response to hypoxia in cells not capable of VM tube formation.

\section{Signaling cascades involved in vasculogenic mimicry}

\section{Key VM signaling pathways}

VE-cadherin was one of the first molecules to be identified as an important player in melanoma VM. This adhesion molecule is a member of the cadherin-family specifically expressed in endothelial cells. Its role in maintaining vascular integrity was established using a VE-cadherin knockout mouse that was found non-vital and showed embryonic death during midgestation due to vascular malformations ${ }^{29}$. In plastic tumor cells adapting endothelial characteristics, VE-cadherin has an important role as cells lacking VE-cadherin are incapable of VM tube formation ${ }^{16}$.

In 2006 Hess et al. showed that in VM melanoma VE-cadherin co-localizes with EphA2 at areas of cell-cell contact and that these two molecules are able to (in)directly interact during the process of $\mathrm{VM}^{30}$. EphA2 is a tyrosine kinase receptor that was shown to be overexpressed and constitutively active in aggressive melanomas with a metastatic VM phenotype. Transient knockdown of VE-cadherin in aggressive cutaneous melanoma- and uveal melanoma cell lines capable of VM (C8161 and MUM-2B, respectively), demonstrated a re-localization of EphA2 to the cytoplasm. Additionally, loss of VE-cadherin resulted in an apparent decreased phosphorylation of EphA2. As described before, diminished VE-cadherin expression is related to decreased VM tube formation potential ${ }^{16}$. Loss of EphA2 expression or induced phosphorylation on tyrosine residues did not affect VE-cadherin localization at the cell-cell adhesion sites, suggesting that VE-cadherin and EphA2 activation occur sequentially.

Although loss of EphA2 expression was shown not to affect VE-cadherin localization, decreased EphA2 expression was shown to inhibit VM tube formation in vitro ${ }^{17,31}$. Overexpression of EphA2 caused increased expression of MMP-2, an important player in tumor invasiveness ${ }^{32}$. Consistent with these findings, implantation of pancreatic 
EphA2-overexpressing cells in mice resulted in a significant increase in liver metastases compared to EphA2-siRNA treated animals ${ }^{33}$. The role of EphA2 in inducing MMP-2 expression and cellular invasiveness was shown to be, at least partially, dependent on focal adhesion kinase (FAK), as EphA2 overexpression increases FAK phosphorylation $^{32}$. FAK is a tyrosine kinase responsible for mediating various cellular responses, including cell survival, migration and invasion. Although FAK expression shows little difference among poorly and highly aggressive melanoma, FAK activation is enhanced in aggressive melanoma cells due to increased phosphorylation, specifically on the tyrosine residues at positions 397 and 576 (Tyr $^{397}$ and $\left.\mathrm{Tyr}^{576}\right)^{34}$. Phosphorylation on these two domains indicates a fully active FAK, which is associated with increased invasive behavior and VM. Consistent with this, diminished FAK phosphorylation results in disrupted VM. Activated FAK mediates its signal via enhanced phosphorylation of extracellular signal-regulated kinase 1 and 2 (ERK1/2), which subsequently enhances MMP-2 and MT1-MMP activity ${ }^{34}$.

As stated before, aggressive melanoma cells capable of inducing VM have a higher expression of the ECM component laminin 5 \%2 chain compared to poorly aggressive melanoma cells ${ }^{3}$. Immunostaining in three-dimensional cultures of highly aggressive melanoma cells revealed laminin5 42 -rich networks, similar to VM networks visualized by periodic acid-Schiff (PAS) staining. Diminished expression of laminin $5 \gamma 2$ caused hampered VM network formation ${ }^{3}$. The laminin 5 2 chain can be cleaved by activated MMP-2 and MT1-MMP - upregulated in VM as stated above - thereby producing the cleaved fragments $\gamma 2^{\prime}$ and $\gamma 2 x^{3,35,36}$. Both these fragments are implicated in tumor cell invasion and metastasis. In vitro treatment with specific antibodies against MMP-2 or MT1-MMP demonstrated diminished expression of cleaved laminin $5 \gamma 2$ fragments, together with increased amounts of uncleaved laminin $52^{3}$. This change was associated with an inhibition of VM network formation, therefore suggesting that the ability of aggressive melanoma cells to modify their ECM by MMP-2 and MT1-MMP is of critical importance to initiate or promote VM network formation.

Following the identification of the above described molecules involved in VM, Hendrix et al. suggested a model of the signaling cascade implicated in $\mathrm{VM}^{27}$ (Figure 3.1). In this model VE-cadherin regulates the ability of EphA2 to translocate to the cell membrane. This enables EphA2 to interact with its membrane-bound ligand, resulting in its phosphorylation. Via an interaction with phosphorylated EphA2, FAK becomes activated. Downstream of activated FAK, phosphoinositide 3-kinase (PI3K) activation is triggered. However, colocalization of VE-cadherin and EphA2 can also activate PI3K independent of activated FAK. Activated PI3K subsequently induces the expression and activation of MT1-MMP, which then activates MMP- $2^{37}$. Together, MT1-MMP and MMP-2 promote the cleavage of laminin $5 \gamma 2$ chain to the pro-migratory $\gamma 2^{\prime}$ and $\gamma 2 x$ fragments. Release of these fragments into the tumor microenvironment can increase migration, invasion, and may ultimately result in VM. Consistent with the proposed cascade, inhibition of these cleaved fragments was shown to abrogate melanoma VM 
tube formation ${ }^{38}$. However, what initially triggers this pathway to become activated remains unknown. As VE-cadherin expression was found to be essential for VM network formation and is upstream in the proposed signaling cascade, transcriptional induction of this gene may be crucial for the initiation of tumor cell plasticity resulting in VM. Expression of VE-cadherin is controlled by a basal, non-endothelial specific 140 bp promoter $(-139 /+24)^{39}$. In contrast, endothelial specific VE-cadherin expression is regulated within a $2.5 \mathrm{~kb}$ genomic DNA region $2.5 \mathrm{~kb}$ upstream of the transcription start site $(-2486 /+24)^{40}$. It was found that this latter region contains six putative hypoxia responsive elements (HRE). These genomic regions are binding sites for HIF$1 \alpha$ and HIF- $2 \alpha$, transcription factors that are stabilized during conditions of oxygen depletion, i.e. hypoxia. HIF-mediated transcriptional regulation during hypoxia is critical as they induce genes which are essential for tumor cell adaptation to this (hostile) environment. As a result, expression of HIF target genes is associated with increased malignancy. Although VE-cadherin expression is not hypoxia-regulated, HIF$2 \alpha$, but not HIF- $1 \alpha$, activates the VE-cadherin promoter via binding to HRE during normoxic conditions ${ }^{41}$. As HIF- $2 \alpha$ expression is associated with developing endothelium ${ }^{42}$, proper vascular development ${ }^{43}$ and increased tumor malignancy ${ }^{44,45}$, it may be an important protein for inducing tumor cell plasticity. Possibly, HIF-2a expression in aggressive tumor cells is associated with dedifferentiation towards the endothelial lineage by transcriptional induction of VE-cadherin. Consistent with the assumption of HIF- $2 \alpha$ as an inducer of dedifferentiation, HIF- $2 \alpha$ specifically regulates Oct-4 gene transcription ${ }^{46,47}$. Oct- 4 is a transcription factor essential for maintaining stem cell pluripotency. Its expression is induced in order to stimulate a dedifferentiation response. Indeed, in HIF-2 $\alpha$ knock-in tumors, an increased fraction of undifferentiated cells was characterized, which could be reversed by knockdown of Oct- $4{ }^{46,48}$. The above indicates a role for HIF-2 $\alpha$-mediated regulation of (endothelial) differentiation, together with increased expression in aggressive tumors, thereby making it an interesting candidate gene in the study of VM.

\section{Cyclic AMP signaling}

Following the identification of the above-mentioned key molecules in VM tube formation, additional studies have discovered novel signaling components implicated in this process. One of these components is cyclic AMP (CAMP), a second messenger controlling various biological phenomena among which cell growth and differentiation. Second messenger proteins transmit signals within a cell, thereby being implicated in multiple signaling pathways. CAMP is produced from ATP following activation of adenylyl cyclases, due to ligand binding to G-protein-coupled receptors (GPCR) ${ }^{49}$. Signal transmission through CAMP can be mediated via a protein kinase-A (PKA)dependent or PKA-independent pathway. Binding of cAMP to PKA causes downstream phosphorylation of various substrates involved in signal transduction. PKAindependent responses are mediated by exchange proteins directly activated by CAMP (Epac)-1 and Epac-2, although Epac responses can cooperate with PKA responses ${ }^{50,51}$. 


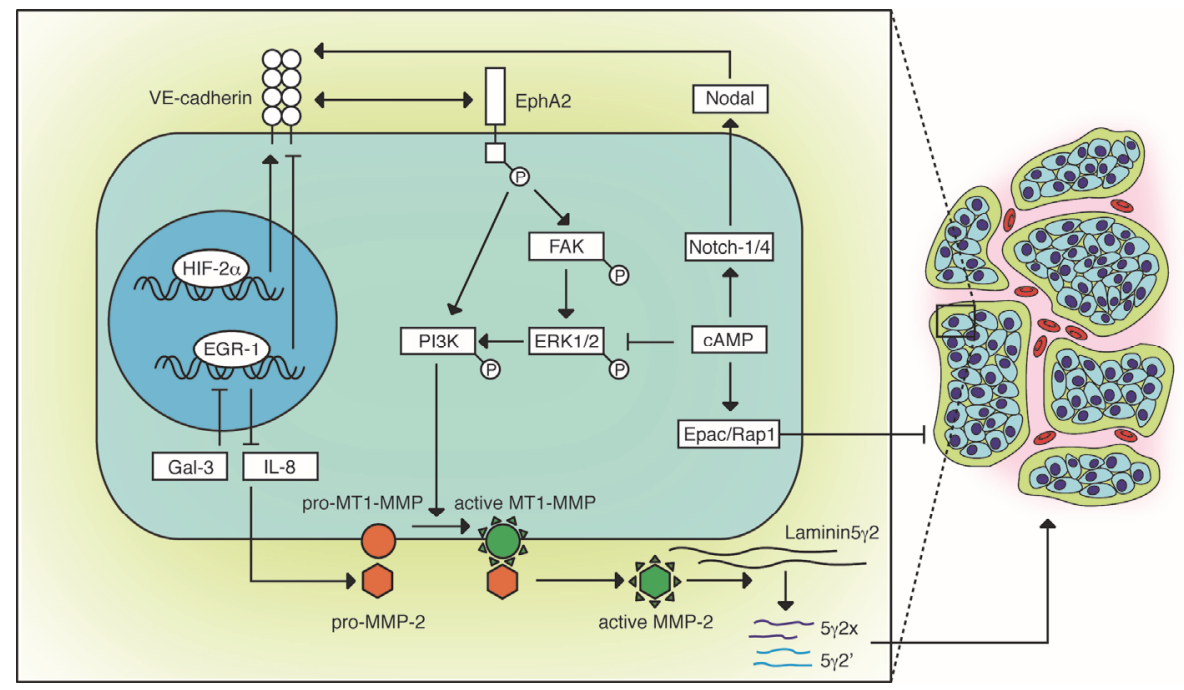

Figure 3.1 Overview of the signaling molecules implicated in the formation of VM networks. A schematic model of the signaling molecules that are implicated in the formation of vasculogenic-like networks is shown. The main signaling cascade is initiated by transcriptional upregulation of VE-cadherin by HIF-2 $\alpha$. VEcadherin induces a re-localization of EphA2 to the cell membrane where both proteins then co-localize resulting in the phosphorylation of EphA2. Activated EphA2 can phosphorylate FAK, which results in activation of ERK1/2 and subsequently PI3K. However, PI3K can also be activated by VE-cadherin/EphA2 signaling independent of FAK. Active PI3K regulates the transition of pro-MT1-MMP to active MT-MMP, which subsequently activates pro-MMP2. Both MT1-MMP and MMP-2 promote the cleavage of laminin5 22 to the pro-migratory fragments $5 \gamma 2^{\prime}$ and $5 \gamma 2 x$. The release of these fragments in the extracellular microenvironment (green) may eventually result in the formation of VM networks (as depicted on the right). Galectin-3 (Gal-3) positively influences this process by repression of the EGR-1 transcription factor, which causes transcriptional repression of VE-cadherin and IL-8. The latter stimulates the expression of MMP-2. cAMP can influence VM network formation in multiple ways. By stimulation of Epac/Rap1, cAMP inhibits tube formation. Additionally, it inhibits ERK1/2, thereby manipulating the main signaling cascade. However, the stimulatory effect of cAMP on (Notch-1 and) Notch-4 may cause increased expression of Nodal, which subsequently positively regulates VE-cadherin expression. By this latter effect cAMP may also have a positive effect on VM network formation.

In vitro analysis demonstrated that CAMP signaling is implicated in the ability of aggressive melanoma cells (MUM-2B and C8161) to form VM networks ${ }^{52}$ (Figure 3.1). In this process increased cAMP levels, mediated by forskolin treatment, an activator of adenylyl cyclases, reversibly lead to VM inhibition. This effect was mediated by activation of Epac/Rap1. Additionally, enhanced CAMP expression induced an inhibition of ERK1/2, which was independent of Epac and PKA. It was shown that ERK1/2 inactivation is associated with abolished VM. Moreover, increased CAMP expression caused restrained PI3K/Akt signaling. 
Although little is known about cAMP during vascular development, it was recently reported that CAMP is important for endothelial cell differentiation. In vascular endothelial growth factor receptor 2 positive (VEGF-R2+) vascular progenitor cells activation of cAMP directs vascular progenitor commitment to arterial endothelial cell development rather than venous endothelial cell development ${ }^{53}$. This was found to be associated with an increased expression/activation of Notch-1 and Notch-4, both expressed in endothelial cells. Notch signaling is a fundamental pathway in many mammalian cell types undergoing differentiation, mainly acting to regulate cell fate specification (see paragraph Signaling molecules in embryonic vasculogenesis). The linkage between CAMP and Notch activation remains to be elucidated. However, it was reported that in neuronal cells, presenilin-1 is transcriptionally activated by CAMP-responsive element-binding (CREB) protein ${ }^{54}$. Presenilin-1 is a component of $y$ secretase, which is crucial for Notch intracellular domain (NICD) cleavage and thereby Notch activation.

In addition to its role in endothelial differentiation, CAMP signaling is also related to VEcadherin localization. Human umbilical vein endothelial cells (HUVEC) treated with the CAMP elevating reagents prostacyclin and forskolin showed enhanced accumulation of VE-cadherin at the cell-cell contact regions. Increased VE-cadherin expression, mediated by CAMP-Epac-Rap1 signaling, was shown to strengthen cell adhesion and endothelial cell barrier properties ${ }^{55}$. However, cAMP signaling was described to have opposite effects on endothelial barriers of different origin ${ }^{56}$. In relation to diminished VM tube formation, the role of CAMP on VE-cadherin remains unknown.

As CAMP is able to mediate activation of various pathways, one could speculate that the effect on a specific target is dependent on the cellular context and signaling route. All together, it appears that the involvement of cAMP in tumor cell plasticity is not mediated through a single mechanism, but rather involves multiple pathways.

\section{Tumor galectins}

Galectin-3 (Gal-3) has recently been discovered as a novel molecule required for the formation of VM networks (Figure 3.1). Gal-3 is one of the 15 mammalian members of the galectin family of well-conserved carbohydrate-binding proteins. Of these members, Gal-3 is the only chimera-type galectin, a one carbohydrate-recognition domain (CRD) containing an unusual tandem repeat of short amino-acid stretches fused onto the CRD. Gal-3 is known to have oncogenic ${ }^{57,58}$ and angiogenic ${ }^{59}$ potential. In human melanoma, Gal-3 expression levels were shown to be upregulated when progressing to a more malignant or metastatic melanoma ${ }^{60}$. In addition, high expression levels of Gal-3 were also shown in highly metastatic breast carcinoma cells ${ }^{61}$.

Galectins can function both extracellular, by interacting with the ECM and cell-surface glycoproteins and -lipids, and intracellular, via interaction with various proteins thereby modulating signaling pathways. Under normal conditions, galectin expression 
is modulated upon differentiation and development. In cancer, galectins contribute to neoplastic transformation, survival, angiogenesis and metastasis (reviewed in $^{62}$ ). During neoplastic progression and metastasis, intracellular Gal-3 is accumulated in several human malignancies, including colon and liver carcinoma. It has pleiotropic functions depending on its subcellular localization and the cellular context.

In the aggressive cutaneous melanoma cell line C8161-c9, silencing of Gal-3 by means of short hairpin RNA (shRNA) abolished the capacity of these cells to form the VM characteristic tubular networks in a three-dimensional type-I collagen gel ${ }^{60}$. Together with this, the invasiveness of the Gal-3 silenced cells decreased. Gal-3 expression in tumor cells can promote the activation of RAF1 and PI3K, and contributes to selective activation of signaling cascades and the transcriptional regulation of gene expression $^{63}$. Microarray analysis showed that Gal-3 silencing had a negative influence on endothelial markers like VE-cadherin, fibronectin-1, and endothelial cell differentiation gene (EDG)-1. Additionally, the production of the angiogenic interleukin (IL)-8 decreased following diminished Gal-3 expression ${ }^{60}$. IL-8 is known to regulate the expression of MMP- $2^{64}$, which was described previously to be important for VM tube formation. Although shRNA against Gal-3 caused less than 3-fold downregulation of MMP-2 gene expression, gelatin zymography demonstrated a significant reduction of proteinase activity of MMP-2. Consistent with in vitro data, VE-cadherin, IL-8, and MMP-2 expression were downregulated in C8161-c9 tumors xenografts. Additional studies suggested that the stimulatory effect of Gal-3 on VEcadherin and IL-8 was due to a common mechanism, i.e. diminished early growth response protein (EGR)-1 binding to their promoter regions ${ }^{60}$. EGR-1 is a transcriptional regulator that translates extracellular stimuli to cellular responses, such as differentiation and proliferation. Possibly, EGR-1- mediated transcriptional repression of VE-cadherin and IL-8 is important for maintaining a differentiated state in normal tissues. In malignant tumors, increased Gal-3 expression might eliminate EGR-1 promoter binding, thereby allowing their transcription. Taken together, these data suggest a novel pathway induced by Gal-3 and mediated by EGR-1, causing increased expression of VE-cadherin and activated MMP-2.

\section{Signaling molecules in embryonic vasculogenesis}

Many biological properties that are significant to embryogenesis are also critical for tumor progression. Aggressive tumor cells express signaling molecules involved in embryonic vasculogenesis, i.e. development of endothelial cells from precursor cells $^{3,65}$. During embryonic vasculogenesis endothelial precursors, known as angioblasts, differentiate and connect to form a primitive microcirculation often resembling a "honeycomb-like network" of tubular structures that are homogenous in length and size ${ }^{65,66}$. Interestingly, the characteristic pattern of VM networks appears to recapitulate this embryonic morphology. The ability of plastic tumor cells to express endothelium-associated genes is possibly due to the reactivation of embryonic signaling cascades causing aggressive tumor cells to dedifferentiate. The 
section below will discuss the most important signaling molecules implicated in embryonic signaling during vasculogenesis that are also deregulated in aggressive melanoma.

\section{Nodal/Notch}

Recently, it was shown that expression of Nodal, a potent embryonic morphogen from the transforming growth factor (TGF) $\beta$ family, correlates to melanoma progression and plasticity ${ }^{67,68}$. During embryonic development Nodal is responsible for left-right patterning, maintenance of pluripotency/self-renewal capacity of embryonic stem cells, and appears to be essential for maintaining their undifferentiated status ${ }^{69-71}$. Although Nodal expression is lost during differentiation of human embryonic stem cells (hESCs), it is re-expressed in a deregulated fashion in aggressive melanoma ${ }^{72}$ and breast cancer cells ${ }^{73}$. Nodal is secreted in the ECM where it exerts its signal by binding to its co-receptor Cripto and type I (ALK4/7) and type II (ActRIIB) activin-like kinase receptors ${ }^{74}$. This subsequently results in phosphorylation of SMAD2 and possibly $\mathrm{SMAD3}^{74}$. Phosphorylated SMAD2/3 associates with SMAD4 and subsequently translocates to the nucleus. There it regulates target gene expression by connecting to transcription factors, such as forkhead box H1 (FOXH1). LEFTY1 and LEFTY2, both inhibitors of Nodal, are among the Nodal target genes, thereby providing a negative feedback mechanism to ensure no excessive Nodal signaling ${ }^{74}$. Although hESCs have a high expression of both Nodal and LEFTY1/2, aggressive melanoma cells only show Nodal expression without LEFTY ${ }^{75}$. However, these aggressive tumor cells do express Cripto, a co-receptor enhancing the responsiveness to Nodal. Within aggressive melanoma cells, diminished Nodal signaling is associated with reduced VE-cadherin mRNA and protein while enhancing pigment production levels ${ }^{67}$. The above suggests that Nodal is required for maintaining the dedifferentiated state of hESCs as well as plastic tumor cells. Consistent with this, Nodal inhibition promotes the reversion of melanoma cells towards a melanocytic phenotype, accompanied by loss of plasticity $^{67,76}$.

Nodal was previously shown to be a direct transcriptional target of Notch signaling, preferentially via Notch-4 signaling ${ }^{68,77}$ (reviewed in ${ }^{78}$ ) (Figure 3.1). Notch is a highly conserved transmembrane receptor that regulates cell fate specification, self-renewal and differentiation. Four Notch isoforms (Notch-1/2/3/4) and five ligands (Jagged-1/2, Delta-like-1/3/4) have been identified. Notch activation upon ligand binding triggers Notch intracellular cleavage by $\gamma$-secretase, thereby releasing its Notch intracellular domain (NICD). The NICD subsequently translocates to the nucleus where it associates with co-factors to regulate gene transcription (reviewed $\mathrm{in}^{79}$ ). The outcome of Notch receptor/ligand signaling is highly dependent on the cellular context. In the vasculature, Notch-1 and Notch-4 direct the differentiation of endothelial cells into vascular networks ${ }^{80}$. Mice with targeted deletions of Notch-1 die due to severe defects in angiogenic vascular remodelling ${ }^{81}$. Although Notch-4 null mice develop a normal vasculature, Notch- $1 /$ Notch- 4 double mutants revealed more severe effects 
than Notch-1 null mice ${ }^{81}$. The critical role of Notch isoforms in vascular development and their relation to Nodal, together with the knowledge that Notch signaling is implicated in several human cancers ${ }^{82-84}$, suggests a function for Notch in the process of VM. Possibly, deregulated Notch expression provides tumor cells with endotheliallike properties and mediates their ability to form tubular networks. Thus far, only Notch-4 was reported to be increasingly expressed in aggressive melanoma cells in the context of $\mathrm{VM}^{27,85}$. Enhanced Notch-4 expression was speculated to increase the expression of Nodal in these aggressive cells ${ }^{68}$. As mentioned, Nodal signaling is known to support VM and is associated with expression of VE-cadherin ${ }^{67}$. Although not described in relation to VM, the Notch-1 pathway was found to be active in human melanoma. In vitro studies demonstrated that Notch-1 signaling increased the metastatic capacity of primary melanoma cells, which was mediated by increasing $\beta$-catenin expression ${ }^{86}$.

\section{Wingless}

The Wingless (Wnt) family consists of a large protein family that controls various processes like embryonic patterning, migration, and cell differentiation. Wnt signaling, in particular Wnt5a signaling, is required for endothelial cell differentiation of ESCS and proper embryonic vascular development ${ }^{87,88}$. During $\mathrm{mESC}$ endothelial differentiation, Wnt5a mediates its signaling by downstream activation of $\beta$-catenin and protein kinase C (PKC)-alpha. Knockdown of either one of these downstream targets resulted in inhibition of endothelial differentiation mediated by Wnt5a. Furthermore, consistent with the previous findings, the effects of endothelial differentiation in Wnt5a -/- mice could solely be reversed by transfection of both $\beta$-catenin and PKC-alpha ${ }^{88}$.

The role of Wnt5a in tumors is still controversial (reviewed $\mathrm{in}^{89}$ ). While it has been described as a tumor suppressor in some malignancies ${ }^{90,91}$, there is increasing evidence of pro-migratory and pro-invasive effects in others ${ }^{92,93}$. In human melanoma biopsies, Wnt5a expression was found to correlate with increasing tumor aggressiveness ${ }^{72,94}$, suggesting its involvement in tumor progression to more malignant stages. In vitro analysis using melanoma cells transfected with vectors constitutively overexpressing Wnt5a, showed increased melanoma cell invasion ${ }^{94}$. As Wnt5a overexpression triggered increased activation of PKC-alpha, while not affecting $\beta$-catenin expression or localization, the pro-invasive effects of Wnt5a were supposed to be mediated predominantly via PKC-alpha. Microarray analysis of Wnt5a loss-offunction and Wnt5a gain-of-function melanoma cells demonstrated that Wnt5a downregulates genes involved in metastasis suppression (KISS-1) and pigmentation (DCT and HPS4) $^{95}$. Among the few genes upregulated were CD44, a tumor homing and metastasis antigen, and the intermediate filament vimentin ${ }^{95}$. The latter is associated to epithelial to mesenchymal transition (EMT), an event associated with tumor progression. 
Interestingly, besides their above described roles in vascular development, TGF $\beta$, Notch, and Wnt signaling molecules have, among others, also been described to induce EMT, a key process during embryonic morphogenesis. As tumors often reactivate embryonic properties, EMT is re-engaged during tumor progression causing metastatic behavior (reviewed $\mathrm{in}^{96}$ ). Among the characteristics related to EMT are increased cell motility and invasiveness, and the gain of stem cell properties. On gene expression, EMT is characterized by loss of E-cadherin, while increasing the expression of the mesenchymal marker vimentin and stem-like marker CD44. However, whether there actually is a relationship between the gain of tumor cell plasticity, i.e. VM, and EMT remains to be elucidated.

\section{Biological phenomenon related to vasculogenic mimicry}

\section{Cancer stem cells}

Cells capable of VM display a high degree of plasticity, causing them to resemble dedifferentiated cell types. The most well known dedifferentiated cell is the stem cell, as it holds the capacity to generate various novel cell types. Lately, the concept of cancer stem cells (CSCs) is gaining interest. Like physiological stem cells, CSCs are capable of self-renewal and differentiation, and indefinite proliferation, the latter being critical for tumor growth. Malignant melanoma VM is characterized by an undifferentiated molecular signature together with embryonic-like differentiation plasticity, thereby implying a link between CSCs and aggressive tumor cells capable of VM (reviewed in ${ }^{97}$ ). Indeed, these two cell types share the potential for unlimited proliferation potential, cellular plasticity and the expression of genes involved in maintaining pluripotency and/or plasticity ${ }^{13,98}$. Various developmental signaling molecules, known to influence stem cell renewal and differentiation, including Nodal, Notch and Wnt, were shown to be expressed in aggressive melanoma cells ${ }^{27,86,94,99}$. The interplay between these pathways provide a critical balance between selfrenewal and differentiation ${ }^{100}$. Interestingly, in addition to their role in sustaining stem cell potency, these molecules are also important during vascular development, as described previously. These findings are in accordance with the assumption that aggressive melanoma cells acquire a multipotent, plastic phenotype.

Although little is known about signaling cascades governing the pluripotent state, TGF $\beta$ signaling has been shown to be prominent in the maintenance of an undifferentiated state in hESCs. Various components of the TGF $\beta$ signaling cascade are highly expressed in stem cells, including Nodal and its regulators Cripto and LEFTY1/2 $2^{101,102}$. Expression of Nodal has been shown to be high in undifferentiated cells while diminished following differentiation. The TGF $\beta /$ activin/nodal branch of the TGF $\beta$ signaling pathway was found to be activated in undifferentiated cells ${ }^{103}$. This branch involves the activation of SMAD2/3 via $A L K 4 / 5 / 7^{104}$. In order to retain 
pluripotency the TGF $\beta$ /activin/nodal signaling collaborates with Wnt signaling, in which the latter (in)directly influences $\operatorname{SMAD2/3}$ activation ${ }^{103}$. Besides the TGF $\beta$ /activin/nodal branch, TGF $\beta$ also signals through the SMAD1/5 branch, which is activated upon binding of bone morphology protein (BMP) and growth differentiation factor (GDF) ligand to type I receptors ALK1/2/3/6. The contribution of the latter branch in stem cells is largely unknown, although their role in cell proliferation is suggested. Interestingly, BMP4 expression has been linked to the capacity of aggressive melanoma to form tubular structures ${ }^{105}$. This effect appeared to be mediated by positive regulation of VE-cadherin and EphA2 expression.

Notch(-1/-4) expression was previously described to be particularly important for vascular development and endothelial differentiation. However, Notch activation is also critical for maintaining stem cell self-renewal potency in diverse stem cell niches, among which skin ${ }^{106,107}$, probably due to inhibition of differentiation ${ }^{108}$. These results indicate that Notch signaling can have diverse signaling outcomes dependent on the cellular context/microenvironment, as it is able to induce (endothelial) differentiation in some circumstance, while promoting self-renewal potency in others. This latter effect might be due to Notch(-4) induced activation of Nodal, which was described to be critical for maintaining pluripotency ${ }^{68}$. Like Notch signaling, the Wnt pathway regulates stem cell maintenance in a context-dependent manner. Wnt signaling, mediated by $\beta$-catenin, is essential for sustained stemness of intestinal epithelial stem cells ${ }^{109}$ and skin stem cells ${ }^{110}$. However, Wnt signaling may also promote lineage commitment as mesenchymal stem cells require $\mathrm{Wnt}$ for differentiation ${ }^{111}$. Also, as described, Wnt5a signaling is required for endothelial differentiation ${ }^{88}$. Together, it seems that proteins that are important for self-renewal capacity of stem cells are often also implicated in proper direction of differentiation. This suggests that the precise function of these proteins is dependent on the (microenvironmental) trigger activating them.

Embryonic stem cells are maintained in an undifferentiated state by an embryonic microenvironment, which consists of a dynamic yet regulated network of cellular communication. The microenvironment serves as a scaffold for various signal molecules, which can trigger diverse effects depending on the target cell or tissue. The resemblance between aggressive melanoma cells and embryonic stem cells with respect to markers and signaling molecules may imply that the tumor microenvironment gains embryonic characteristics. By presenting an embryonic microenvironment to tumor cells they might adapt a plastic, dedifferentiated phenotype. Aggressive cutaneous melanoma cells (C8161) exposed to hESC preconditioned 3D matrices formed spheroidal clusters in a manner similar to the morphology characteristics of stem cells ${ }^{76,98}$. After removal from the preconditioned matrix, the melanoma cells reverted to their original morphology by day 7. Protein expression analysis of the melanoma cells grown on hESC matrix showed a significant 
downregulation of VE-cadherin. Its expression started increasing again seven days after removal of the melanoma cells from the conditioned matrix. Aggressive tumor cells themselves are also able to modify their microenvironment. As mentioned before, plastic vasculogenic melanoma cells show increased secretion of laminin $5 \mathrm{\gamma} 2$ chain, MMP-2 and other basement membrane constituents that are essential for VM network formation ${ }^{3}$. This illustrates that the tumor microenvironment is an important factor during VM. Human melanocytes grown in a 3-D type-I collagen matrix preconditioned with $\mathrm{C} 8161$ cells were induced to form VM-like networks. Coincident with this was an increased expression of VE-cadherin ${ }^{98}$. Consistent with these data, the poorly aggressive cutaneous melanoma cell line C81-61, which is normally incapable of VM, was able to form tubular structures when grown in type-I collagen matrix preconditioned with the aggressive cutaneous melanoma cell line $\mathrm{C} 8161^{3}$. Although the above mentioned study did not examine whether the induced VM capacity correlated to genetic alterations, a related study which investigated the interaction between the microenvironment of aggressive melanoma cells (C8161) and normal human melanocytes did. It was shown that matrix preconditioned with aggressive melanoma cells reprograms normal melanocytes to express genes associated with a multipotent, plastic phenotype similar to aggressive C8161 melanoma cells ${ }^{112}$.

The susceptibility of melanocytes to preconditioned matrix was not cell type dependent. hESCs cultured in the type-I collagen matrix preconditioned with C8161 cells showed a striking morphological transformation from spheroidal clusters to a mesenchymal-like morphology ${ }^{98}$. Gene expression levels in the hESCs demonstrated a downregulation of embryonic stem cell markers associated with pluripotency and an undifferentiated state like Nodal, while increasing genes associated with a differentiated phenotype like vimentin (mesenchymal marker) and VE-cadherin. Nevertheless, the data indicate that aggressive tumor cells have the ability to manipulate their surroundings without requiring cell-cell contact or direct communication.

Oxygen tension is another important microenvironmental factor in stem cell biology. Stem cells often show dependency on a hypoxic microenvironment in order to maintain their undifferentiated state. Interestingly, pimonidazole staining demonstrated that the areas surrounding VM structures in Ewing sarcoma are hypoxic $^{8}$, as stated previously. Furthermore, hypoxic conditions were shown to enhance the expression of Notch-1 in neuroblastoma cells in vitro, which stimulated dedifferentiation by downregulation of lineage specific genes ${ }^{47,113}$. The phenomenon of hypoxia-induced dedifferentiation was also observed in breast ${ }^{114}$ and prostate ${ }^{115}$ malignancies and non-malignancies ${ }^{116}$. As stem cells often show dependency on a hypoxic microenvironment in order to maintain their undifferentiated state, the hypoxic regions surrounding VM networks are possibly important for maintaining their plastic phenotype. Also, this may imply a relationship between tumor areas 
showing tumor cell-lined tubular structures and stem cell niches.

In 2008 Hajek et al. developed a human glioblastoma (GBM) model in immunodeficient rats that gradually changed its phenotype by serial passages in vivo, from a highly invasive, non-angiogenic tumor expressing stem cell markers, to a typical glioblastoma with rapid cell proliferation, angiogenesis and necrosis ${ }^{117}$. It was speculated that as the first tumor was established by transplantation of spheroids derived directly from a human GBM biopsy, the resulting tumor was formed by stem cell-like cells most capable of adapting to the new microenvironment. Consistently, the first generation tumors showed a more pronounced anaerobic metabolism, indicative for hypoxia, a condition preferred by stem cells in order to maintain in an undifferentiated state. It is likely that the non-invasive tumors have developed from adaptation to the host, whereas the first generation tumors had the plasticity to adapt themselves to a new environment. Possibly, this latter adaption is mediated by differentiating towards an endothelial-like phenotype i.e. VM, though so far no data are present to support this hypothesis.

When linking plastic tumor cells to the presence of CSCs, it is interesting to consider their derivation. One could speculate that in order for a tumor to survive or progress, CSCs partially differentiate towards an endothelial-like phenotype enabling the newly formed tumor cells to form channel-like structures that contribute in nutrient supply or provide a route for metastasis. However, the opposite should also be considered. This would imply that CSCs originate from a dedifferentiation process, starting with 'normal' tumor cells that (gradually) lose cell type-specific functions and markers. Throughout this process, tumor cells expressing endothelial/stem cell markers might develop. As these cells may be beneficial for tumor survival they are retained. Moreover, plastic tumor cells could originate from a physiological fusion event between a CSC and a more differentiated (endothelial) cell ${ }^{118,119}$.

\section{Endothelial cell mutation}

An important concept in tumor angiogenesis is the assumption that tumor blood vessels, although abnormally structured, contain genetically stable endothelial cells, in contrast to genetically instable tumor cells. However, tumor endothelial cells show phenotypical abnormalities compared to normal endothelial cells, suggestive of alterations in gene and protein expression. Several reports have focused on this hypothesis, thereby challenging the theory of genetically stable endothelial cells. Karyotype analysis of tumor endothelial cells showed characteristics of aneuploidy ${ }^{120,121}$. Additionally, using multiple-colored fluorescent in situ hybridization (M-FISH), it was established that tumor endothelial cells, both cultured and noncultured, hold various structural aberrations including nonreciprocal translocations, missing chromosomes, marker chromosomes, and double minutes, indicating chromosomal instability ${ }^{121}$. As different cytogenetic profiles were observed within one 
population, it was speculated that tumor endothelial cells are heterogeneous rather than clonal. Interestingly, other studies reported on tumor-derived endothelial cells holding the same genetic aberrations as tumor cells ${ }^{122,123}$. Streubel et al. showed that $15-85 \%$ of the microvascular endothelial cells in B-cell lymphomas harbored lymphoma-specific chromosomal translocations ${ }^{122}$. In addition, Pezzolo et al. demonstrated the presence of MYCN-amplified endothelial cells in sections of MYCNamplified tumors ${ }^{123}$. Both studies suggest that microvascular endothelial cells are partially tumor-related. To explain the presence of tumor-derived endothelial cells bearing tumor-related aberrations both endothelial and tumor origin of these cells should be considered. For endothelial origin the concept of cellular fusion between tumor cells and endothelial cells was postulated. Such process would form hybrid cells which would then express both tumor and endothelial markers. This hypothesis was supported by the identification of double-positive cells in NOD/Scid eGFP transgenic mice transplanted with U87 dsRed-expressing tumors ${ }^{124}$. Interestingly, this study also identified specific tumor areas where eGFP-expressing endothelial lining was not evident, although erythrocytes were present in the lumen, suggesting the occurrence of VM. In addition, gene transfer by means of endothelial uptake of apoptotic bodies derived from tumor cells was suggested to explain the presence of endothelial cells carrying tumor-specific genetic alterations. However, thus far there are no results supporting this latter hypothesis. In agreement with the assumption of cell interactions, previous in vitro studies have shown that co-culturing MUM-2B and endothelial cells (HUVEC or HMEC-1) resulted in endothelial cell lysis within 48 hours, indeed suggesting an interaction between the two cell populations ${ }^{26}$.

Alternatively, when considering tumor origin, it was hypothesized that genetically altered endothelial cells may have arisen from a tumor cell ${ }^{122}$. The plasticity of tumor cells could cause them to transdifferentiate or dedifferentiate into an endothelial-like phenotype. This may result in the ability of tumor cells to mimic endothelial cell activities and to participate in the formation of vascular structures.

\section{Clinical significance of tumor cell plasticity}

Over the last years, anti-angiogenesis therapy has been emerging as a promising strategy in the treatment of cancer. Treatment modalities are aimed at inhibiting endothelial proliferation and/or migration of endothelial cells to hypoxic tumor regions, thereby hampering the supply of oxygen and nutrition to tumor cells and inducing cell death. The observation that tumor cells can form tubular networks when grown in three-dimensional culture, together with expression of genes associated with an endothelial phenotype, may suggest that VM could be targeted by angiogenesis inhibitors similar to the way they inhibit endothelial cell-driven angiogenesis. However, treatment with angiogenesis inhibitors did not inhibit tube formation of aggressive uveal and cutaneous melanoma cells in vitro ${ }^{125}$, thereby 
showing that plastic tumor cells do not acquire sensitivity. In contrast to this, the antiangiogenesis drug thalidomide was reported to diminish the presence of VM vessels (visualized by CD34-PAS double staining) and reduce tumor growth in C57BL/6 mice subcutaneously injected with B16F10 murine melanoma cells ${ }^{126}$. Concomitant with this was an increased necrotic fraction and inhibition of VEGF, NF-KB, MMP-2 and MMP-9 expression. However, so far data on the effect of anti-angiogenesis treatment on VM network formation remain inconsistent.

Interestingly, recent findings indicated that anti-angiogenesis treatment may elicit malignant progression of tumors ${ }^{127,128}$. VEGF receptor inhibition in mouse models of pancreatic carcinoma reveals an initial antitumoral response indicated by vascular withdraw and tumor stasis. However, these conditions elicit an 'evasive resistance' response causing tumor adaptation and progression to stages of greater malignancy as indicated by increased invasion and metastasis ${ }^{127}$. Furthermore, continuous treatment of mice with sunitinib, an approved tyrosine kinase inhibitor with potent anti-angiogenesis activity by targeting both VEGFR and platelet derived growth factor receptor (PDGFR) signaling, showed to induce a more aggressive tumor phenotype following 5 weeks of treatment ${ }^{127}$. In addition, short-term sunitinib treatment facilitated metastatic dissemination of both human breast cancer cells and syngeneic melanomas in mice following orthotopic or intravenous inoculation ${ }^{128}$. These results suggest that inhibition of VEGF signaling could elicit a tumor response associated with an increased malignancy.

However, the finding that anti-angiogenesis drugs can stimulate tumor progression and metastasis had already been described in $1997^{129}$. In the rat tumor (sarcoma) cell line LY80 the effects of AGM-1470 (TNP-470) were analyzed on tumor growth and metastasis. AGM-1470 is a potent angiogenesis inhibitor that inhibits endothelial cell proliferation in both in vitro and in vivo models and prevents tumor growth in vivo. However, it was not able to inhibit tumor cell network formation in vitro ${ }^{125}$, as stated before. Following eight days of subcutaneous treatment, AGM-1470 had suppressed primary tumor growth. However, the presence of metastatic foci in the lymph nodes was more marked in the AGM-1470-treated animals, in which the cortex and the medulla of the axillary lymph nodes were almost entirely replaced by tumor cells ${ }^{129}$. Vessel density was not compared between the primary tumors of the experimental groups, although this was reported to be similar within lymph nodes tumors. However, at this latter stage, animals were no longer treated with AGM-1470.

The above suggests anti-angiogenesis modalities elicit a tumor response that directs malignant progression. This would imply that such treatment, although initially resulting in tumor stasis, would ultimately be detrimental to the patient as it allows the tumor to select for those cells capable of surviving when angiogenesis is hampered. This escape mechanism is possibly mediated by plastic tumor cells gaining endothelial characteristics, i.e. VM. As VM might function both as a complementary means of tumor perfusion, as well as an additional route for tumor metastasis, these 
findings raise the possibility that under angiogenesis hampering conditions, tumors relapse to additional vascularization mechanisms by altering their tumor cell characteristics. To examine this possibility it would be interesting to determine whether the presence of tumor-lined vascular-like channels is occurring or increasing in these studies. Notable, although murine models have indicated a resistance mechanism and tumor progression, no clinical study has reported increased tumor malignancy in patients following anti-angiogenesis therapy so far. Nevertheless, as a tumor is comprised of a highly heterogeneous cell population, the assumption that tumors are capable of adaptation and even progression by means of selection is not impossible. These considerations may contribute to the insight that is needed to develop more accurate antivascular and antitumor strategies.

\section{Concluding remarks}

Since 1999 research on VM has increased our knowledge of the molecular events causing aggressive tumor cells to gain plasticity resulting in their ability to mimic vasculature. It is noteworthy that several molecules are implicated in multiple pathways critical in VM. Therefore, it appears that the process of VM does not rely on a sole signaling cascade, but rather the similar outcome of different signaling events resulting in the activation/expression of VM key signal transduction molecules. This would explain for differences in expression levels of VM-associated genes in different tumor types, although all capable of VM. As single knockdown studies on VE-cadherin and MMP-2 showed hampered network formation, these genes are potential signaling outcomes enabling tumor cells to adapt a plastic phenotype. In addition, genes like Notch, and its downstream target Nodal, have drawn attention as they are implicated in embryonic vasculogenesis as well as stem cell biology. As anti-angiogenesis therapies do not (consistently) inhibit VM network formation, and might even elicit VM as a resistance mechanism, research should focus on VM-targeting strategies. Currently Notch inhibitors ( $\gamma$-secretase inhibitors) are being tested in clinical trials, which would allow for examining its potential value as VM inhibitor. Interestingly, inhibition of Notch signaling has been shown to inhibit tumor angiogenesis in a mouse model $^{130}$. Additionally, as phosphorylation events were shown to be critical in various VM signaling pathways, specific kinase inhibitors might also efficiently target VM.

For a tumor to progress to a more malignant stage there is a constant selection for cells providing advantage to the tumor. Although the exact function of VM networks remains to be elucidated, the correlation of VM with tumor grade suggests a functional contribution of plastic tumor cells to increase malignancy. Research on the molecular mechanisms underlying VM and its functional relevance will improve our understanding of this process and may ultimately contribute to the development of more accurate treatment modalities. 


\section{Summary}

Vasculogenic mimicry (VM) describes the ability of plastic tumor cells to express multiple cellular phenotypes, and gain endothelial characteristics, together with their ability to form vasculogenic-like networks.

- In order to increase our knowledge on VM, studies have been focusing on identifying signaling molecules implicated in this process. Besides the early discovered VM key molecules such as VEcadherin, EphA2 and MMPs, novel molecules were identified, among which cAMP, galectin-3, Nodal, and Notch.

- $\quad$ VM signaling molecules are often critical during embryonic vasculogenesis, suggestive of a reactivation of embryonic signaling cascades in aggressive tumor cells.

- $\quad$ The biological relevance of VM networks in vivo remains unclear, although studies have demonstrated the potential to transport fluid indicating a possible function as an additional route for nutrient supply and/or metastasis.

- $\quad$ Plastic tumor cells engaged in VM display a highly dedifferentiated phenotype. This raises the question whether aggressive tumor cells may be related to the presence of multipotent cancer stem cells (CSCs).

- $\quad$ Endothelial cells have been considered to be genetically stable, in contrast to genetically instable tumor cells. However, the finding that tumor endothelial cells can harbor tumor-specific mutations may be of importance to the VM research field.

- $\quad$ Despite of the ability of plastic tumor cells to express endothelial characteristics, anti-angiogenesis therapies do not consistently inhibit VM.

- $\quad$ Anti-angiogenesis treatment increases malignant progression, suggesting an evasive mechanism in tumors as angiogenesis is hampered. Possibly, the capacity of aggressive tumor cells to adapt an endothelial phenotype (VM) may provide tumors with an escape mechanism. 


\section{References}

1. Maniotis AJ, Folberg R, Hess A, et al. Vascular channel formation by human melanoma cells in vivo and in vitro: vasculogenic mimicry. Am J Pathol, 1999; 155:739-52.

2. Folberg R, Maniotis AJ. Vasculogenic mimicry. Apmis, 2004; 112:508-25.

3. Seftor RE, Seftor EA, Koshikawa N, et al. Cooperative interactions of laminin 5 gamma2 chain, matrix metalloproteinase-2, and membrane type-1-matrix/metalloproteinase are required for mimicry of embryonic vasculogenesis by aggressive melanoma. Cancer Res, 2001; 61:6322-7.

4. Shirakawa K, Tsuda H, Heike $\mathrm{Y}$, et al. Absence of endothelial cells, central necrosis, and fibrosis are associated with aggressive inflammatory breast cancer. Cancer Res, 2001; 61:445-51.

5. Sood AK, Seftor EA, Fletcher MS, et al. Molecular determinants of ovarian cancer plasticity. Am J Pathol, 2001; 158:1279-88.

6. Sood AK, Fletcher MS, Zahn CM, et al. The clinical significance of tumor cell-lined vasculature in ovarian carcinoma: implications for anti-vasculogenic therapy. Cancer Biol Ther, 2002; 1:661-4.

7. Sharma N, Seftor RE, Seftor EA, et al. Prostatic tumor cell plasticity involves cooperative interactions of distinct phenotypic subpopulations: role in vasculogenic mimicry. Prostate, 2002; 50:189-201.

8. van der Schaft DW, Hillen F, Pauwels $P$, et al. Tumor cell plasticity in Ewing sarcoma, an alternative circulatory system stimulated by hypoxia. Cancer Res, 2005; 65:11520-8.

9. Passalidou $\mathrm{E}$, Trivella $\mathrm{M}$, Singh $\mathrm{N}$, et al. Vascular phenotype in angiogenic and non-angiogenic lung non-small cell carcinomas. Br J Cancer, 2002; 86:244-9.

10. Vartanian AA, Stepanova EV, Gutorov SL, et al. Prognostic significance of periodic acid-Schiff-positive patterns in clear cell renal cell carcinoma. Can J Urol, 2009; 16:4726-32.

11. Folberg R, Rummelt V, Parys-Van Ginderdeuren R, et al. The prognostic value of tumor blood vessel morphology in primary uveal melanoma. Ophthalmology, 1993; 100:1389-98.

12. Sun B, Zhang $\mathrm{S}$, Zhao $\mathrm{X}$, et al. Vasculogenic mimicry is associated with poor survival in patients with mesothelial sarcomas and alveolar rhabdomyosarcomas. Int J Oncol, 2004; 25:1609-14.

13. Seftor EA, Meltzer PS, Schatteman GC, et al. Expression of multiple molecular phenotypes by aggressive melanoma tumor cells: role in vasculogenic mimicry. Crit Rev Oncol Hematol, 2002; 44 17-27.

14. Seftor EA, Meltzer PS, Kirschmann DA, et al. Molecular determinants of human uveal melanoma invasion and metastasis. Clin Exp Metastasis, 2002; 19:233-46.

15. Bittner $\mathrm{M}$, Meltzer $\mathrm{P}, \mathrm{Chen} \mathrm{Y}$, et al. Molecular classification of cutaneous malignant melanoma by gene expression profiling. Nature, 2000; 406:536-40.

16. Hendrix MJ, Seftor EA, Meltzer PS, et al. Expression and functional significance of VE-cadherin in aggressive human melanoma cells: role in vasculogenic mimicry. Proc Natl Acad Sci U S A, 2001; 98:8018-23.

17. Hess AR, Seftor EA, Gardner LM, et al. Molecular regulation of tumor cell vasculogenic mimicry by tyrosine phosphorylation: role of epithelial cell kinase (Eck/EphA2). Cancer Res, 2001; 61:3250-5.

18. Carmeliet P. Mechanisms of angiogenesis and arteriogenesis. Nat Med, 2000; 6:389-95.

19. Gitay-Goren H, Halaban R, Neufeld G. Human melanoma cells but not normal melanocytes express vascular endothelial growth factor receptors. Biochem Biophys Res Commun, 1993; 190:702-8.

20. Kim EJ, Park HY, Yaar M, et al. Modulation of vascular endothelial growth factor receptors in melanocytes. Exp Dermatol, 2005; 14:625-33.

21. Ruf W, Seftor EA, Petrovan RJ, et al. Differential role of tissue factor pathway inhibitors 1 and 2 in melanoma vasculogenic mimicry. Cancer Res, 2003; 63:5381-9.

22. Contrino J, Hair G, Kreutzer DL, et al. In situ detection of tissue factor in vascular endothelial cells: correlation with the malignant phenotype of human breast disease. Nat Med, 1996; 2:209-15.

23. Rao CN, Reddy $\mathrm{P}$, Liu $\mathrm{Y}$, et al. Extracellular matrix-associated serine protease inhibitors ( $\mathrm{Mr} 33,000$, 31,000 , and 27,000 ) are single-gene products with differential glycosylation: cDNA cloning of the 33kDa inhibitor reveals its identity to tissue factor pathway inhibitor-2. Arch Biochem Biophys, 1996; 335:82-92.

24. Clarijs R, Otte-Holler I, Ruiter DJ, et al. Presence of a fluid-conducting meshwork in xenografted cutaneous and primary human uveal melanoma. Invest Ophthalmol Vis Sci, 2002; 43:912-8. 
25. Kobayashi H, Shirakawa K, Kawamoto S, et al. Rapid accumulation and internalization of radiolabeled herceptin in an inflammatory breast cancer xenograft with vasculogenic mimicry predicted by the contrast-enhanced dynamic MRI with the macromolecular contrast agent G6-(1B4M-Gd)(256). Cancer Res, 2002; 62:860-6.

26. Maniotis AJ, Chen X, Garcia C, et al. Control of melanoma morphogenesis, endothelial survival, and perfusion by extracellular matrix. Lab Invest, 2002; 82:1031-43.

27. Hendrix MJ, Seftor EA, Hess AR, et al. Vasculogenic mimicry and tumour-cell plasticity: lessons from melanoma. Nat Rev Cancer, 2003; 3:411-21.

28. Evidence for novel non-angiogenic pathway in breast-cancer metastasis. Breast Cancer Progression Working Party. Lancet, 2000; 355:1787-8.

29. Gory-Faure S, Prandini $\mathrm{MH}$, Pointu $\mathrm{H}$, et al. Role of vascular endothelial-cadherin in vascular morphogenesis. Development, 1999; 126:2093-102.

30. Hess AR, Seftor EA, Gruman LM, et al. VE-cadherin regulates EphA2 in aggressive melanoma cells through a novel signaling pathway: implications for vasculogenic mimicry. Cancer Biol Ther, 2006; 5:228-33.

31. Margaryan NV, Strizzi L, Abbott DE, et al. EphA2 as a promoter of melanoma tumorigenicity. Cancer Biol Ther, 2009; 8.

32. Duxbury MS, Ito $\mathrm{H}$, Zinner $\mathrm{MJ}$, et al. Ligation of EphA2 by Ephrin A1-Fc inhibits pancreatic adenocarcinoma cellular invasiveness. Biochem Biophys Res Commun, 2004; 320:1096-102.

33. Duxbury MS, Ito $\mathrm{H}$, Zinner MJ, et al. EphA2: a determinant of malignant cellular behavior and a potential therapeutic target in pancreatic adenocarcinoma. Oncogene, 2004; 23:1448-56.

34. Hess AR, Postovit LM, Margaryan NV, et al. Focal adhesion kinase promotes the aggressive melanoma phenotype. Cancer Res, 2005; 65:9851-60.

35. Giannelli G, Falk-Marzillier J, Schiraldi O, et al. Induction of cell migration by matrix metalloprotease-2 cleavage of laminin-5. Science, 1997; 277:225-8.

36. Koshikawa N, Giannelli G, Cirulli V, et al. Role of cell surface metalloprotease MT1-MMP in epithelial cell migration over laminin-5. J Cell Biol, 2000; 148:615-24.

37. Hess AR, Seftor EA, Seftor RE, et al. Phosphoinositide 3-kinase regulates membrane Type 1-matrix metalloproteinase (MMP) and MMP-2 activity during melanoma cell vasculogenic mimicry. Cancer Res, 2003; 63:4757-62.

38. Seftor RE, Seftor EA, Kirschmann DA, et al. Targeting the tumor microenvironment with chemically modified tetracyclines: inhibition of laminin 5 gamma2 chain promigratory fragments and vasculogenic mimicry. Mol Cancer Ther, 2002; 1:1173-9.

39. Gory S, Dalmon J, Prandini MH, et al. Requirement of a GT box (Sp1 site) and two Ets binding sites for vascular endothelial cadherin gene transcription. J Biol Chem, 1998; 273:6750-5.

40. Gory S, Vernet $\mathrm{M}$, Laurent $\mathrm{M}$, et al. The vascular endothelial-cadherin promoter directs endothelialspecific expression in transgenic mice. Blood, 1999; 93:184-92.

41. Le Bras A, Lionneton F, Mattot V, et al. HIF-2alpha specifically activates the VE-cadherin promoter independently of hypoxia and in synergy with Ets-1 through two essential ETS-binding sites. Oncogene, 2007; 26:7480-9.

42. Tian H, McKnight SL, Russell DW. Endothelial PAS domain protein 1 (EPAS1), a transcription factor selectively expressed in endothelial cells. Genes Dev, 1997; 11:72-82.

43. Peng J, Zhang L, Drysdale L, et al. The transcription factor EPAS-1/hypoxia-inducible factor 2alpha plays an important role in vascular remodeling. Proc Natl Acad Sci U S A, 2000; 97:8386-91.

44. Giatromanolaki A, Koukourakis MI, Sivridis E, et al. Relation of hypoxia inducible factor 1 alpha and 2 alpha in operable non-small cell lung cancer to angiogenic/molecular profile of tumours and survival. Br J Cancer, 2001; 85:881-90.

45. Giatromanolaki A, Sivridis E, Fiska A, et al. Hypoxia-inducible factor-2 alpha (HIF-2 alpha) induces angiogenesis in breast carcinomas. Appl Immunohistochem Mol Morphol, 2006; 14:78-82.

46. Covello KL, Kehler J, Yu H, et al. HIF-2alpha regulates Oct-4: effects of hypoxia on stem cell function, embryonic development, and tumor growth. Genes Dev, 2006; 20:557-70.

47. Lofstedt $T$, Fredlund E, Holmquist-Mengelbier L, et al. Hypoxia inducible factor-2alpha in cancer. Cell Cycle, 2007; 6:919-26.

48. Covello KL, Simon MC, Keith B. Targeted replacement of hypoxia-inducible factor-1alpha by a hypoxiainducible factor-2alpha knock-in allele promotes tumor growth. Cancer Res, 2005; 65:2277-86. 
49. Kamenetsky M, Middelhaufe S, Bank EM, et al. Molecular details of cAMP generation in mammalian cells: a tale of two systems. J Mol Biol, 2006; 362:623-39.

50. Bos JL. Epac proteins: multi-purpose cAMP targets. Trends Biochem Sci, 2006; 31:680-6.

51. Roscioni SS, Elzinga CR, Schmidt M. Epac: effectors and biological functions. Naunyn Schmiedebergs Arch Pharmacol, 2008; 377:345-57.

52. Lissitzky JC, Parriaux D, Ristorcelli E, et al. Cyclic AMP signaling as a mediator of vasculogenic mimicry in aggressive human melanoma cells in vitro. Cancer Res, 2009; 69:802-9.

53. Yurugi-Kobayashi $\mathrm{T}$, Itoh $\mathrm{H}$, Schroeder $\mathrm{T}$, et al. Adrenomedullin/cyclic AMP pathway induces Notch activation and differentiation of arterial endothelial cells from vascular progenitors. Arterioscler Thromb Vasc Biol, 2006; 26:1977-84.

54. Mitsuda N, Ohkubo N, Tamatani M, et al. Activated cAMP-response element-binding protein regulates neuronal expression of presenilin-1. J Biol Chem, 2001; 276:9688-98.

55. Fukuhara S, Sakurai A, Sano H, et al. Cyclic AMP potentiates vascular endothelial cadherin-mediated cell-cell contact to enhance endothelial barrier function through an Epac-Rap1 signaling pathway. Mol Cell Biol, 2005; 25:136-46.

56. Bindewald K, Gunduz D, Hartel F, et al. Opposite effect of cAMP signaling in endothelial barriers of different origin. Am J Physiol Cell Physiol, 2004; 287:C1246-55.

57. Honjo $\mathrm{Y}$, Nangia-Makker $\mathrm{P}$, Inohara $\mathrm{H}$, et al. Down-regulation of galectin-3 suppresses tumorigenicity of human breast carcinoma cells. Clin Cancer Res, 2001; 7:661-8.

58. Takenaka Y, Inohara H, Yoshii T, et al. Malignant transformation of thyroid follicular cells by galectin3. Cancer Lett, 2003; 195:111-9.

59. Nangia-Makker P, Honjo Y, Sarvis R, et al. Galectin-3 induces endothelial cell morphogenesis and angiogenesis. Am J Pathol, 2000; 156:899-909.

60. Mourad-Zeidan AA, Melnikova VO, Wang $H$, et al. Expression profiling of Galectin-3-depleted melanoma cells reveals its major role in melanoma cell plasticity and vasculogenic mimicry. Am J Pathol, 2008; 173:1839-52.

61. Khaldoyanidi SK, Glinsky VV, Sikora L, et al. MDA-MB-435 human breast carcinoma cell homo- and heterotypic adhesion under flow conditions is mediated in part by Thomsen-Friedenreich antigengalectin-3 interactions. J Biol Chem, 2003; 278:4127-34.

62. Liu FT, Rabinovich GA. Galectins as modulators of tumour progression. Nat Rev Cancer, 2005; 5:29-41.

63. Elad-Sfadia G, Haklai R, Balan E, et al. Galectin-3 augments K-Ras activation and triggers a Ras signal that attenuates ERK but not phosphoinositide 3-kinase activity. J Biol Chem, 2004; 279:34922-30.

64. Luca M, Huang S, Gershenwald JE, et al. Expression of interleukin-8 by human melanoma cells upregulates MMP-2 activity and increases tumor growth and metastasis. Am J Pathol, 1997; 151: 1105-13.

65. Hess AR, Margaryan NV, Seftor EA, et al. Deciphering the signaling events that promote melanoma tumor cell vasculogenic mimicry and their link to embryonic vasculogenesis: role of the Eph receptors. Dev Dyn, 2007; 236:3283-96.

66. Conway EM, Collen D, Carmeliet P. Molecular mechanisms of blood vessel growth. Cardiovasc Res, 2001; 49:507-21.

67. Topczewska JM, Postovit LM, Margaryan NV, et al. Embryonic and tumorigenic pathways converge via Nodal signaling: role in melanoma aggressiveness. Nat Med, 2006; 12:925-32.

68. Postovit LM, Seftor EA, Seftor RE, et al. Targeting Nodal in malignant melanoma cells. Expert Opin Ther Targets, 2007; 11:497-505.

69. Brennan J, Norris DP, Robertson EJ. Nodal activity in the node governs left-right asymmetry. Genes Dev, 2002; 16:2339-44.

70. Valdimarsdottir G, Mummery C. Functions of the TGFbeta superfamily in human embryonic stem cells. Apmis, 2005; 113:773-89.

71. Vallier L, Alexander M, Pedersen RA. Activin/Nodal and FGF pathways cooperate to maintain pluripotency of human embryonic stem cells. J Cell Sci, 2005; 118:4495-509.

72. Postovit LM, Margaryan NV, Seftor EA, et al. Role of nodal signaling and the microenvironment underlying melanoma plasticity. Pigment Cell Melanoma Res, 2008; 21:348-57.

73. Strizzi L, Postovit LM, Margaryan NV, et al. Emerging roles of nodal and Cripto-1: from embryogenesis to breast cancer progression. Breast Dis, 2008; 29:91-103.

74. Schier AF. Nodal signaling in vertebrate development. Annu Rev Cell Dev Biol, 2003; 19:589-621. 
75. Postovit LM, Costa FF, Bischof JM, et al. The commonality of plasticity underlying multipotent tumor cells and embryonic stem cells. J Cell Biochem, 2007; 101:908-17.

76. Hendrix MJ, Seftor EA, Seftor RE, et al. Reprogramming metastatic tumour cells with embryonic microenvironments. Nat Rev Cancer, 2007; 7:246-55.

77. Krebs LT, Iwai N, Nonaka $\mathrm{S}$, et al. Notch signaling regulates left-right asymmetry determination by inducing Nodal expression. Genes Dev, 2003; 17:1207-12.

78. Strizzi L, Hardy KM, Seftor EA, et al. Development and cancer: at the crossroads of Nodal and Notch signaling. Cancer Res, 2009; 69:7131-4.

79. Fortini ME. Notch signaling: the core pathway and its posttranslational regulation. Dev Cell, 2009; 16:633-47.

80. Gridley T. Notch signaling during vascular development. Proc Natl Acad Sci U S A, 2001; 98:5377-8.

81. Krebs LT, Xue $\mathrm{Y}$, Norton $C R$, et al. Notch signaling is essential for vascular morphogenesis in mice. Genes Dev, 2000; 14:1343-52.

82. Shou J, Ross $\mathrm{S}$, Koeppen $\mathrm{H}$, et al. Dynamics of notch expression during murine prostate development and tumorigenesis. Cancer Res, 2001; 61:7291-7.

83. Weijzen S, Rizzo P, Braid M, et al. Activation of Notch-1 signaling maintains the neoplastic phenotype in human Ras-transformed cells. Nat Med, 2002; 8:979-86.

84. Zagouras $\mathrm{P}$, Stifani S, Blaumueller CM, et al. Alterations in Notch signaling in neoplastic lesions of the human cervix. Proc Natl Acad Sci U S A, 1995; 92:6414-8.

85. Demou ZN, Hendrix MJ. Microgenomics profile the endogenous angiogenic phenotype in subpopulations of aggressive melanoma. J Cell Biochem, 2008; 105:562-73.

86. Balint K, Xiao M, Pinnix CC, et al. Activation of Notch1 signaling is required for beta-catenin-mediated human primary melanoma progression. J Clin Invest, 2005; 115:3166-76.

87. Wang $\mathrm{H}$, Charles PC, Wu Y, et al. Gene expression profile signatures indicate a role for Wnt signaling in endothelial commitment from embryonic stem cells. Circ Res, 2006; 98:1331-9.

88. Yang DH, Yoon JY, Lee SH, et al. Wnt5a is required for endothelial differentiation of embryonic stem cells and vascularization via pathways involving both $\mathrm{Wnt} /$ beta-catenin and protein kinase Calpha. Circ Res, 2009; 104:372-9.

89. McDonald SL, Silver A. The opposing roles of Wnt-5a in cancer. Br J Cancer, 2009; 101:209-14.

90. Blanc E, Goldschneider D, Douc-Rasy S, et al. Wnt-5a gene expression in malignant human neuroblasts. Cancer Lett, 2005; 228:117-23.

91. Bui TD, Zhang L, Rees MC, et al. Expression and hormone regulation of Wnt2, 3, 4, 5a, 7a, 7b and 10b in normal human endometrium and endometrial carcinoma. Br J Cancer, 1997; 75:1131-6.

92. Ripka S, Konig A, Buchholz M, et al. WNT5A--target of CUTL1 and potent modulator of tumor cell migration and invasion in pancreatic cancer. Carcinogenesis, 2007; 28:1178-87.

93. Taki M, Kamata N, Yokoyama K, et al. Down-regulation of Wnt-4 and up-regulation of Wnt-5a expression by epithelial-mesenchymal transition in human squamous carcinoma cells. Cancer Sci, 2003; 94:593-7.

94. Weeraratna AT, Jiang Y, Hostetter G, et al. Wnt5a signaling directly affects cell motility and invasion of metastatic melanoma. Cancer Cell, 2002; 1:279-88.

95. Dissanayake SK, Wade M, Johnson CE, et al. The Wnt5A/protein kinase C pathway mediates motility in melanoma cells via the inhibition of metastasis suppressors and initiation of an epithelial to mesenchymal transition. J Biol Chem, 2007; 282:17259-71.

96. Wu Y, Zhou BP. New insights of epithelial-mesenchymal transition in cancer metastasis. Acta Biochim Biophys Sin (Shanghai), 2008; 40:643-50.

97. Schatton T, Frank MH. Cancer stem cells and human malignant melanoma. Pigment Cell Melanoma Res, 2008; 21:39-55.

98. Abbott DE, Bailey CM, Postovit LM, et al. The Epigenetic Influence of Tumor and Embryonic Microenvironments: How Different are They? Cancer Microenviron, 2008; 1:13-21.

99. Hoek K, Rimm DL, Williams KR, et al. Expression profiling reveals novel pathways in the transformation of melanocytes to melanomas. Cancer Res, 2004; 64:5270-82.

100. Morrison SJ, Kimble J. Asymmetric and symmetric stem-cell divisions in development and cancer. Nature, 2006; 441:1068-74.

101. Rosler ES, Fisk GJ, Ares X, et al. Long-term culture of human embryonic stem cells in feeder-free conditions. Dev Dyn, 2004; 229:259-74. 
102. Sato N, Sanjuan IM, Heke M, et al. Molecular signature of human embryonic stem cells and its comparison with the mouse. Dev Biol, 2003; 260:404-13.

103. James D, Levine AJ, Besser D, et al. TGFbeta/activin/nodal signaling is necessary for the maintenance of pluripotency in human embryonic stem cells. Development, 2005; 132:1273-82.

104. Shi Y, Massague J. Mechanisms of TGF-beta signaling from cell membrane to the nucleus. Cell, 2003; 113:685-700.

105. Rothhammer T, Bataille F, Spruss T, et al. Functional implication of BMP4 expression on angiogenesis in malignant melanoma. Oncogene, 2007; 26:4158-70.

106. Calvi LM, Adams GB, Weibrecht KW, et al. Osteoblastic cells regulate the haematopoietic stem cell niche. Nature, 2003; 425:841-6.

107. Pinnix CC, Herlyn M. The many faces of Notch signaling in skin-derived cells. Pigment Cell Res, 2007; 20:458-65.

108. Henrique D, Hirsinger E, Adam J, et al. Maintenance of neuroepithelial progenitor cells by Delta-Notch signalling in the embryonic chick retina. Curr Biol, 1997; 7:661-70.

109. Fevr T, Robine S, Louvard D, et al. Wnt/beta-catenin is essential for intestinal homeostasis and maintenance of intestinal stem cells. Mol Cell Biol, 2007; 27:7551-9.

110. Malanchi I, Peinado $H$, Kassen D, et al. Cutaneous cancer stem cell maintenance is dependent on beta-catenin signalling. Nature, 2008; 452:650-3.

111. Matushansky I, Hernando E, Socci ND, et al. Derivation of sarcomas from mesenchymal stem cells via inactivation of the Wnt pathway. J Clin Invest, 2007; 117:3248-57.

112. Seftor EA, Brown KM, Chin L, et al. Epigenetic transdifferentiation of normal melanocytes by a metastatic melanoma microenvironment. Cancer Res, 2005; 65:10164-9.

113. Jogi A, Vallon-Christersson J, Holmquist L, et al. Human neuroblastoma cells exposed to hypoxia: induction of genes associated with growth, survival, and aggressive behavior. Exp Cell Res, 2004; 295:469-87.

114. Helczynska K, Kronblad A, Jogi A, et al. Hypoxia promotes a dedifferentiated phenotype in ductal breast carcinoma in situ. Cancer Res, 2003; 63:1441-4.

115. Ghafar MA, Anastasiadis AG, Chen MW, et al. Acute hypoxia increases the aggressive characteristics and survival properties of prostate cancer cells. Prostate, 2003; 54:58-67.

116. Lin Q, Lee YJ, Yun Z. Differentiation arrest by hypoxia. J Biol Chem, 2006; 281:30678-83.

117. Thorsen F, Jirak D, Wang J, et al. Two distinct tumor phenotypes isolated from glioblastomas show different MRS characteristics. NMR Biomed, 2008; 21:830-8.

118. Spees JL, Olson SD, Ylostalo J, et al. Differentiation, cell fusion, and nuclear fusion during ex vivo repair of epithelium by human adult stem cells from bone marrow stroma. Proc Natl Acad Sci U S A, 2003; 100:2397-402.

119. Wang $\mathrm{X}$, Willenbring $\mathrm{H}$, Akkari $\mathrm{Y}$, et al. Cell fusion is the principal source of bone-marrow-derived hepatocytes. Nature, 2003; 422:897-901.

120. Hida K, Hida Y, Amin DN, et al. Tumor-associated endothelial cells with cytogenetic abnormalities. Cancer Res, 2004; 64:8249-55.

121. Hida K, Klagsbrun M. A new perspective on tumor endothelial cells: unexpected chromosome and centrosome abnormalities. Cancer Res, 2005; 65:2507-10.

122. Streubel B, Chott A, Huber D, et al. Lymphoma-specific genetic aberrations in microvascular endothelial cells in B-cell lymphomas. N Engl J Med, 2004; 351:250-9.

123. Pezzolo A, Parodi F, Corrias MV, et al. Tumor origin of endothelial cells in human neuroblastoma. J Clin Oncol, 2007; 25:376-83.

124. Niclou SP, Danzeisen C, Eikesdal HP, et al. A novel eGFP-expressing immunodeficient mouse model to study tumor-host interactions. Faseb J, 2008; 22:3120-8.

125. van der Schaft DW, Seftor RE, Seftor EA, et al. Effects of angiogenesis inhibitors on vascular network formation by human endothelial and melanoma cells. J Natl Cancer Inst, 2004; 96:1473-7.

126. Zhang S, Li M, Gu Y, et al. Thalidomide influences growth and vasculogenic mimicry channel formation in melanoma. J Exp Clin Cancer Res, 2008; 27:60.

127. Paez-Ribes $M$, Allen $\mathrm{E}$, Hudock J, et al. Antiangiogenic therapy elicits malignant progression of tumors to increased local invasion and distant metastasis. Cancer Cell, 2009; 15:220-31.

128. Ebos JM, Lee CR, Cruz-Munoz W, et al. Accelerated metastasis after short-term treatment with a potent inhibitor of tumor angiogenesis. Cancer Cell, 2009; 15:232-9. 
129. Hori K, Li HC, Saito S, et al. Increased growth and incidence of lymph node metastases due to the angiogenesis inhibitor AGM-1470. Br J Cancer, 1997; 75:1730-4.

130. Funahashi $Y$, Hernandez SL, Das I, et al. A notch1 ectodomain construct inhibits endothelial notch signaling, tumor growth, and angiogenesis. Cancer Res, 2008; 68:4727-35. 


\section{Chapter 4}

\section{Imatinib reduces the vasculogenic potential of plastic tumor cells}

Yvette WJ Paulis, Domenica Dinnes, Patricia MMB Soetekouw, Peter J Nelson, Stefan Burdach, Robert P Loewe, Vivianne CG Tjan-Heijnen, Irene von Luettichau, Arjan W Griffioen

Current Angiogenesis. 2012;1:64-71 


\section{Abstract}

Aggressive tumor cells can obtain the ability to form vascular-like structures that may contribute to blood circulation. This process is referred to as vasculogenic mimicry (VM). The occurrence of VM networks is associated with increased tumor malignancy and poor prognosis. In addition, this process is speculated to contribute to resistance to angiostatic therapy. Various signaling molecules involved in the formation of vasculogenic structures have been identified and phosphorylation events have been shown to be required for VM network formation. Here, we show by microarray analysis that highly aggressive $\mathrm{VM}$-positive $\left(\mathrm{VM}^{+}\right)$Ewing sarcoma cells show increased expression of c-Kit tyrosine kinase. This result urged us to investigate the effect of the c-Kit targeting compound imatinib (Gleevec ${ }^{\circledR}$, STI571) on the process of VM. It was found that treatment of $\mathrm{VM}^{+}$tumor cells with imatinib reduced VM network formation in 3-dimensional cultures on Matrigel and collagen. This diminished capacity to form networks was associated with reduced expression of VE-cadherin and MMP-2, proteins described to be essential for VM, and reduced phosphorylation of EphA2. The data presented here demonstrate the potential of clinically used imatinib as a possible drug to target VM. 


\section{Introduction}

Solid tumors require an adequate blood supply in order to grow and metastasize. Although the process of tumor angiogenesis has been considered the main mechanism by which tumors recruit new blood vessels, an alternative mechanism, not involving endothelial cells, has been described. This process, called vasculogenic mimicry (VM), describes the unique ability of highly aggressive, plastic tumor cells to form vasculogenic structures of matrix-embedded networks containing blood ${ }^{1,2}$. The occurrence of VM is relatively rare and its incidence varies between tumor types. The presence of VM-associated matrix-embedded networks in patient tumor tissues was found to correlate to increased disease aggressiveness ${ }^{2-4}$.

Tumor cells capable of VM were shown to display a transdifferentiated phenotype, as they express markers of endothelial cells ${ }^{5,6}$. Genes involved in angiogenesis and vasculogenesis, such as vascular endothelial (VE)-cadherin, Ephrin receptor A2 (EphA2) and laminin-5 $\gamma_{2}$ chain, were found to be highly expressed in aggressive - $\mathrm{VM}^{+}$ - tumor cells compared to poorly aggressive - $\mathrm{VM}^{-}$- tumor cells ${ }^{7,8}$. In addition, $\mathrm{VM}^{+}$ tumor cells display an enhanced expression of metalloproteinases (MMP), including MMP-2. MMPs act in a cooperative manner with laminin-5 52 to induce VM network formation ${ }^{9}$. The functional relevance of the tubular networks formed by aggressive tumor cells remains to be elucidated. Due to the presence of blood components in these structures, and the observation of blood flow in these VM networks, they have been speculated to form a self-vascularizing mechanism contributing to oxygenation $^{10}$. This suggests that VM network formation has evolved as a survival mechanism for tumor cells resulting in resistance to angiogenesis inhibitors. In addition, as VM networks appear to be in contact with the circulation, the formation of the VM-characteristic structures may facilitate tumor cell metastasis to distant organs.

As the presence of VM is associated with increased malignancy, inhibition of VM network formation may be an efficient treatment strategy to delay tumor progression. Although these plastic tumor cells resemble endothelial cells, it was found that VM network formation was not hampered by angiogenesis inhibitors ${ }^{11}$, suggesting that other pathways and signaling molecules are implicated in vasculogenic network formation. Over the years, research has focused on identifying the key molecules required for VM (reviewed in ${ }^{12}$ ).

Tyrosine phosphorylation is critical in signal transduction and regulation, and the use of tyrosine kinase inhibitors (TKIs) has been shown to be effective in the treatment of various malignancies. TKIs act by competitive inhibition of ATP at the binding site of the catalytic domain. Notably, overall inhibition of tyrosine kinase activity in aggressive $\mathrm{VM}^{+}$melanoma cells resulted in diminished capacity to form complete tubular networks in vitro ${ }^{8}$. Since this report, clinical trials have identified novel TKIs that target specific tyrosine kinases. In the present study, we demonstrated that the receptor tyrosine kinase c-Kit, also known as CD117 or stem cell factor (SCF) receptor, 
is highly expressed in aggressive - $\mathrm{VM}^{+}$- Ewing sarcoma cells. Previous studies suggested that c-Kit is closely related to the process of malignant transformation and to the pathogenesis of specific types of human solid tumors ${ }^{13,14}$. Imatinib (Gleevec ${ }^{\circledR}$, STI571) is a TKI targeting the tyrosine kinase domain of c-Kit, but also of the bcr-abl fusion protein and the platelet-derived growth factor receptor (PDGFR).

We studied the effect of imatinib on VM in aggressive Ewing sarcoma and melanoma cells. We demonstrated that imatinib treatment resulted in decreased expression of genes associated with VM-related plasticity. Furthermore, imatinib reduced the potential of tumor cells to form VM-characteristic networks. The current results suggest that imatinib may be a useful treatment for aggressive tumors, either as a targeting strategy or as a method to reduce the initiation of resistance.

\section{Materials and methods}

\section{Cell culture}

The human Ewing sarcoma cell line RD-ES was maintained in RPMI-1640 (Lonza) supplemented with $10 \%$ fetal bovine serum (FBS) (PAA). The human cutaneous (C8161) and uveal (C918) melanoma cell lines have been described previously ${ }^{2,5,15}$ and were maintained in RPMI-1640 supplemented with $10 \%$ FBS. All cells were cultured at $37^{\circ} \mathrm{C}$ under a humidified atmosphere containing $5 \% \mathrm{CO}_{2}$. Experiments were performed at $70-80 \%$ confluency. Cell cultures were routinely checked for mycoplasma infection. For TKI treatment, cells were seeded onto a 24-well plate and allowed to adhere overnight. The following day cells were treated with imatinib (Gleevec ${ }^{\circledR}$, Novartis Pharmaceuticals Corporation) $(10 \mu \mathrm{M})$ or docetaxel (Taxotere ${ }^{\circledR}$, Sanofi-Aventis) (20 nM), a chemotherapeutic antitumor compound without TKI activity, for 48 hours. Afterwards, cells were used for further analysis.

\section{3-Dimensional culture}

Matrigel (BD Biosciences) was allowed to thaw at $4^{\circ} \mathrm{C}$. Wells of cooled 96-well plates were coated with $40 \mu \mathrm{l}$ of Matrigel and the Matrigel was allowed to solidify for 30 minutes at $37^{\circ} \mathrm{C}$. Per well, 20,000 cells were seeded on top of the Matrigel in a final volume of $50 \mu \mathrm{l}$ complete medium with or without treatment conditions. Cells were incubated for 16 hours after which VM network formation was analyzed.

Tube formation on collagen was assessed in 24-well plates coated with $2 \mathrm{mg} / \mathrm{ml}$ rat tail collagen $(125 \mu \mathrm{l} /$ well, mainly collagen $\mathrm{l})$. Cells were seeded at an initial density of 50.000 cells per well. Medium +/- $10 \mu \mathrm{M}$ imatinib was refreshed every two days and cells were cultured for 96 hours. Both Matrigel networks and collagen tubular networks were imaged using the Leica DMI3000B microscope. 


\section{Cell viability assay}

Cells were seeded at an initial density of 7,000 cells per well in a 96-well plate and allowed to adhere for 5 hours. Medium was aspirated and drugs were added to the wells in increasing concentrations. At 72 hours after treatment, cell viability was analyzed using the CellTiter-Glo Luminescent Cell Viability Assay (Promega). Plates were cooled to room temperature and CellTiter-Glo Reagent was added directly to the cell culture medium. Cells were allowed to lyse for 2-5 minutes on a shaker platform and subsequently incubated for 10 minutes at room temperature. Luminescence signal was recorded using the Tecan Infinite F200 Microplate Reader.

\section{Quantitative Real-Time PCR analysis}

Total RNA was isolated from the cells using RNeasy Mini Kit (Qiagen) including DNasel treatment. RNA quantity and quality were examined by the Nanodrop (ND1000, Isogen Life Science). $1 \mu \mathrm{g}$ of total RNA was reverse transcribed to cDNA using the iScript cDNA synthesis kit (Bio-Rad). Real-time quantitative PCR mixes were composed of 1 XSYBR Green (Bio-Rad), $400 \mathrm{nM}$ of each primer and cDNA equivalent to $30 \mathrm{ng}$ total RNA per reaction. Reactions were run in an IQ5 real-time detection system (Bio-Rad). Data were analyzed using IQ5 software (Bio-Rad). Melting curves were generated to monitor proper product. Primer sequences are provided in Table 4.1. Geometric averages of $C(t)$ values of the reference genes cyclophilin $A$ and $\beta$-actin were subtracted from the $\mathrm{C}(\mathrm{t})$ values of the examined genes to generate $\Delta C(\mathrm{t})$ values. Relative expression was calculated as $2^{-\Delta C(t)}$.

Table 4.1 Quantitative real-time PCR primer sequences.

\begin{tabular}{lll}
\hline Gene name & Forward primer $\left(5^{\prime}>3^{\prime}\right)$ & Reverse primer $\left(5^{\prime}>3^{\prime}\right)$ \\
\hline$\beta$-actin & GCTGTGCTACGTCGCCCTG & GGAGGAGCTGGAAGCAGCC \\
Cyclophilin A & CTCGAATAAGTTTGACTTGTGTTT & CTAGGCATGGGAGGGAACA \\
VE-cadherin & TCCCGGAGCAGAAGACGTC & GAGAAAAGAAAGAGAGCATGGATTG \\
MMP-2 & AGATGCCTGGAATGCCAT & GGTTCTCCAGCTTCAGGTAAT \\
Laminin-5ץ2 & CCAACGAAATGGGTCTCCTG & CTAGTCGTTGGGCTGAGCTAAC \\
EphA2 & AGACGCTGAAAGCCGGCTAC & CAGGGCCCCATTCTCCATG \\
\hline
\end{tabular}

\section{FACS analysis}

To avoid epitope destruction, cells were harvested using $5 \mathrm{mM}$ EDTA, followed by fixation with $1 \%$ paraformaldehyde for 20 minutes at room temperature. Cells were incubated with a rabbit polyclonal antibody to human VE-cadherin (Cayman chemicals, 160840). Primary antibody binding was detected using secondary FITCconjugated swine-anti-rabbit IgG antibody (Dako, F0205). Antibodies were diluted in PBS/0.1\% BSA. Stained cells were analyzed on a FACSCalibur flow cytometer using Cell Quest software (BD Biosciences). 


\section{Tyrosine kinase expression array}

Data used for the gene expression analysis of tyrosine kinases was mainly downloaded via GEO, gene expression omnibus, (http://www.ncbi.nlm.nih.gov/geo/) a publically available repository. RD-ES microarray files came from GSM 213308 (GPL570); A673 were from GSE7007 and GSM161547 (GPL96) and SKNMC were from GSE1824 and GSM31857 (GPL96). SBSR-AKS microarray data were kindly provided by Dr. Guenther Richter. The data files are also available on GEO under GSE24806 (GPL96) with single files GSM610740 and GSM610741. In terms of software Excel (Microsoft), RMAexpress, TreeView and Cluster3.0 were used. After normalization with RMAexpress probe sets for tyrosine kinases (available on both array types GPL96 and GPL570) were formatted in Excel (tyrosine kinases list came from KEGG and gene ontology) and subsequently hierarchically clustered with Cluster3.0. TreeView was used for visualization.

\section{PamGene tyrosine kinase array}

Cells were lysed using M-PER Mammalian Protein Extraction Reagent (Thermo Science) supplemented with $1 x$ Halt Protease and Phosphatase Inhibitor Cocktail and 1x Halt Phosphatase Inhibitor Cocktail (Thermo Scientific). Cell lysates were scraped and centrifuged 15 minutes at $10,000 \times g, 4^{\circ} \mathrm{C}$. The supernatant was collected and snapfrozen in liquid nitrogen. Samples were stored at $-80^{\circ} \mathrm{C}$. Protein amounts were determined using the Micro BCA protein assay kit (Thermo Scientific) according to manufacturer's instruction.

Prior to analysis, PamChip-4 tyrosine kinase arrays (PamGene International) were blocked with $2 \%$ bovine serum albumin (BSA). Chips were loaded with a mastermix composed of 1x ABL Protein Kinase Reaction Buffer solution (New England Biolabs), 1x BSA (New England Biolabs), $400 \mu \mathrm{M}$ ATP (Sigma-Aldrich), and $0.3 \mu \mathrm{g}$ monoclonal anti-phosphotyrosine-FITC (clone Py20, Exalpha Biologicals), to which $10 \mu \mathrm{g}$ of protein was added. The immediate effects of the TKI were analyzed by adding $10 \mu \mathrm{M}$ imatinib to the protein lysate of cells grown under normal conditions. During one hour fluorescent images were taken using a built-in CCD camera (PamGene) at time intervals of 5 minutes at $30^{\circ} \mathrm{C}$. Acquired images were analyzed using BioNavigator software (Version 4, PamGene International). Background subtracted data were shifted with 1 percentile value to correct for negative values.

\section{Statistical analysis}

All data are presented as mean \pm SEM and were statistically analyzed using MannWhitney $U$ test (using SPSS 15.0 software). Results were considered significant when $\mathrm{p} \leq 0.05$. 


\section{Results}

\section{Overexpression of c-Kit in aggressive Ewing sarcoma cells}

It was previously described that tumor cells engaged in VM depend on signaling by certain tyrosine kinase receptors. Our goal was to profile the kinase repertoire of these cells. To that end, RD-ES Ewing sarcoma cells, previously shown to form vascular networks in vitro, were subjected to tyrosine kinase microarray analysis. Results were compared with those of A673 Ewing sarcoma cells, known to be less aggressive and to lack the ability to form tubes in vitro (Figure 4.1). The most differentially expressed tyrosine kinase receptor genes are listed in Table 4.2. Interestingly, we identified the c-Kit transmembrane tyrosine kinase receptor to be increased in the more aggressive RD-ES Ewing sarcoma cells, showing 96.6-fold overexpression in comparison to the poorly aggressive $A 673$ cells. In addition, members of the Ephrin protein family were represented in the most upregulated receptor tyrosine kinases on the arrays, as were the fibroblast growth factor receptors (FGFR)-4 and FGFR-3.

Table 4.2 Ratio of tyrosine kinase receptor expression in $\mathrm{VM}^{+}$Ewing sarcoma cells (RD-ES) compared to VM Ewing sarcoma cells (A673).

\begin{tabular}{lllc}
\hline $\begin{array}{l}\text { Accession } \\
\text { number }\end{array}$ & Official gene name & Symbol & $\begin{array}{c}\text { Ratio } \\
\text { RD-ES/A673 }\end{array}$ \\
\hline NM_004438.3 & EPH receptor A4 & EPHA4 & 515.6 \\
NM_000222.2 & v-kit Hardy-Zuckerman 4 feline sarcoma viral oncogene homolog & KIT & 96.6 \\
NM_004442.6 & EPH receptor B2 & EPHB2 & 18.1 \\
NM_021913.3 & AXL receptor tyrosine kinase & AXL & 15.2 \\
NM_004441.4 & EPH receptor B1 & EPHB1 & 14.7 \\
NM_001982.3 & v-erb-b2 erythroblastic leukemia viral oncogene homolog 3 (avian) ERBB3 & 14.7 \\
NM_002011.3 & fibroblast growth factor receptor 4 & FGFR4 & 11.9 \\
NM_000142.4 & fibroblast growth factor receptor 3 & FGFR3 & 11.5 \\
NM_004440.3 & EPH receptor A7 & EPHA7 & 10.4 \\
NM_000757.4 & colony stimulating factor 1 & CSF1 & 10.0 \\
NM_004448.2 & v-erb-b2 erythroblastic leukemia viral oncogene homolog & 2, ERBB2 & 7.3 \\
& neuro/glioblastoma derived oncogene homolog (avian) & & 6.8 \\
NM_001954.4 & discoidin domain receptor tyrosine kinase 1 & DDR1 & EPHA2 \\
NM_004431.3 & EPH receptor A2 & EGFR & 5.9 \\
NM_005228. & epidermal growth factor receptor & ROR1 & 5.0 \\
NM_005012.2 & receptor tyrosine kinase-like orphan receptor 1 & & \\
\hline
\end{tabular}

\section{Imatinib alters the expression of VM-associated plasticity genes}

The identification of c-Kit as an overexpressed tyrosine kinase in $\mathrm{VM}^{+}$Ewing sarcoma cells suggested that imatinib, a TKI with inhibitory activity for c-Kit, may have an effect on the plasticity of the more aggressive Ewing sarcoma cells. To that end, cell cultures of $\mathrm{VM}^{+}$cells were treated with imatinib and monitored for gene expression. To ensure that we did not examine proliferation-associated influences, imatinib was applied to tumor cells at concentrations where cellular growth/viability remained within 90- 
Chapter 4

$100 \%$, as compared to untreated cells (Figure $4.2 \mathrm{a}$ ). In parallel $\mathrm{VM}^{+} \mathrm{C} 918$ uveal melanoma cells and C8161 cutaneous melanoma cells were also tested.

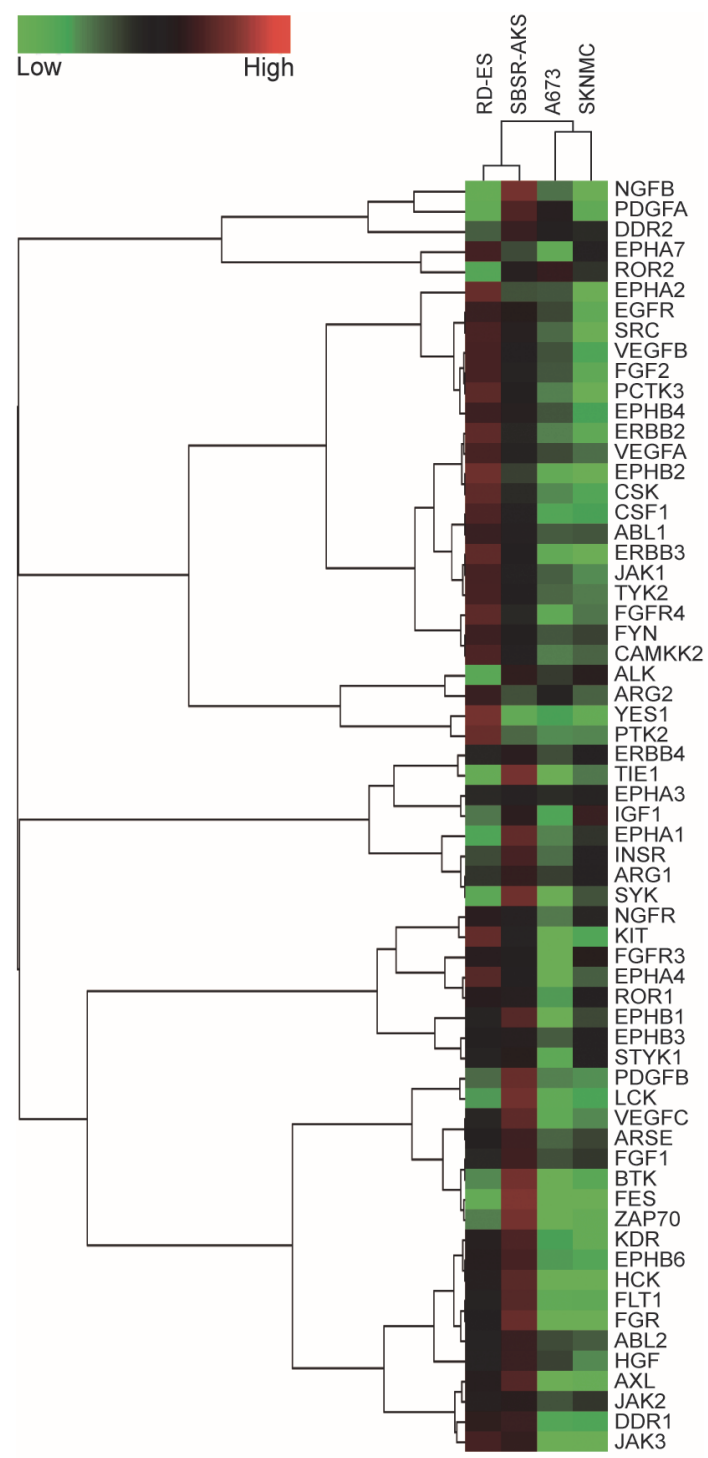

Figure 4.1 Tyrosine kinase expression in $\mathrm{VM}^{+}$Ewing sarcoma cell lines (RD-ES, SBSR-AKS) and VM Ewing sarcoma cell lines (A673, SKNMC) (hierarchical clustering). Heatmap with hierarchical clustering of tyrosine kinases. Samples were normalized against global mean and signal intensity. After normalization individual genes of interest were compared in the different cell lines regarding their deviation from the mean. The color scale is visualizing the downregulation (low expression; green) or upregulation (high expression; red) from the mean. 

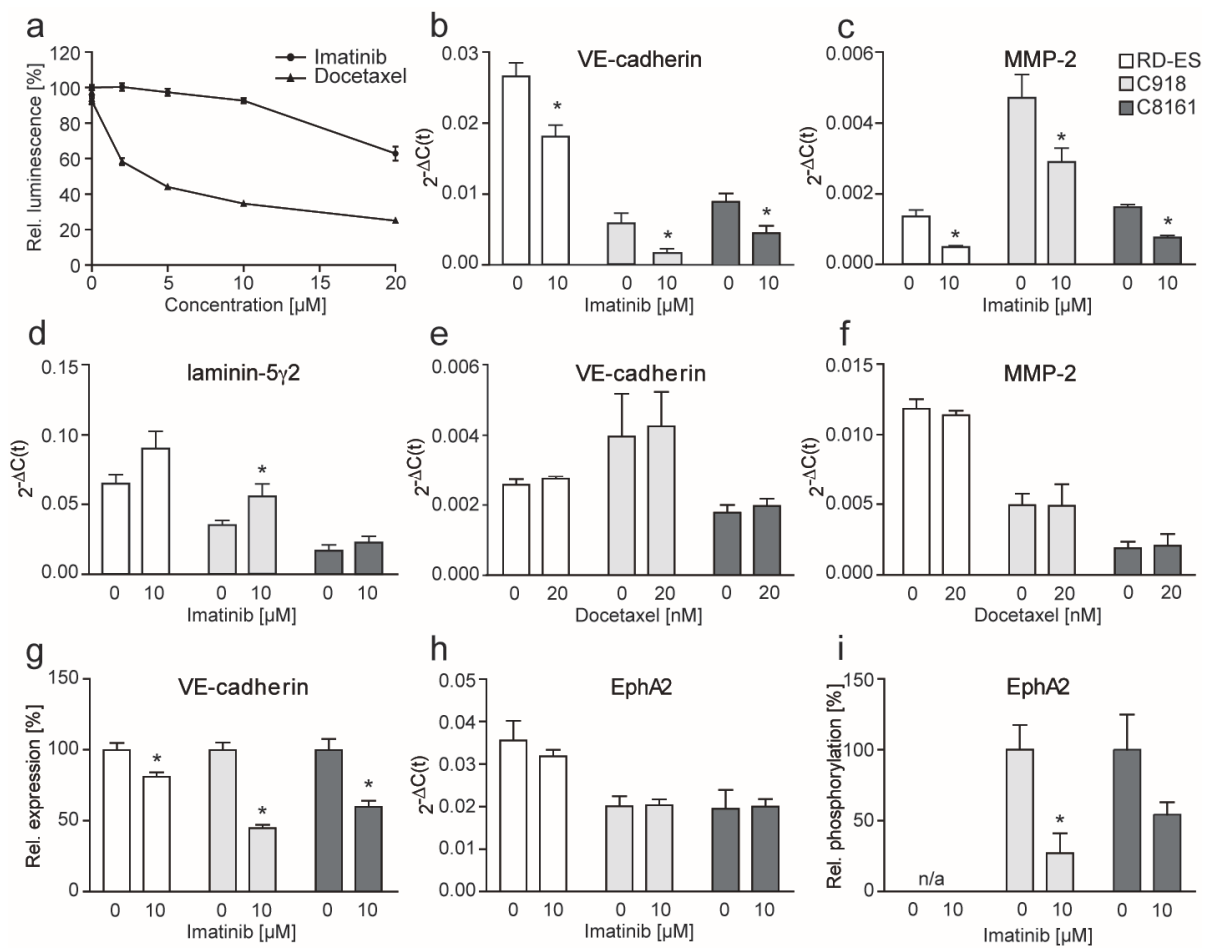

Figure 4.2 Imatinib alters the expression of VM-associated marker genes in vitro. a. Viability of melanoma cells incubated with different concentrations of imatinib or docetaxel for 72 hours. b-d. Quantitative RT-PCR analysis of VE-cadherin (b), MMP-2 (c), and laminin-5Y2 (d) in RD-ES, C918, and C8161 cell lines after 48 hours exposure to imatinib. e-f. qRT-PCR analysis of VE-cadherin (e) and MMP-2 (f) after 48 hours docetaxel treatment. g. FACS analysis of VE-cadherin protein expression on RD-ES, C918, and C8161 cell lines following 48 hours imatinib treatment. h. qRT-PCR analysis of EphA2 expression in RD-ES, C918, and C8161 cell lines after 48 hours exposure to imatinib. i. EphA2 peptide phosphorylation by cell lysates of C 918 and C8161 cells in the presence of imatinib as analyzed by PAMstation. $n / a=$ not assessed. Data are represented as mean \pm SEM $(n=3) . * p \leq 0.05$.

Quantitative real-time PCR analysis (qRT-PCR) demonstrated that imatinib treatment influenced the expression of genes associated with VM-related plasticity in Ewing sarcoma and melanoma cell lines ${ }^{6}$. Interestingly, exposure to imatinib significantly reduced transcription of VE-cadherin and MMP-2 in both $\mathrm{VM}^{+}$Ewing sarcoma and melanoma cells (Figure $4.2 \mathrm{~b}, \mathrm{c}$ ). In contrast, the expression level of laminin-5 22 was slightly increased following imatinib exposure (Figure 4.2d). On the other hand, treatment with the chemotherapeutic docetaxel at non-cytotoxic (metrononic) concentrations did not affect steady state levels of VM-associated marker genes (Figure 4.2e,f). To verify our findings, we determined the expression of VE-cadherin protein at the cellular membrane of RD-ES, C918 and C8161 cells following imatinib 
treatment. Consistent with the previous qRT-PCR data, the expression of VE-cadherin at the cell membrane was reduced after imatinib treatment (Figure $4.2 \mathrm{~g}$ ).

Despite the mRNA expression differences in the above-mentioned VM-associated genes, not all genes related to VM were regulated by imatinib. We observed that EphA2, a gene previously described in VM with respect to its phosphorylation status, was not influenced. Therefore, we analyzed the capacity of protein lysates - isolated from $\mathrm{VM}^{+}$melanoma cells - to phosphorylate EphA2 peptides in the absence or presence of imatinib. Although the transcript levels of EphA2 remained constant when exposed to imatinib (Figure $4.2 \mathrm{~h}$ ), the capacity of melanoma lysate proteins to phosphorylate EphA2 at tyrosine positions $587\left(\mathrm{Tyr}^{587}\right)$ and $593\left(\mathrm{Tyr}^{593}\right)$ was reduced in response to $10 \mu \mathrm{M}$ imatinib. In C918 cell lysates the decrease of EphA2 phosphorylation was found to be significant (Figure 4.2i).

\section{Tyrosine kinase inhibition by imatinib inhibits vascular network formation by aggressive tumor cells}

Our results, showing that imatinib may interfere with the expression and posttranslational modification of VM-associated genes, suggested a functional relationship with the vascular network formation by $\mathrm{VM}^{+}$cells. To verify this we performed 3-dimensional cultures on Matrigel and collagen gel and evaluated the effect of imatinib on the capacity of highly aggressive melanoma cell lines to display VM in vitro. The aggressive tumor cells C918 and C8161 were cultured with $10 \mu \mathrm{M}$ imatinib and showed a loss in their capacity to form vascular networks on Matrigel, as compared to non-treated cells. This effect was evidenced by a less refined network structure (Figure 4.3a). The ability of aggressive tumor cells to form networks on Matrigel was inversely related to imatinib concentrations. As shown above, imatinib also reduced tumor cell proliferation at higher concentrations. Consistent with the gene expression data, highly aggressive melanoma cells treated with docetaxel remained their network forming capacity (data not shown). In addition to network formation on Matrigel, the VM capacity of melanoma cells in response to imatinib was examined on collagen matrix. After reaching confluence, untreated $\mathrm{VM}^{+}$tumor cells seeded on collagen gel rearranged and aligned in such a way that tubular-like structures were formed. These structures appeared to have a well-defined border and formed a visible lumen. Tubular structure formation on the collagen matrix started within four days after seeding on collagen matrix (Figure 4.3b, left and middle panels, tubular structures are indicated by arrows). At that time point, tubular structures could not be detected in cultures of $\mathrm{VM}^{+}$melanoma cells grown in the presence of imatinib (Figure 4.3b, right panels). Although imatinib-treated cells did appear to form linear structures on the collagen matrix at later time points, these tubular structures were not as well developed or matured as compared to the tubes formed by untreated cells. 
a
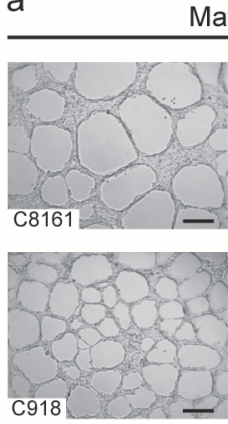

Matrigel
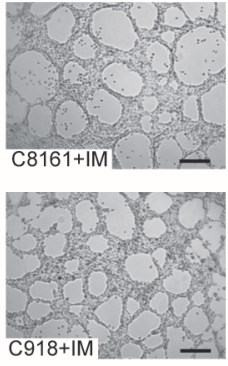

b
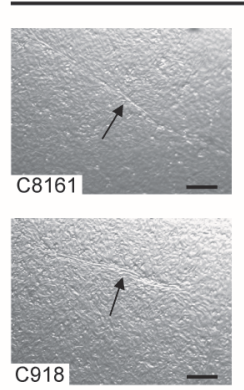

Collagen
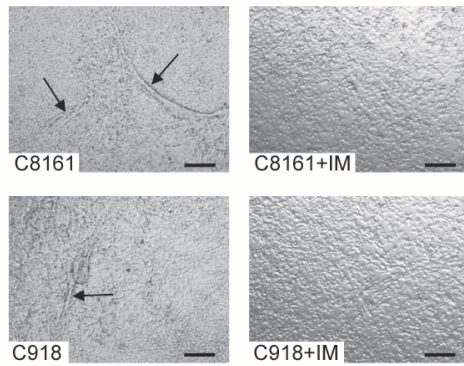

Figure 4.3 Imatinib inhibits VM network formation in vitro. a. Bright field microscopy of $\mathrm{VM}^{+} \mathrm{C} 8161$ and C918 melanoma cells grown on Matrigel for 16 hours, in the presence or absence of $10 \mu \mathrm{M}$ imatinib (IM). Magnification 50x. Scale bars represent $200 \mu \mathrm{m}$. b. Bright field microscopy of tube formation on collagencoated wells for 96 hours with or without $10 \mu \mathrm{M}$ imatinib exposure. Arrows indicate VM-characteristic tubular structures formed by $\mathrm{VM}^{+}$melanoma cells in confluent cultures on collagen matrix. Magnification 50x. Representative images are shown. Scale bars represent $200 \mu \mathrm{m}$.

\section{Discussion}

VM is a phenomenon associated with increased tumor malignancy. In the present study, microarray tyrosine kinase profiling showed that $\mathrm{VM}^{+}$tumor cells combine their aggressiveness with a marked increased expression of c-Kit receptor tyrosine kinase. c-Kit is a target for the clinically applied TKI imatinib (Gleevec ${ }^{\circledR}$, STI571). Imatinib is a 2-phenylaminopyrimidine derivative that targets the tyrosine kinase domain in abl, PDGFR and c-Kit receptor. It is currently a treatment for gastrointestinal stromal tumors (GIST) and chronic myeloid leukemia (CML). The effects of imatinib treatment on other tumor types, including Ewing sarcoma and melanoma, have also been evaluated in clinical trials and in vitro studies ${ }^{16-21}$. To date, the results from these studies have been variable. The influence of imatinib on the occurrence of VM has not been examined in any of the reports.

c-Kit activation influences downstream signaling to MAPK, phosphatidylinositol 3-kinase (PI3K) and JAK/STAT pathways. Intracellular signaling through c-Kit also plays a critical role in development of various cell types, such as mast cells, hematopoietic stem cells, germ cells, and melanocytes ${ }^{22-24}$.

In tumor biology, c-Kit kinase activity is often deregulated by mutation resulting in constitutive kinase activity ${ }^{13,14}$. This phenomenon has been described in tumors such as GIST $^{25}$, small-cell lung carcinoma ${ }^{26}$, acute myeloid leukemia $(\mathrm{AML})^{27}$, melanoma ${ }^{28}$, ovarian carcinoma, and breast carcinoma ${ }^{29}$. In addition, c-Kit and its ligand stem cell factor (SCF) have been implicated in angiogenesis and vasculogenesis through modulation in the expression of vascular endothelial growth factor (VEGF) by tumor cells $^{30-33}$. Interestingly, downregulation of VE-cadherin was previously observed in 
endothelial cells in response to imatinib treatment resulting in reduced cell-to-cell cohesiveness $^{34}$. In addition, imatinib is described to result in lower secretion of VEGF ${ }^{35}$ and interleukin (IL)-8 (Legros L, et al. Abstracts at the 44th Annual Meeting of the American Society of Hematology; 2002; Abstract 3106), the latter is described to stimulate the expression of MMP-2. Also, murine studies have shown the ability of imatinib to inhibit new blood vessel formation by inactivation of PDGFR ${ }^{36,37}$. The success of imatinib as a treatment strategy may therefore be partially due to its ability to inhibit angiogenesis. Therapeutic strategies targeting angiogenesis and vasculogenesis are widely used to inhibit tumor growth. Although initial effects on tumor growth are promising, the antitumor effects do not last. In some studies, antiangiogenesis drugs appear to even accelerate tumor metastasis ${ }^{38}$. It is thought that inhibition of angiogenesis may help select for cells that survive better in an oxygendeprived microenvironment, i.e. resistant tumor cells. The vascular phenotype of highly aggressive tumor cells engaged in VM suggests that they may hold an important role in drug resistance. By mimicking endothelial cells, tumor cells may enable themselves to compensate for the loss of newly formed blood vessels.

Invasive $\mathrm{VM}^{+}$tumor cells express specific marker proteins described in relation to $\mathrm{VM}^{2,6,39}$. We examined the effect of imatinib on the expression of several of these markers. In response to imatinib, MMP-2 and the endothelial cell marker VE-cadherin were found to be downregulated in $\mathrm{VM}^{+}$tumor cells. Studies focusing on the signaling cascades in VM have identified the co-localization of VE-cadherin with EphA2 at the cellular membrane. Via an interaction with phosphorylated EphA2 downstream kinases such as PI3K and Focal Adhesion Kinase (FAK) become activated. This signaling cascade ultimately leads to the activation of MMP-2. This protein causes cleavage of laminin-5 $\gamma 2$ into pro-migratory fragments laminin- $\gamma 2 x$ and laminin- $-22^{\prime}$, which are required to modify the extracellular matrix (ECM) and initiate or promote the formation of VM-characteristic tubular structures ${ }^{9,40}$. In this pathway, kinases are of high importance to transduce the initial signal to ECM modification. Interestingly, both VE-cadherin and MMP-2, which we found to be reduced in their expression following imatinib treatment, have been identified as melanoma cell proteins pivotal in VM. Reduced expression of either of these proteins inhibits vascular network formation. Three-dimensional cultures with aggressive melanoma cells in the presence of blocking antibodies against MMP-2 resulted in an inhibition of tubular network formation due to increased amounts of uncleaved laminin-5 $2^{2}{ }^{9}$. Moreover, diminished expression of VE-cadherin was associated with decreased tube formation potential ${ }^{7}$. Reduced expression of VE-cadherin may imply reduced capacity of $\mathrm{VM}^{+}$ tumor cells to mimic endothelial characteristics. In agreement with these data, we found that decreased expression of VE-cadherin and MMP-2 in response to imatinib treatment resulted in reduced tubular network formation.

Imatinib treatment has previously been described in relation to MMPs. It was shown that the expression of membrane type (MT)1-MMP was reduced in colon carcinoma in response to imatinib treatment ${ }^{41}$. MT1-MMP is required for the cleavage of pro- 
MMP-2, resulting in the active form of MMP-2. In the presence of imatinib both the pro-MMP-2 and the active MMP-2 were found to be suppressed ${ }^{41}$. Due to its critical function during basement membrane and ECM degradation, the expression of MMP-2 is associated with tumor cell invasion and metastasis. Therefore, the effects of imatinib on VM may be due to a diminished capacity of aggressive $\mathrm{VM}^{+}$melanoma cells to modify their extracellular matrix, i.e. cleave laminin-5 52 , as a consequence of reduced MMP-2 expression.

Although EphA2 expression did not change in the presence of imatinib, treatment did significantly reduce the ability of protein lysates from the treated cells to phosphorylate EphA2 on $\mathrm{Tyr}^{587}$ and $\mathrm{Tyr}^{593}$. It has been suggested that $\mathrm{EphA2}$ requires phosphorylation after co-localization with VE-cadherin to signal downstream to MMP2 and laminin $-5 y 2^{8}$. These observations are consistent with the previous observations that reduced expression of VE-cadherin results in decreased EphA2 phosphorylation ${ }^{42}$. This suggests that the function of the kinases responsible for phosphorylation of EphA2 at $\mathrm{Tyr}^{587}$ and $\mathrm{Tyr}^{593}$ are hindered by imatinib. EphA2 signal transduction and tumor angiogenesis in vivo have been shown to dependent on phosphorylation of EphA2 at $\mathrm{Tyr}^{587}$ and $\mathrm{Tyr}^{593}{ }^{43}$. Phosphorylation of $\mathrm{Tyr}^{587}$ has been described to have an important role in endothelial cell assembly in vitro and in endothelial cell incorporation into tumor vasculature in vivo. Phosphorylation of $\mathrm{Tyr}^{593}$ is also observed in vascular endothelial cells. In tumor biology, elevated levels tyrosine kinase activity are associated with increased malignancy ${ }^{44,45}$.

Considering the target molecules of imatinib, the reduced potential of $\mathrm{VM}^{+}$cells to mimic endothelial cells in response to this drug may be due to the direct inhibition of c-Kit, PDGFR or abl. Although data are scarce, these molecules have been associated with endothelial cell characteristics. For example, following endothelial injury, c-Kit expression has been described in relation to endothelial regeneration by bone marrow-derived $\mathrm{c}-\mathrm{Kit}^{+} / \mathrm{Flk} \mathrm{1}^{+}$progenitor cells ${ }^{46}$. In addition c-Kit expression is stemness-related and is considered to be a hematopoietic marker ${ }^{47}$. During ontology, hematopoietic and endothelial cells have a close association. Besides the relation between c-Kit and endothelium, hematopoietic/endothelial precursors have been described to co-express PDGFR with endothelial markers. The activation of the PDGFR on these precursors accelerated endothelial cell differentiation ${ }^{48}$. Furthermore it was shown that acute lymphoblastic leukemia (ALL) cells respond to stromal cell contact by upregulating the bcr-abl fusion gene, stabilizing beta-catenin, and promoting the expression of VE-cadherin ${ }^{49}$. Together these data demonstrate that there is a possible link between the targets of imatinib and the effect of this drug on reducing the endothelial mimicking capacity of tumor cells. The mechanism by which this is actually occurring in $\mathrm{VM}^{+}$tumor cells remains to be elucidated. However, it should also be considered that the effects of imatinib on VM may not be a direct effect of targeting the above-mentioned molecules, but a resultant of other pathways influenced by kinase inhibition.

The identification of novel targets to suppress VM is an important goal in cancer 
research. Nodal is a promising target originally identified in aggressive $\mathrm{VM}^{+}$melanoma cells ${ }^{50}$. It is a potent embryonic morphogen from the transforming growth factor (TGF)- $\beta$ family. Expression of Nodal is positively correlated with the plastic capacity of melanoma cells - i.e. process of VM - and with tumor progression. Inhibition of Nodal expression in aggressive forms of melanoma leads to reduced plasticity.

It is still an open question if specific targeting will provide better treatment results for patients than that seen with more robust 'dirty' targeting. Imatinib exerts its effect via the blockage of signal transduction of several tyrosine kinase receptors. Our data demonstrate that imatinib may represent a novel treatment strategy against VM. Targeting VM by means of TKI may be effective. TKI drugs are often referred to as 'dirty drugs' as they frequently, if not always, target more than one tyrosine kinase domain. Imatinib is thought to block several domains of abl, PDGFR and c-Kit. It is feasible that the success of current TKIs for the treatment of cancer is dependent on the broad and non-specific nature of these compounds. The application of imatinib as a treatment strategy for aggressive tumors shows promise as a therapy through the targeting of VM. 


\section{References}

1. Folberg R, Maniotis AJ. Vasculogenic mimicry. Apmis, 2004; 112:508-25.

2. Maniotis AJ, Folberg R, Hess A, et al. Vascular channel formation by human melanoma cells in vivo and in vitro: vasculogenic mimicry. Am J Pathol, 1999; 155:739-52.

3. Folberg R, Rummelt V, Parys-Van Ginderdeuren R, et al. The prognostic value of tumor blood vessel morphology in primary uveal melanoma. Ophthalmology, 1993; 100:1389-98.

4. Sun B, Zhang S, Zhao X, et al. Vasculogenic mimicry is associated with poor survival in patients with mesothelial sarcomas and alveolar rhabdomyosarcomas. Int J Oncol, 2004; 25:1609-14.

5. Bittner $\mathrm{M}$, Meltzer $\mathrm{P}, \mathrm{Chen} \mathrm{Y}$, et al. Molecular classification of cutaneous malignant melanoma by gene expression profiling. Nature, 2000; 406:536-40.

6. Seftor EA, Meltzer PS, Schatteman GC, et al. Expression of multiple molecular phenotypes by aggressive melanoma tumor cells: role in vasculogenic mimicry. Crit Rev Oncol Hematol, 2002; 44: 17-27.

7. Hendrix MJ, Seftor EA, Meltzer PS, et al. Expression and functional significance of VE-cadherin in aggressive human melanoma cells: role in vasculogenic mimicry. Proc Natl Acad Sci U S A, 2001; 98:8018-23.

8. Hess AR, Seftor EA, Gardner LM, et al. Molecular regulation of tumor cell vasculogenic mimicry by tyrosine phosphorylation: role of epithelial cell kinase (Eck/EphA2). Cancer Res, 2001; 61:3250-5.

9. Seftor RE, Seftor EA, Koshikawa N, et al. Cooperative interactions of laminin 5 gamma2 chain, matrix metalloproteinase-2, and membrane type-1-matrix/metalloproteinase are required for mimicry of embryonic vasculogenesis by aggressive melanoma. Cancer Res, 2001; 61:6322-7.

10. Ricci-Vitiani L, Pallini R, Biffoni M, et al. Tumour vascularization via endothelial differentiation of glioblastoma stem-like cells. Nature, 2010; 468:824-8.

11. van der Schaft DW, Seftor RE, Seftor EA, et al. Effects of angiogenesis inhibitors on vascular network formation by human endothelial and melanoma cells. J Natl Cancer Inst, 2004; 96:1473-7.

12. Paulis YW, Soetekouw PM, Verheul HM, et al. Signalling pathways in vasculogenic mimicry. Biochim Biophys Acta, 2010; 1806:18-28.

13. Heinrich MC, Blanke CD, Druker BJ, et al. Inhibition of KIT tyrosine kinase activity: a novel molecular approach to the treatment of KIT-positive malignancies. J Clin Oncol, 2002; 20:1692-703.

14. Went PT, Dirnhofer S, Bundi M, et al. Prevalence of KIT expression in human tumors. J Clin Oncol, 2004; 22:4514-22.

15. Carmeliet P. Mechanisms of angiogenesis and arteriogenesis. Nat Med, 2000; 6:389-95

16. Hofmann UB, Kauczok-Vetter CS, Houben R, et al. Overexpression of the KIT/SCF in uveal melanoma does not translate into clinical efficacy of imatinib mesylate. Clin Cancer Res, 2009; 15:324-9.

17. Kim KB, Eton O, Davis DW, et al. Phase II trial of imatinib mesylate in patients with metastatic melanoma. Br J Cancer, 2008; 99:734-40.

18. Yerushalmi R, Nordenberg J, Beery E, et al. Combined antiproliferative activity of imatinib mesylate (STI-571) with radiation or cisplatin in vitro. Exp Oncol, 2007; 29:126-31.

19. Hotfilder $M$, Lanvers $C$, Jurgens $H$, et al. c-KIT-expressing Ewing tumour cells are insensitive to imatinib mesylate (STI571). Cancer Chemother Pharmacol, 2002; 50:167-9.

20. Gonzalez I, Andreu EJ, Panizo A, et al. Imatinib inhibits proliferation of Ewing tumor cells mediated by the stem cell factor/KIT receptor pathway, and sensitizes cells to vincristine and doxorubicin-induced apoptosis. Clin Cancer Res, 2004; 10:751-61.

21. Chao J, Budd GT, Chu P, et al. Phase II clinical trial of imatinib mesylate in therapy of KIT and/or PDGFRalpha-expressing Ewing sarcoma family of tumors and desmoplastic small round cell tumors. Anticancer Res, 2010; 30:547-52.

22. Galli SJ, Tsai M, Wershil BK, et al. Regulation of mouse and human mast cell development, survival and function by stem cell factor, the ligand for the c-kit receptor. Int Arch Allergy Immunol, 1995; 107:51-3.

23. Garrido MC, Bastian BC. KIT as a therapeutic target in melanoma. J Invest Dermatol, 2010; 130:20-7.

24. Nishikawa $S$, Kusakabe $M$, Yoshinaga $K$, et al. In utero manipulation of coat color formation by a monoclonal anti-c-kit antibody: two distinct waves of c-kit-dependency during melanocyte development. Embo J, 1991; 10:2111-8. 
25. Lux ML, Rubin BP, Biase TL, et al. KIT extracellular and kinase domain mutations in gastrointestinal stromal tumors. Am J Pathol, 2000; 156:791-5.

26. Arber DA, Tamayo R, Weiss LM. Paraffin section detection of the c-kit gene product (CD117) in human tissues: value in the diagnosis of mast cell disorders. Hum Pathol, 1998; 29:498-504.

27. Tajima F, Kawatani T, Ishiga K, et al. Serum soluble c-kit receptor and expression of c-kit protein and mRNA in acute myeloid leukemia. Eur J Haematol, 1998; 60:289-96.

28. Ohashi A, Funasaka Y, Ueda M, et al. c-KIT receptor expression in cutaneous malignant melanoma and benign melanotic naevi. Melanoma Res, 1996; 6:25-30.

29. Hines SJ, Organ C, Kornstein MJ, et al. Coexpression of the c-kit and stem cell factor genes in breast carcinomas. Cell Growth Differ, 1995; 6:769-79.

30. Beppu K, Jaboine J, Merchant MS, et al. Effect of imatinib mesylate on neuroblastoma tumorigenesis and vascular endothelial growth factor expression. J Natl Cancer Inst, 2004; 96:46-55.

31. Heissig B, Werb Z, Rafii S, et al. Role of c-kit/Kit ligand signaling in regulating vasculogenesis. Thromb Haemost, 2003; 90:570-6.

32. Litz J, Krystal GW. Imatinib inhibits c-Kit-induced hypoxia-inducible factor-1alpha activity and vascular endothelial growth factor expression in small cell lung cancer cells. Mol Cancer Ther, 2006; 5:1415-22.

33. Zhang W, Stoica G, Tasca SI, et al. Modulation of tumor angiogenesis by stem cell factor. Cancer Res, 2000; 60:6757-62.

34. Vrekoussis T, Stathopoulos EN, De Giorgi U, et al. Modulation of vascular endothelium by imatinib: a study on the EA.hy 926 endothelial cell line. J Chemother, 2006; 18:56-65.

35. Legros L, Bourcier C, Jacquel A, et al. Imatinib mesylate (STI571) decreases the vascular endothelial growth factor plasma concentration in patients with chronic myeloid leukemia. Blood, 2004; 104: 495-501.

36. Kim SJ, Uehara H, Yazici S, et al. Targeting platelet-derived growth factor receptor on endothelial cells of multidrug-resistant prostate cancer. J Natl Cancer Inst, 2006; 98:783-93.

37. Uehara H, Kim SJ, Karashima T, et al. Effects of blocking platelet-derived growth factor-receptor signaling in a mouse model of experimental prostate cancer bone metastases. J Natl Cancer Inst, 2003; 95:458-70.

38. Paez-Ribes $M$, Allen $E$, Hudock J, et al. Antiangiogenic therapy elicits malignant progression of tumors to increased local invasion and distant metastasis. Cancer Cell, 2009; 15:220-31.

39. Hendrix MJ, Seftor EA, Hess AR, et al. Vasculogenic mimicry and tumour-cell plasticity: lessons from melanoma. Nat Rev Cancer, 2003; 3:411-21.

40. Giannelli G, Falk-Marzillier J, Schiraldi $\mathrm{O}$, et al. Induction of cell migration by matrix metalloprotease-2 cleavage of laminin-5. Science, 1997; 277:225-8.

41. Stahtea $\mathrm{XN}$, Roussidis $\mathrm{AE}$, Kanakis I, et al. Imatinib inhibits colorectal cancer cell growth and suppresses stromal-induced growth stimulation, MT1-MMP expression and pro-MMP2 activation. Int J Cancer, 2007; 121:2808-14.

42. Hess AR, Seftor EA, Gruman LM, et al. VE-cadherin regulates EphA2 in aggressive melanoma cells through a novel signaling pathway: implications for vasculogenic mimicry. Cancer Biol Ther, 2006; 5:228-33.

43. Fang WB, Brantley-Sieders DM, Hwang $Y$, et al. Identification and functional analysis of phosphorylated tyrosine residues within EphA2 receptor tyrosine kinase. J Biol Chem, 2008; 283:16017-26.

44. Malik RK, Parsons JT. Integrin-mediated signaling in normal and malignant cells: a role of protein tyrosine kinases. Biochim Biophys Acta, 1996; 1287:73-6.

45. Patarca R. Protein phosphorylation and dephosphorylation in physiologic and oncologic processes. Crit Rev Oncog, 1996; 7:343-432.

46. Takamiya $M$, Okigaki $M$, Jin D, et al. Granulocyte colony-stimulating factor-mobilized circulating cKit+/Flk-1+ progenitor cells regenerate endothelium and inhibit neointimal hyperplasia after vascular injury. Arterioscler Thromb Vasc Biol, 2006; 26:751-7.

47. Katayama N, Shih JP, Nishikawa S, et al. Stage-specific expression of c-kit protein by murine hematopoietic progenitors. Blood, 1993; 82:2353-60.

48. Rolny C, Nilsson I, Magnusson $\mathrm{P}$, et al. Platelet-derived growth factor receptor-beta promotes early endothelial cell differentiation. Blood, 2006; 108:1877-86. 
49. Wang L, O'Leary H, Fortney J, et al. Ph+/VE-cadherin+ identifies a stem cell like population of acute lymphoblastic leukemia sustained by bone marrow niche cells. Blood, 2007; 110:3334-44.

50. Topczewska JM, Postovit LM, Margaryan NV, et al. Embryonic and tumorigenic pathways converge via Nodal signaling: role in melanoma aggressiveness. Nat Med, 2006; 12:925-32. 


\section{Chapter}

Intratumoral perivascular cell invasion predicts increased aggressiveness by tumor cell plasticity

Yvette WJ Paulis, Patricia MMB Soetekouw, Victor L Thijssen, Joost J van den Oord, Mary J Hendrix, Carl-Henrik Heldin, Vivianne CG Tjan-Heijnen, Arjan W Griffioen 


\section{Abstract}

During blood vessel formation, perivascular cells are recruited by platelet-derived growth factor-B (PDGF-B)-expressing endothelial cells to remodel, stabilize and support immature blood vessels. In a process called vasculogenic mimicry (VM) highly aggressive tumor cells gain the unique ability to transdifferentiate and obtain endothelial characteristics. Also, these vasculogenic tumor cells are able to form vasculogenic tubular structures that resemble immature vessels. We hypothesized that tumor cells engaged in VM also mimic the interaction of endothelial cells with perivascular cells to structurally support their vasculogenic networks. Immunohistochemical analysis of a series of human cutaneous melanoma tissues showed the presence of $\alpha$-smooth muscle actin positive $\left(\alpha-\mathrm{SMA}^{+}\right)$cells within VM-characteristic matrix networks. PDGF-B expression was observed in $\mathrm{VM}^{+}$tumor cells both in vivo and in vitro, while its expression was low or even absent in $\mathrm{VM}^{-}$tumor cells. Characterization of the interaction between $\mathrm{VM}^{+}$melanoma cells and perivascular cells in vitro demonstrated that perivascular cells contributed to vasculogenic network stabilization. This effect may be due to the deposition of extracellular matrix and the formation of actin stress fibers. In addition, the interaction between perivascular cells and vasculogenic tumor cells enhanced tumor cell sprouting. In vivo analyses demonstrated that the ability of tumor cells to form vasculogenic networks was associated with the presence of tumor cell-associated $\alpha-\mathrm{SMA}^{+}$cells. In addition, the expression of PDGF-B by vasculogenic tumor cells resulted in an increased number of perivascular cells that were not attached to regular tumor blood vessels. Together, our results demonstrate that highly aggressive $\mathrm{VM}^{+}$tumor cells do not solely mimic endothelial cells phenotypically, but also copy their mechanism for interaction with perivascular cells. The current findings suggest that targeting of perivascular cells may have an unexpected antitumor activity through affecting VM. 


\section{Introduction}

Vasculogenic mimicry (VM) defines the ability of highly aggressive tumor cells to form matrix-rich patterned vascular networks ${ }^{1}$. These networks appear as laminin-rich structures that are positive for periodic acid-Schiff's reagent (PAS) and instead of being lined by endothelial cells, the VM-characteristic channels are lined by tumor cells. It is hypothesized that tumor cell-lined extravascular networks contribute to tumor blood flow and facilitate metastasis ${ }^{2}$. Indeed, the presence of VM networks in cancer patients is correlated with increased risk of metastasis and recurrence, and therefore VM is associated with poor clinical outcome ${ }^{3,4}$. However, both the exact functional contribution of VM to tumor progression as well as the mechanisms underlying this phenomenon remain to be elucidated.

Gene expression analysis demonstrated that aggressive melanoma cells capable of VM have increased expression of endothelial-associated genes. In addition, the expression of genes involved in vasculogenesis and angiogenesis, such as vascular endothelial (VE)-cadherin, receptor protein tyrosine kinase erythropoietin-producing hepatocellular carcinoma-A2 (EphA2), and laminin-5 $\gamma 2$-chain, is increased in $\mathrm{VM}^{+}$ tumor cells $s^{5-7}$. These molecules and their ligands are important for the growth of new blood vessels in tumors ${ }^{8}$ and they support the hypothesis that $\mathrm{VM}^{+}$tumor cells adapt to an endothelial-like phenotype. This is exemplified by the observation that $\mathrm{VM}^{+}$ tumor cells are capable of forming tube-like structures in vitro and in vivo ${ }^{1}$.

In physiological angiogenesis, the formation of a functional and mature vasculature requires stabilization of newly formed tubular structures by perivascular cells (pericytes or vascular smooth muscle cells) ${ }^{9,10}$. Perivascular cells, which are characterized by long cytoplasmic processes and contractile abilities, envelope endothelial cells. They release signals that promote endothelial differentiation and quiescence $^{11}$, and regulate microvascular blood flow via a contractile mechanism ${ }^{12,13}$.

Several molecules are involved in the regulation and modulation of the interaction between endothelial cells and perivascular cells. Perivascular cell recruitment is mainly regulated by the platelet-derived growth factor-B (PDGF-B/PDGFR- $\beta$ ) signaling cascade. Sprouting endothelial cells secrete PDGF-B homodimers into the microenvironment to induce the recruitment of immature perivascular cells expressing the receptor PDGFR- $\beta^{14,15}$. PDGF-B deficiency results in failure to recruit perivascular cells, which subsequently leads to vascular instability and regression ${ }^{16-18}$. Although endothelial cells are a main source for PDGF-B production, it is also expressed by various solid tumors where its expression is related to tumor initiation, maintenance and progression ${ }^{19}$. In fact, the expression of PDGF-B by tumor cells is associated with increased tumor malignancy.

Tumor cells engaged in VM resemble endothelial cells. They express endothelial markers and form tubular structures resembling immature vessels. We hypothesized 
that $\mathrm{VM}^{+}$tumor cells seek structural support for their vasculogenic networks by attracting perivascular cells, thereby functionally resembling mature blood vessels. Here, we show that $\mathrm{VM}^{+}$tumor cells copy the endothelial mechanism for perivascular cell recruitment and functionally benefit from their interaction with these supportive cells. These findings may provide novel insights for the current debate on tumor perivascular cell targeting.

\section{Materials and methods}

\section{Immunohistochemistry}

Formalin-fixed paraffin-embedded melanoma tissues were sliced in $5 \mu \mathrm{m}$ sections. Tissues sections were deparaffinized and rehydrated. Immersing the slides in $0.3 \% \mathrm{H}_{2} \mathrm{O}_{2}$ in methanol for 20 minutes blocked endogenous peroxidase activity. Heatinduced epitope treatment was performed by autoclave treatment. After washing with PBS, aspecific antibody binding was blocked by PSB containing $5 \%$ bovine serum albumin (BSA). Perivascular cells were labeled with mouse anti- $\alpha$-SMA primary antibody (Dako, M0851) for 1 hour in PBS containing 0.5\% BSA. For PDGF-B detection, sections were stained with rabbit anti PDGF-B (Neomarkers, RB-9257-P0) for 1 hour in PBS containing $0.5 \%$ BSA. Visualization of primary antibody binding was established using the EnVision ${ }^{\mathrm{TM}}$ Detection System (Dako). Afterwards, tissues were counterstained with hematoxylin and eosin. For double staining of endothelial cells and perivascular cells, anti-CD31 antibodies (Santa Cruz Biotechnology, sc-1506) and anti- $\alpha$-SMA antibodies (Dako, M0851) were used, respectively. Primary antibodies were detected using either biotinylated rabbit-anti-goat antibodies (Dako, E0466) visualized by streptavidin ABComplex/HRP (Dako, K0377), or biotinylated rabbit-antimouse antibodies (Dako, E0413) visualized by streptavidin ABComplex/AP (Dako, K0391). For PAS staining, tissues were deparaffinized and rehydrated, and subsequently incubated with $0.5 \%$ periodic acid for 5 minutes. After washing with demiwater, Schiff's reagent was applied to the tissues for 10 minutes. PAS stained tissues were counterstained with hematoxylin. Stained tumor sections were analyzed by conventional light microscopy using a Leica DM 4000B microscope equipped with a Leica DC 500 digital camera.

\section{Cell culture}

The human cutaneous (C81-61, C8161) and uveal (OCM-1, C918) melanoma cell lines have been described previously ${ }^{1,20,21}$ and were maintained in RPMI-1640 (Lonza) supplemented with $10 \%$ fetal bovine serum gold (FBS) (PAA). Cells were grown on standard tissue culture dishes (Greiner Bio-One) at $37^{\circ} \mathrm{C}$ under a humidified atmosphere containing $5 \% \mathrm{CO}_{2}$. Cell cultures were routinely checked to be negative for mycoplasma infection. 
Human perivascular cells were acquired from the vena saphena magna according to the Dutch guidelines for secondary use material ${ }^{22}$ and maintained in advanced Dulbecco's modified Eagle's medium (Gibco), supplemented with 10\% FBS, 2 mM L-glutamine, and $1 \%$ penicillin/streptamycin (Lonza).

\section{Quantitative real-time RT-PCR}

Total RNA was isolated from the cells using RNeasy Mini Kit (Qiagen) including DNasel treatment. RNA quantity and quality were examined by the nanodrop (Isogen Life Science, ND-1000). One microgram of total RNA was reverse transcribed to cDNA using the iScript cDNA synthesis kit (Bio-Rad). Real-time quantitative PCR mixes were composed of 1xSYBR Green (Bio-Rad), $400 \mathrm{nM}$ of each primer and CDNA equivalent to $30 \mathrm{ng}$ total RNA per reaction. Reactions were run in a $\mathrm{C} 1000^{\mathrm{TM}}$ Thermal System equipped with a CFX96 ${ }^{\text {TM }}$ Real-Time System (Bio-Rad). Data were analyzed using IQ5 software (Bio-Rad). Melting curves were generated to monitor proper product. Primer sequences are provided in Table 5.1. Geometric averages of $\mathrm{C}(\mathrm{t})$ values of the reference genes cyclophilin $A$ and $\beta$-actin were subtracted from the $C(t)$ values of the examined genes to generate $\Delta C(t)$ values. Relative expression was calculated as $2^{-\Delta C(t)}$.

Table 5.1 Quantitative real-time PCR primer sequences.

\begin{tabular}{lll}
\hline Gene name & Forward primer $\left(5^{\prime}>3^{\prime}\right)$ & Reverse primer $\left(5^{\prime}>3^{\prime}\right)$ \\
\hline$\beta$-actin & GCTGTGCTACGTCGCCCTG & GGAGGAGCTGGAAGCAGCC \\
Cyclophilin A & CTCGAATAAGTTTGACTTGTGTTT & CTAGGCATGGGAGGGAACA \\
PDGF-B & GCGAGCTGGAGAGCTTGG & GGTGCGGTCTATGAGGCG \\
PDGFR- $\beta$ & ATGAGGAGTTTCTGAGGAGTG & GTCGTTGTCACCCTCATTG \\
\hline
\end{tabular}

\section{PDGF-BB Elisa}

Quantification of PDGF-BB protein levels accumulating in the medium of confluent cell cultures was made using the Quantikine human PDGF-BB immunoassay (R\&D Systems) Briefly, cells were cultured for five days on medium containing $5 \%$ FBS. Conditioned medium was analyzed for human PDGF-BB expression according to manufacturer's protocol. Optical density was measured at $450 \mathrm{~nm}$ with wavelength correction set to $540 \mathrm{~nm}$ using the Tecan SpectraFluor Absorbance Microplate Reader.

\section{Conditioned culture medium}

Conditioned culture medium was obtained as described for the Elisa experiments. To avoid $\mathrm{pH}$-induced effects throughout subsequent experiments, the conditioned medium was twenty-fold concentrated by centrifugation through $10 \mathrm{~K}$ Amicon Ultra Centrifugal Filter Units (Millipore). Conditioned medium was stored at $-20^{\circ} \mathrm{C}$ and was not thawed for more than one time. In following experiments, the conditioned medium was applied in a ten-fold dilution in serum-free medium. 


\section{Fluorescent labeling of perivascular cells}

Perivascular cells were harvested and labeled with 5-(and 6-)-carboxyfluorescein diacetate, succinimidyl ester (CFSE) (Invitrogen, Molecular Probes). CFSE was diluted in PBS to a concentration of $5 \mu \mathrm{M}$. Perivascular cells were incubated with CFSE for 10 minutes in a $37^{\circ} \mathrm{C}$ water bath after which complete medium was added in a 1:1 ratio. Following three washes in complete medium, cells were subsequently used in the Matrigel assay and sprouting assay.

\section{Matrigel assay}

Wells of a 96-well plate were coated with $40 \mu$ growth factor reduced (GFR-) Matrigel (BD Biosciences) for $30-60$ minutes at $37^{\circ} \mathrm{C} . \mathrm{VM}^{+}$melanoma cells were seeded onto the Matrigel at a density of 20,000 cells per well in a volume of $50 \mu$ l. 2,000 additional cells, being either $\mathrm{VM}^{+}$, or $\mathrm{VM}^{-}$tumor cells, immortalized endothelial cells (RF-24), or perivascular cells were added to the wells in a volume of $25 \mu \mathrm{l}$. Network formation was analyzed after 24 hours and 96 hours. Images were captured using the Leica DMI3000B microscope.

\section{Sprouting assay}

Cells were suspended in RPMI-1640 containing 10\% FBS and 20\% methylcellulose (Sigma-Aldrich, M0512). Spheroids were formed by the hanging drop method in which each drop was formed by a volume of $25 \mu$ containing 1,000 cells. Combination spheroids were composed of $750 \mathrm{VM}^{+}$tumor cells added with $250 \mathrm{VM}^{-}$tumor cells or 250 perivascular cells. After overnight incubation at $37^{\circ} \mathrm{C}$, spheroids were harvested and suspended in a collagen matrix containing $66.7 \% \mathrm{PureCol}^{\mathrm{TM}}$ collagen (Nutacon), 8.3\% M199 10x cell culture medium (Gibco), 14.9\% methylcellulose, 10\% new born calf serum, and $0.1 \%$ heparin. The collagen gel was neutralized by the addition of $0.2 \mathrm{M} \mathrm{NaOH}$. Following an incubation of 60 minutes at $37^{\circ} \mathrm{C}$, serum-free medium was added to the wells. Sprouting was imaged after 8 hours and 24 hours using the Leica DMI3000B microscope. The images were quantified for the average sprout length using Image J (version 1.140).

\section{Matrigel invasion assay}

Perivascular cell invasion was measured in a 24-well plate transwell system (Falcon, Becton Dickinson) containing fluorescence blocking $8.0 \mu \mathrm{m}$ pore polycarbonate filter inserts (HTS FluoroBlok Insert, Falcon, Becton Dickinson). Inserts were coated overnight with $100 \mu \mathrm{l}$ matrigel $(50 \mu \mathrm{g} / \mathrm{ml}$ in PBS) (Sigma-Aldrich). Per insert 50,000 cells were seeded in serum-free advanced DMEM containing L-glutamine. Serum-free medium enriched with concentrated melanoma cell conditioned medium (ten-fold diluted) or PDGF-BB $(100 \mathrm{ng} / \mathrm{ml})$ was added to the bottom compartment. In the presence of tyrosine kinase inhibition, $5 \mu \mathrm{M}$ imatinib or $5 \mu \mathrm{M}$ erlotinib was added 
to both the insert as the bottom compartment. Cells were allowed to invade for 8 hours, after which invading cells were fixated with $4 \%$ paraformaldehyde and permeabilized with $0.1 \%$ Triton-X. Subsequently, cells were stained with rhodamine phalloidin (Invitrogen, Molecular Probes) for visualization. Cells were imaged by fluorescence microscopy using the Leica DFC 345 FX microscope.

\section{In vivo murine models}

The generation of B16F10 melanoma cells stably expressing PDGF-B and the animal experiments using these murine melanoma cells were described previously ${ }^{23}$.

\section{Statistical analysis}

All data are expressed as mean values \pm standard error of the mean (SEM). Statistical analyses were performed using a Mann-Whitney $U$ test (SPSS 15.0). $p$-values $\leq 0.05$ were considered statistically significant. $* p \leq 0.05, * * p \leq 0.01, * * * p \leq 0.001$.

\section{Results}

\section{Vasculogenic matrix networks contain perivascular cells}

Stabilization and maturation of (tumor) vasculature is associated with increased perivascular cell coverage of the newly formed blood vessels. To determine whether perivascular cells also play a role in vasculogenic mimicry (VM), we stained a set of 46 primary human cutaneous melanoma tissues, corresponding to 33 patients, with periodic acid-Schiff's (PAS) reagent and $\alpha$-smooth muscle actin ( $\alpha$-SMA). The latter is considered a marker of perivascular cells while PAS stains matrix networks, which are a characteristic of VM. PAS-positive loops (Figure 5.1a) were observed in $27.3 \%$ of the patients. Of the melanomas showing a highly active invasive component, $75 \%$ was scored positive for the presence of PAS loops. In melanoma tissues scored intermediate or negative for invasive activity, respectively $25 \%$ and $18.2 \%$ of the tissues displayed the presence of PAS loops (Supplemental Figure S5.1). This confirms previous studies in which VM has been associated with increased tumor aggressiveness ${ }^{24-26}$. Staining with $\alpha$-SMA was performed to identify perivascular cells, which have an important function in vascular stability. Indeed, $\alpha$-SMA-positive staining was observed in perivascular cells lining vasculature formed by endothelial cells (Figure 5.1b, arrowheads). Interestingly, in $66,7 \%$ of the melanoma tissues containing PAS loops, we also observed apparent presence of $\alpha$-SMA-positive ( $\alpha$ $\mathrm{SMA}^{+}$) cells within the extracellular matrix network and lining tumor cells (Figure 5.1b, magnification). These cells displayed an elongated phenotype and they were never observed in PAS loop negative regions, i.e. $\mathrm{VM}^{-}$tumor areas. Double staining for both endothelial cells (CD31) and perivascular cells ( $\alpha$-SMA) clearly demonstrated that the 
perivascular cells present within the VM-characteristic matrix networks were not associated with endothelial cells (Figure 5.1c).

An important factor to stimulate and attract perivascular cells is platelet-derived growth factor (PDGF)-B. It is secreted by sprouting endothelial cells and increased PDGF-B expression by tumor cells has also been related to increased malignancy. We thus questioned whether PDGF-B is responsible for perivascular cell attraction in $\mathrm{VM}^{+}$ tumor areas. Using immunohistochemical staining, we observed that PDGF-B was mostly expressed by tumor cells directly lining the VM-characteristic PAS loops (Figure 5.1d). This could thus explain the presence of perivascular cells within VM areas.

a

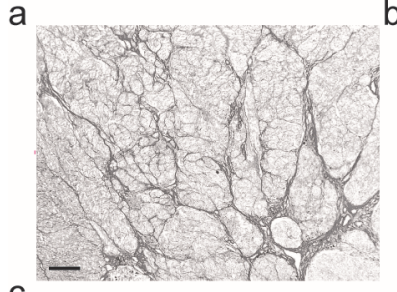

C

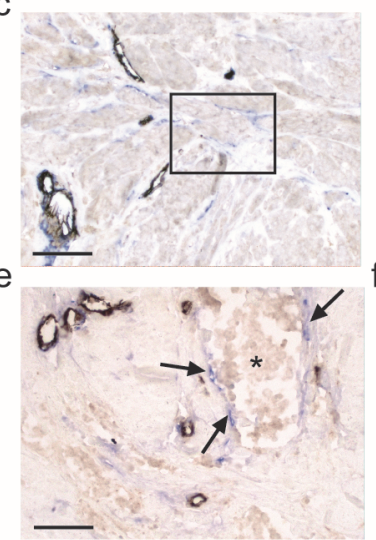

b

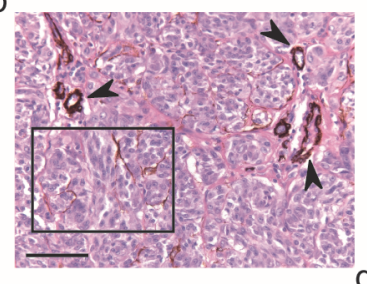

d
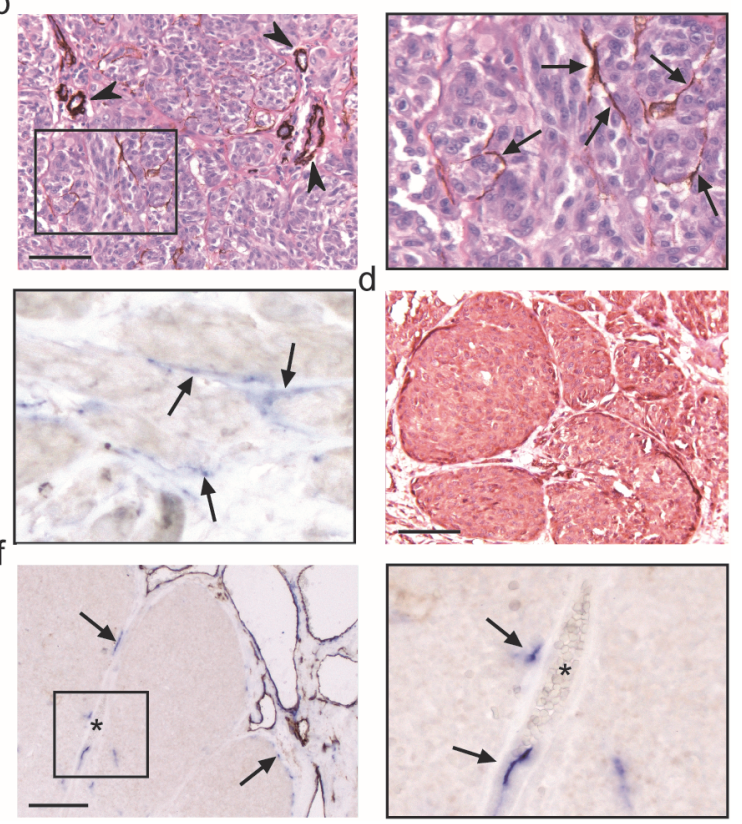

Figure 5.1 Vasculogenic mimicry is characterized by matrix network-associated $\alpha-\mathrm{SMA}^{+}$perivascular cells. (a) PAS staining of VM-characteristic patterned vascular networks in human melanoma tissue sections. Scale bar represents $200 \mu \mathrm{m}$. (b) $\alpha$-SMA staining of melanoma tissue sections counterstained with hematoxylin and eosin. A magnification of the square area is shown at the upper right. Arrowheads indicate $\alpha$-SMA-positive staining around regular blood vessels; arrows show the presence of $\alpha$-SMA ${ }^{+}$cells associated to vasculogenic matrix networks. Scale bars indicate $100 \mu \mathrm{m}$. (c) Double staining for endothelial CD31 (brown) and perivascular $\alpha$-SMA (blue) in human melanoma tissue sections. Higher magnification of the area indicated with a square is shown at the center of this figure. Scale bar represents $100 \mu \mathrm{m}$. (d) PDGF-B staining in human melanoma tissue sections counterstained with hematoxylin and eosin. Scale bar is 100 $\mu \mathrm{m}$. (e-f) Double staining of human Ewing sarcoma tissues. Arrows indicate $\alpha-\mathrm{SMA}^{+}$cells not associated to endothelial cells. Scale bars represent $50 \mu \mathrm{m}$ (e) and $100 \mu \mathrm{m}$ (f). Magnification of the area indicated with a square in (f) is shown at the bottom right. * indicates VM-characteristic blood lakes. 
To investigate the commonality of our findings, we also analyzed a series of human Ewing sarcoma tissues. In these tumors, VM is displayed by characteristic blood lakes, which are pools of red blood cells lines by tumor cells that have adopted an endothelial cell-like phenotype. As for melanoma, double staining revealed the presence of non-endothelial cell-associated perivascular cells within matrix networks. In addition, these perivascular cells were located around the VM-characteristic blood lakes (Figure 5.1e,f). These data show that, similar to blood vessels, VM vessels are covered by perivascular cells, which suggests a functional contribution of perivascular cells to VM.

\section{Vasculogenic networks formed by tumor cells are supported by perivascular cells}

We next questioned whether perivascular cells actually contribute to the stability of VM networks. First, we tested whether perivascular cells could enhance vasculogenic network formation. To test this, $\mathrm{VM}^{+}$melanoma cells were co-cultured with perivascular cells. $\mathrm{VM}^{+}$cells have the ability to form honeycomb-like networks when grown on Matrigel (Figure 5.2a). The added perivascular cells in this assay efficiently took part in the network formation after 24 hours (Figure 5.2b, insert). Interestingly, we observed 'tip-like' cells in the networks that protruded into the Matrigel (Figure 5.2b). Fluorescent labeling of the perivascular cells with CFSE demonstrated that the 'tip-like' cells were of perivascular origin (Figure 5.2c-e).

To investigate whether perivascular cells have a functional contribution to the network formation, $\mathrm{VM}^{+}$melanoma cells were allowed to form networks in the absence of growth factors. Under these conditions, cells efficiently formed networks but these networks started to collapse after 3-4 days (Figure 5.2f). Interestingly, in the presence of perivascular cells, the networks maintained integrity throughout this time period and even after 4 days the networks were still intact (Figure 5.2g). Quantification after 4 days of the remaining number of mesh areas, i.e. circular areas enclosed by tumor cells, demonstrated the significant contribution of perivascular cells in network maintenance (Figure 5.2h). This stabilizing effect was specific for perivascular cells since networks were not maintained by addition of other cells, such as VM- melanoma cells, or ecRF-24 endothelial cells (Supplemental Figure S5.2). In summary, these data suggest that perivascular cells are essential for structural support of VM-characteristic networks.

An important mechanism by which perivascular cells exert their supportive function on blood vessels is by generation of contractile force and constant reshaping of the extracellular matrix. Endothelial cells can regulate perivascular cell contraction via paracrine signaling through various factors ${ }^{27}$. We therefore analyzed whether conditioned medium of $\mathrm{VM}^{+}$melanoma cells could influence the actin stress fiber generation in perivascular cells. Staining of perivascular cells with rhodamine phalloidin demonstrated more actin stress fibers present in cells cultured in 
conditioned medium from $\mathrm{VM}^{+}$cells compared to that of $\mathrm{VM}^{-}$cells (Figure $5.2 \mathrm{i}, \mathrm{j}$ ). Another important stabilizing factor is the deposition of matrix proteins. Therefore, we determined matrix deposition in co-cultures of perivascular cells together with $\mathrm{VM}^{+}$melanoma cells. PAS staining demonstrated the deposition of matrix in a VMcharacteristic patterned network as observed in tissue sections (Figure $5.2 \mathrm{k}, \mathrm{l}$ ). The deposition of matrix in VM-characteristic patterns was not observed when perivascular cells were cultured in combination with $\mathrm{VM}^{-}$melanoma cells, or when cultured alone. These data further suggest that perivascular cells are involved in stabilization of VM networks, similar as in physiological angiogenesis.
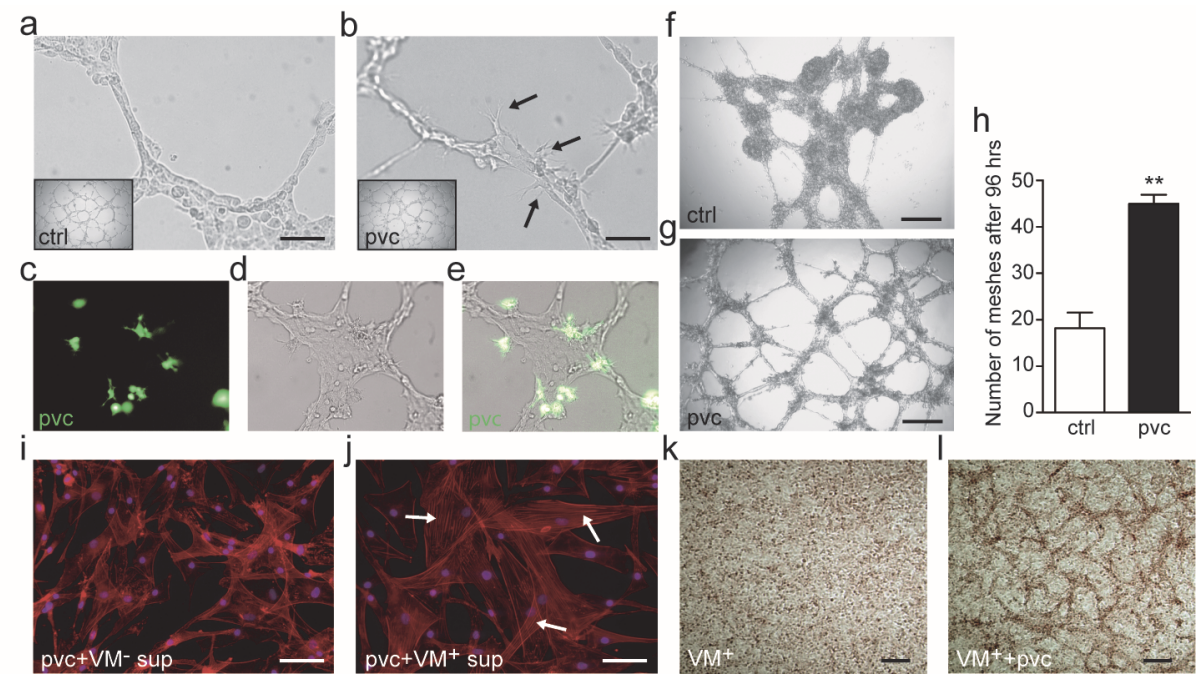

Figure 5.2 Perivascular cells provide structural support to vasculogenic networks. (a-b) VM-characteristic networks on Matrigel formed by $\mathrm{VM}^{+}$melanoma cells alone (a) or in combination with perivascular cells (pvc) (b) after 24 hours. Inserts indicate overall network structure at lower magnification. Scale bars represent $50 \mu \mathrm{m}$ (c) CFSE-labeled perivascular cells in vasculogenic networks on Matrigel after 24 hours. (d) Bright-field image of the networks formed in the presence of perivascular cells. (e) Overlay of the images shown in $\mathrm{c}$ and $\mathrm{d}$. (f-g) Vasculogenic networks formed by $\mathrm{VM}^{+}$melanoma cells alone (f) or in combination with perivascular cells (g) after 96 hours. Scale bars indicate $200 \mu \mathrm{m}$. (h) Quantification of the remaining number of mesh areas in vasculogenic networks after 96 hours $(n=4)$. (i-j) Phalloidin F-actin staining of perivascular cells cultured on medium conditioned by $\mathrm{VM}^{-}$melanoma cells (i), or $\mathrm{VM}^{+}$melanoma cells (j). Scale bars are $50 \mu \mathrm{m}$. (k-I) PAS staining of confluent cultures containing $\mathrm{VM}^{+}$melanoma cells $(\mathbf{k}) \mathrm{or}^{\mathrm{VM}^{+}}$ melanoma cells combined with perivascular cells. Scale bars indicate $200 \mu \mathrm{m}$. ${ }^{* *} \mathrm{p} \leq 0.01$.

\section{Perivascular cells contribute to the vessel-forming capacity of $\mathrm{VM}^{+}$ melanoma cells}

To further address the contribution of perivascular cells to VM, we performed a sprouting assay. This 3-dimensional assay provides a better representation of in vivo neovessel formation compared to the Matrigel assay. Spheroids were composed of non-vasculogenic melanoma cells, vasculogenic melanoma cells, or perivascular cells 
alone, or vasculogenic melanoma cells in combination with non-vasculogenic melanoma cells or perivascular cells. Analysis prior to transfer into a collagen matrix demonstrated the inability of $\mathrm{VM}^{-}$melanoma cells to form a solid spheroid. Spheroids formed by perivascular cells or by $\mathrm{VM}^{+}$melanoma cells in the presence or absence of perivascular cells did not show phenotypical differences (data not shown). Analysis of sprout formation, 8 hours after transfer of the spheroid into a collagen matrix, revealed no sprouting activity by spheroids formed by perivascular cells alone (Figure 5.3a). As for endothelial cells, $\mathrm{VM}^{+}$tumor cells showed apparent sprouting activity (Figure 5.3b). Spheroids composed of both $\mathrm{VM}^{+}$melanoma cells and perivascular cells appeared to have longer sprouts (Figure 5.3d). Indeed, quantification showed a significant increase in tumor cell sprouting in the presence of perivascular cells (Figure $5.3 e, f)$. Similar as before, this effect was cell type specific since the combination of $\mathrm{VM}^{+}$melanoma cells with $\mathrm{VM}^{-}$melanoma cells did not have any contributing effect (Figure 5.3c,e,f). Labeling the perivascular cells with CFSE indicated that the sprouts were solely of tumor cell origin and that the perivascular cells remained at the center of the spheroid (Figure 5.3g). After a time period of 24 hours, perivascular cells were no longer condensed in the spheroid center, but migrated along the sprouts (Figure $5.3 \mathrm{~h})$.

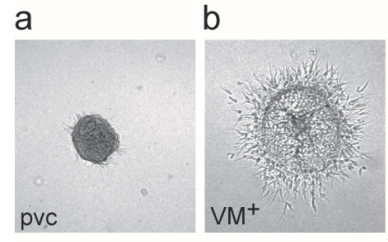

c d

e
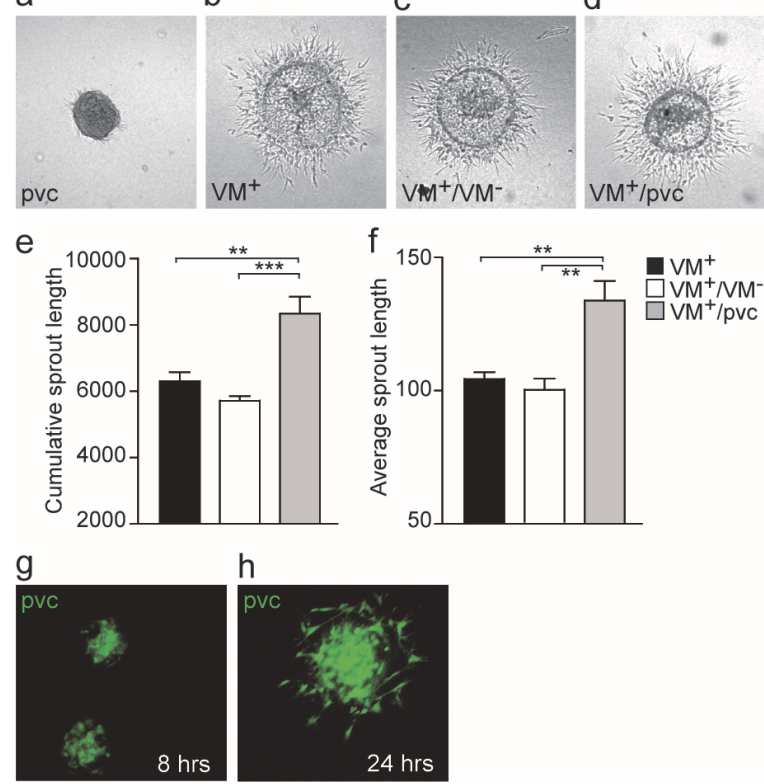

h

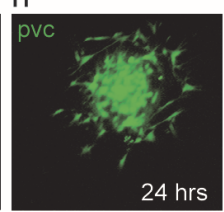

Figure 5.3 Perivascular cells contribute to tumor cell sprouting. (a-d) Sprouting analysis after 8 hours by spheroids composed of perivascular cells (pvc) (a), $\mathrm{VM}^{+}$melanoma cells (b), $\mathrm{VM}^{+}$melanoma cells combined with $\mathrm{VM}^{-}$melanoma cells (c), or $\mathrm{VM}^{+}$melanoma cells combined with perivascular cells (d). (e-f) Quantification of the cumulative sprouting length (e) and average sprouting length per spheroid condition $(\mathbf{f}),(n=3)$. (g) Visualization of CFSE-labeled perivascular cells in a spheroid composed of $\mathrm{VM}^{+}$melanoma cells and perivascular cells 8 hours after embedding in collagen matrix. (h) CFSE-labeled perivascular cells in a combination spheroid 24 hours after embedding in collagen matrix. ${ }^{* *} p \leq 0.01,{ }^{* *} p \leq 0.001$. 


\section{Perivascular cells are attracted by $\mathrm{VM}^{+}$cells in a PDGFR- $\beta$-dependent manner}

To further study the role PDGF-B and perivascular cells in VM we used uveal (OCM-1 and C918) and cutaneous (C81-61 and C8161) melanoma cell lines. Of these, OCM-1 and C81-61 are characterized as poorly aggressive (non-vasculogenic, $\mathrm{VM}^{-}$), while C918 and C8161 are classified as invasive (vasculogenic, $\mathrm{VM}^{+}$). Interestingly, the invasive cell lines displayed elevated PDGF-B mRNA expression as compared to the non-invasive cells (Figure 5.4a). The expression and secretion of the protein homodimer PDGF-BB was verified by ELISA, demonstrating that medium conditioned by $\mathrm{VM}^{+}$melanoma cells contained PDGF-BB protein in a concentration ranging from $20-35 \mathrm{pg} / \mathrm{ml}$ (Figure 5.4b). On the other hand, $\mathrm{VM}^{-}$cell lines demonstrated low PDGF-B mRNA expression and no PDGF-BB protein was detected in their conditioned medium. Quantitative PCR analysis of Ewing sarcoma cell lines showed similar results (Supplemental Figure S5.3). These data suggest that vasculogenic tumor cells have the potential to attract perivascular cells while non-vasculogenic tumor cells have not.
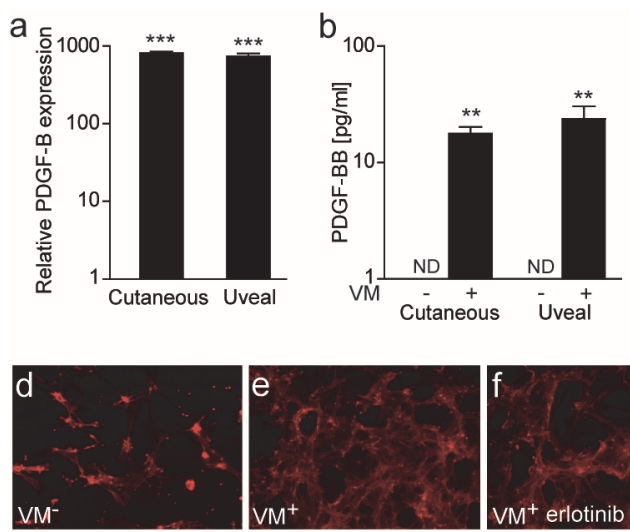
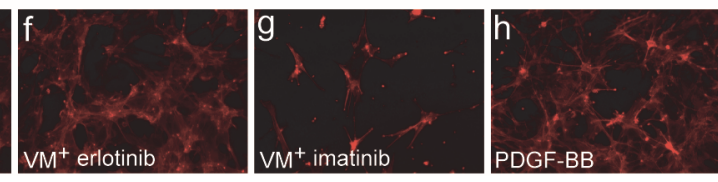

Figure 5.4 $\mathrm{VM}^{+}$melanoma cells produce PDGF-B and induce PDGFR- $\beta$-dependent perivascular cell invasion. (a) qRT-PCR analysis of PDGF-B transcript expression in $\mathrm{VM}^{-}$and $\mathrm{VM}^{+}$melanoma cell lines (cutaneous and uveal). PDGF-B expression in $\mathrm{VM}^{+}$cells is displayed relative compared to its expression in $\mathrm{VM}^{-}$cells $(n=5)$. (b) Human PDGF-BB concentration in medium conditioned by $\mathrm{VM}^{-}$and $\mathrm{VM}^{+}$melanoma cell lines $(n=3)$; $N D=$ not detected. (c) Quantification of the number of perivascular cells invaded to plain medium (ctrl sup), VM conditioned medium, $\mathrm{VM}^{+}$conditioned medium, or plain medium supplemented with human PDGF-BB. Invasion was measured in the presence $(+)$ or absence (-) of imatinib or erlotinib. (d-h) Representative images of perivascular cell invasion towards $\mathrm{VM}^{-}$conditioned medium (d), $\mathrm{VM}^{+}$conditioned medium (e), supplemented with imatinib (f) or erlotinib (g), or plain medium containing PDGF-BB (h). ${ }^{*} \mathrm{p} \leq 0.05,{ }^{* *} \mathrm{p} \leq 0.01$, $* * * \mathrm{p} \leq 0.001$. 
To study the chemo-attractive capacity of PDGF-B produced by $\mathrm{VM}^{+}$melanoma cells, we examined the invasiveness of perivascular cells towards conditioned medium of $\mathrm{VM}^{+}$or $\mathrm{VM}^{-}$melanoma cells. Using cell culture inserts coated with extracellular matrix we observed an apparent induction of perivascular cell invasion by PDGF-BB (Figure 5.4c,h). Furthermore, perivascular cells invaded significantly better towards culture medium conditioned by $\mathrm{VM}^{+}$cells as compared to that conditioned by $\mathrm{VM}^{-}$ cells (Figure 5.4c-e). To confirm that this invasion was dependent on PDGF-B, activation of the PDGF receptor (PDGFR- $\beta$ ) was blocked by addition of the tyrosine kinase inhibitor imatinib (Figure 5.4c,g). This induced a clear inhibition of perivascular cell invasion, while blockage of the epidermal growth factor receptor (EGFR) with erlotinib did not affect perivascular cell invasion (Figure 5.4c,f). These findings demonstrate that $\mathrm{VM}^{+}$cells are able to attract perivascular cells and that this requires functional PDGF-B/PDGFR- $\beta$ signaling.

Increased intratumoral perivascular cell presence is associated with the vasculogenic potential of tumor cells

To verify our in vitro findings, the $\mathrm{VM}^{-}(\mathrm{OCM}-1)$ and $\mathrm{VM}^{+}$(C918) uveal melanoma cell lines were injected in mice as described previously. To confirm the vasculogenic state of the C918 melanoma cells, tumor sections were analyzed for the presence of PAS-positive matrix loops (Figure 5.5a) and extravascular erythrocytes (EEs) (Figure 5.5b). In agreement with their in vitro status, the $\mathrm{VM}^{+} \mathrm{C} 918$ melanomas displayed a significantly increased incidence of both PAS loops and EEs (Figure 5.5c). In contrast, both these VM-characteristics were scarcely observed in poorly aggressive OCM-1 tumors (Figure 5.5a-c). Interestingly, C918 tumors were also characterized by an abundance of perivascular cells, which showed a chaotic distribution throughout the tumor tissue (Figure $5.5 \mathrm{~d}$, right image). In agreement with our previous findings, double stainings revealed the presence of $\alpha-\mathrm{SMA}^{+}$perivascular cells that were not associated with $\mathrm{CD} 31^{+}$endothelial cells within the C918 vasculogenic tumors (Figure 5.5e, right image). Furthermore, tumor cell-associated perivascular cells were absent within the non-vasculogenic poorly aggressive OCM-1 tumors. Quantification demonstrated that, although the amount of mature $\left(\mathrm{CD}_{3} 1^{+} \mathrm{SMA}^{+}\right)$and immature $\left(\mathrm{CD} 1^{+} \mathrm{SMA}^{-}\right)$vessels did not significantly differ between $\mathrm{VM}^{-}$and $\mathrm{VM}^{+}$tumor tissues (Figure 5.5f), the number of perivascular cells not associated with endothelial cells $\left(\mathrm{CD}^{-} \mathrm{SMA}^{+}\right.$) was increased within the vasculogenic C918 tumors (Figure 5.5g). These data verify that during the process of transdifferentiation $\mathrm{VM}^{+}$tumor cells have gained the capacity to attract perivascular cells in vivo as they do in vitro. 
a
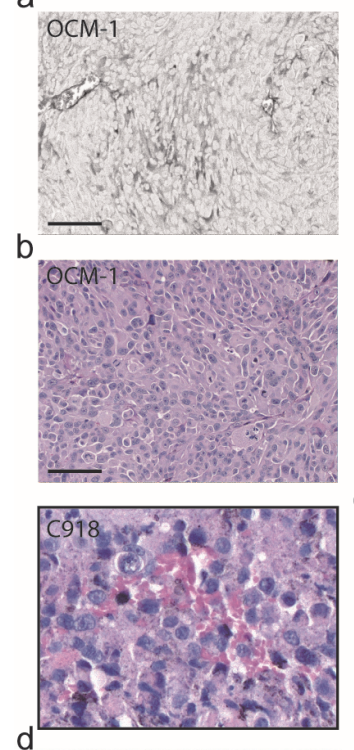

$\mathrm{d}$

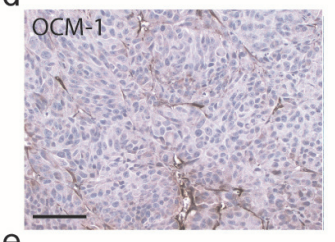

e

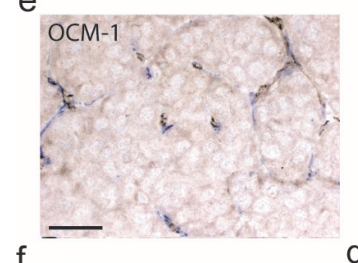

$f$

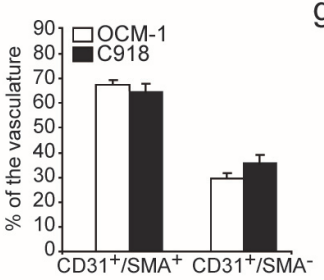

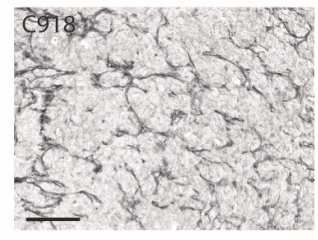

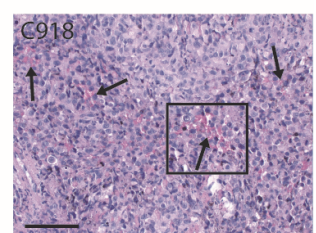

3.5
3.0 믈
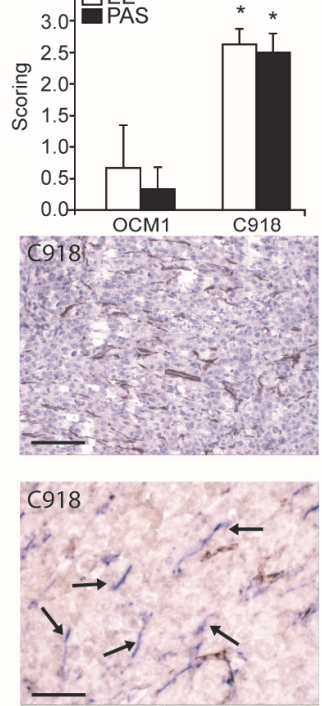

g

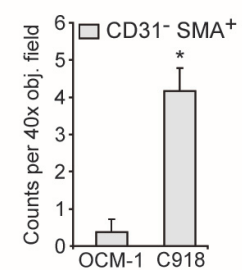

Figure 5.5 $\mathrm{VM}^{+}$melanoma cell lines induce perivascular cell invasion in vivo. (a) PAS staining of OCM-1 tumors (left) and C918 tumors (right). Scale bars indicate $100 \mu \mathrm{m}$. (b) Hematoxylin and eosin staining of OCM-1 and C918 tumors. Scale bars indicate $100 \mu \mathrm{m}$. A magnification of the area indicated by a square is subsequently displayed. (c) Quantification of the presence of PAS loops and extra-vascular erythrocytes (EE) in OCM-1 and C918 tumors. 0, negative; 1 , intermediate; 2, positive; 3 strongly positive. (d) $\alpha$-SMA staining of OCM-1 (left) and C918 (right) tumor sections counterstained with hematoxylin. Scale bars are $100 \mu \mathrm{m}$. (e) Double staining of OCM-1 and C918 tumors for endothelial CD31 (brown) and perivascular $\alpha$-SMA (blue). Arrows show $\alpha-\mathrm{SMA}^{+}$cells not associated to $\mathrm{CD} 1^{+}$endothelial cells. Scale bars indicate $50 \mu \mathrm{m}$. (f) Quantification of the percentage mature $\left(\mathrm{CD} 1^{+} \mathrm{SMA}^{+}\right)$and immature $\left(\mathrm{CD}^{+} 1^{+} \mathrm{SMA} \mathrm{A}^{-}\right)$vessels. (g) Quantification of the number of non-vessel associated $\alpha$-SMA ${ }^{+}$cells per microscopic field. OCM-1 $n=4 ; C 918 n=5 ;{ }^{*} p \leq 0.05$. 


\section{PDGF-B expression increases matrix deposition in VM-characteristic patterns and enhances perivascular cell invasion}

Finally, we assessed whether PDGF-B expression in $\mathrm{VM}^{+}$tumor cells increases vasculogenic network stabilization in vivo. To that end, B16F10 murine melanoma cells either transfected with empty expression vector (mock) or vector containing an expression cassette for PDGF-B were injected in wild type $\mathrm{C} 57 \mathrm{BI} / 6$ mice as described previously $^{23}$. B16F10 cells have recently been described to contribute in vessel formation through $\mathrm{VM}^{28}$. Examination of B16F10 vasculogenic network formation on Matrigel demonstrated that these cells were able to form the VM-characteristic patterned networks (Supplemental Figure S5.4). The production of PDGF-B by murine melanoma cells was associated with an increased tumor growth rate (Figure 5.6a). PAS staining revealed patterned matrix networks lined by tumor cells - characteristic for $\mathrm{VM}^{+}$tumors - in both wild type and PDGF-B (over)expressing B16F10 melanomas (Figure 5.6b,c). Interestingly, these PAS-positive networks were more robust in PDGF$\mathrm{B}$ expressing $\mathrm{VM}^{+}$melanomas compared to wild type $\mathrm{VM}^{+}$melanomas, which is in line with our in vitro data demonstrating VM-characteristic matrix deposition in cocultures of $\mathrm{VM}^{+}$tumor cells and perivascular cells (Figure 5.2I). The PAS-positive networks were found to be connected to areas containing red blood cells lined by tumor cells (Figure 5.6c, arrow). In wild type mice engrafted with PDGF-B expressing melanomas, we observed an increased abundance of $\alpha-\mathrm{SMA}^{+}$cells compared to mice growing wild type tumors (Figure $5.6 \mathrm{~d}, \mathrm{e}$ ). Correlation of these findings to $\mathrm{CD} 31^{+}$ endothelial cells showed that in both wild type and PDGF-B expressing tumors, $\alpha$ $\mathrm{SMA}^{+}$perivascular cells that were located in between tumor cells and associated with the matrix networks were observed (Figure 5.6f,g). Although the microvessel density was not affected by the expression of PDGF-B (Figure 5.6h), we did observe a slight shift towards a more immature vessel phenotype $\left.\left(\mathrm{CD}_{3} 1^{+} \text {and } \alpha-\mathrm{SMA}\right)^{-}\right)$within the PDGF-B expressing melanomas (Figure 5.6i). $\alpha-\mathrm{SMA}^{+}$cells not associated with blood vessels (CD31 and $\alpha-\mathrm{SMA}^{+}$) were found in both tumor tissues. However, the number of perivascular cells that were located in between tumor cells and not associated with blood vessels $\left(\mathrm{CD}^{-} \mathrm{SMA}^{+}\right)$was significantly larger in B16F10 melanoma cells expressing PDGF-B (Figure 5.6i). These data demonstrate that the additional expression of PDGF-B is associated with increased matrix deposition within the vasculogenic networks and enhanced perivascular cell invasion. 

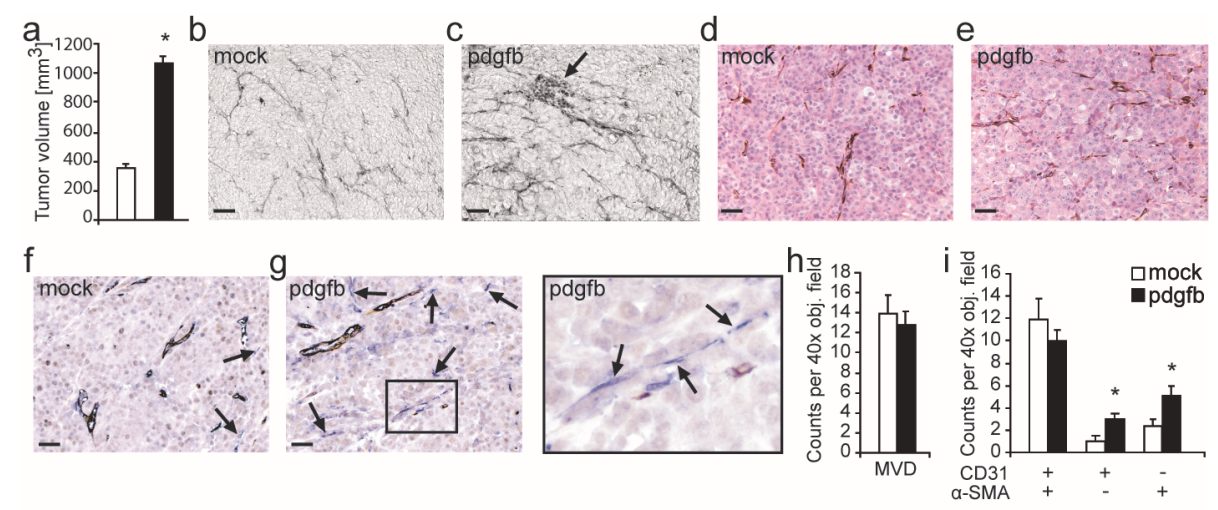

Figure 5.6 PDGF-B expression by vasculogenic tumor cells stimulates intratumoral perivascular cell invasion. (a) Tumor volume of control transfected (mock) or PDGF-B transfected (pdgfb) B16F10 tumors 17 days after tumor injection in the dorsal skinfold of C57B16/J mice. (b-c) PAS staining of mock (b) and PDGF-B (c) transfected tumors. Arrow shows the presence of extravascular erythrocytes associated with the extracellular matrix loops. (d-e) $\alpha$-SMA staining of mock transfected (d) and PDGF-B transfected (e) tumors. (f-h) Double staining of endothelial CD31 (brown) and perivascular $\alpha$-SMA (blue) of mock (f) and PDGF-B (g) tumors. Magnification of the insert is shown on the right. Arrows indicate $\alpha-\mathrm{SMA}^{+}$cells not associated with $\mathrm{CD} 1^{+}$cells. (b-g) Scale bars indicate $50 \mu \mathrm{m}$. (h) Quantification of the microvessel density (MVD) in mock and PDGF-B tumors. (i) Quantification of the vessel status - mature (CD31 $\left.{ }^{+} \mathrm{SMA}^{+}\right)$, immature (CD31 $\left.\left.{ }^{+} \mathrm{SMA}\right)^{-}\right)$, non-vessel-associated $\alpha-S_{M A}{ }^{+}$cells - in mock and PDGFB transfected tumors $(n=3) .{ }^{*} p \leq 0.05$.

\section{Discussion}

In the present study, we describe the functional relevance of perivascular cells during vasculogenic mimicry (VM). VM refers to the unique ability of aggressive tumor cells to resemble endothelial cells based on cell type specific gene expression and vascular network formation. We showed that $\alpha$-smooth muscle actin positive $\left(\alpha-S M A^{+}\right)$cells are located within VM-characteristic matrix networks. This finding suggests that the presence of $\alpha-\mathrm{SMA}^{+}$cells, i.e. perivascular cells, within these network offers a benefit for tumor cells engaged in VM. Perivascular cells are of high importance during blood vessel maturation as they provide structural support to the vasculature. Endothelial cells in developing vasculature produce platelet-derived growth factor (PDGF)-B, which attracts PDGFR- $\beta$-expressing perivascular cells (pericytes, vascular smooth muscle cells). We demonstrated that $\mathrm{VM}^{+}$melanoma cells exploit this PDGF-B/PDGFR$\beta$-dependent mechanism of perivascular cell recruitment. By the production and secretion of PDGF-B $\mathrm{VM}^{+}$melanoma cells were able to induce perivascular cell invasion.

Our current in vitro data reveal that the interaction between $\mathrm{VM}^{+}$melanoma cells and perivascular cells results in stabilization of VM-characteristic vasculogenic networks. This suggests that the interaction of perivascular cells with $\mathrm{VM}^{+}$tumor cells has a comparable result on tube stabilization as compared to their interaction with 
endothelial cells. Once endothelial cells have recruited perivascular cells the interaction between both cell types stabilizes new blood vessels by the suppression of endothelial proliferation and migration, and by the formation of extracellular matrix and basement membrane, which surrounds them both. Recently, it was demonstrated that the co-culture, and therefore interaction, of endothelial cells and perivascular cells caused increased expression of basement membrane proteins ${ }^{29}$. The extracellular matrix of a blood vessel contributes substantially to the diverse functions of the vessel, including its structure and stabilization, as well as regulation of vascular cell proliferation and differentiation ${ }^{30}$. Our data demonstrated that the interaction between $\mathrm{VM}^{+}$melanoma cells and perivascular cells also resulted in the formation of matrix. Interestingly, the matrix was organized in a similar honeycomb-like structure as observed for PAS loops in $\mathrm{VM}^{+}$tumor tissues, i.e. enclosing groups of tumor cells. These data suggest that the interaction between vasculogenic tumor cells and perivascular cells contributes to the formation of vascular matrix networks and by these means to increased stabilization. However, the formation of PAS loops is most likely not solely dependent on the interaction with perivascular cells as $\mathrm{VM}^{+}$ melanoma cells have the capacity to produce matrix components such as laminin-5 22 themselves ${ }^{5}$.

The current findings suggest that the interaction between vasculogenic tumor cells and perivascular cells does not only contribute to network stabilization, but also to an enhanced sprouting activity of $\mathrm{VM}^{+}$melanoma cells. Previous studies have described the contribution of perivascular cells during early angiogenic sprouting and tube formation by endothelial cells ${ }^{31}$. These studies suggest that perivascular cells invade tissues in the absence of endothelial cells to guide the endothelial tube. Others, however, reported that the initial patterning of endothelial vascular networks occurred independent of perivascular cells ${ }^{32}$. Our observations indicate that although perivascular cells appear to have a positive contributing role during $\mathrm{VM}^{+}$tumor cell sprouting, their presence is not required for the initiation of this sprouting. During sprouting angiogenesis, endothelial cells in the sprouting tip direct the formation of the immature vessel throughout the extracellular matrix. The direction of the sprouting tip is governed by the expression of angiogenic factors secreted by other cells into their microenvironment. Although it is unknown what guides the formation of VM tubes, our data suggest that the presence of perivascular cells positively affects melanoma cell sprouting, i.e. vasculogenic network formation. Previously, it was shown that the interaction between perivascular cells and MDA-MB-231 tumor cells derived from an aggressive breast carcinoma with vasculogenic potential enhanced the invasive potential of the tumor cells ${ }^{33}$. The presence of perivascular cells may therefore be responsible for the increased sprouting capacity of vasculogenic melanoma cells through collagen matrix. Throughout the process of new blood vessel formation PDGF-B is mainly expressed by the endothelial cells located at the tip of the sprouting vessel. The expression of PDGF-B by these endothelial cells indicates that 
within this area active perivascular cell recruitment is taking place, i.e. vessel maturation. Consistent with this, we demonstrated that once tumor cells had formed sprouts in vitro, perivascular cells were induced to migrate along the tumor sprouts. The expression of PDGF-B by endothelial cells is indicative for vessel maturation and therefore reflects its functional state ${ }^{34-36}$. The similarity between endothelium and $\mathrm{VM}^{+}$tumor cells concerning their interaction with perivascular cells may imply that PDGF-B expression by $\mathrm{VM}^{+}$tumor cells is also an indicator of new "vessel" formation. Indeed, although the expression of PDGF-B was highest in the tumor cells directly lining VM-matrix networks, not all tumor cells lining the matrix tubes displayed an increased PDGF-B expression. This suggests that monitoring the PDGF-B expression in $\mathrm{VM}^{+}$tumor tissues could indicate which tumor areas are actively forming vasculogenic tubes and may thus contribute to the identification of markers involved in the initiation of VM tube formation.

The data presented in this manuscript demonstrate the ability of $\mathrm{VM}^{+}$tumor cells to resemble endothelial cells not only based on gene expression and tube formation, but also in regard to gaining benefits by their interaction with other cell types. By inducing the expression of PDGF-B, vasculogenic murine melanoma cells gained the capacity to recruit $\alpha-\mathrm{SMA}^{+}$perivascular cells. In agreement with this, a previous study analyzing these tissues reported the presence of completely detached perivascular cells ${ }^{23}$. These cells were scored to be perivascular cells based on morphology. Besides positive staining for $\alpha$-SMA, these cells were also found positive for high molecular weightmelanoma antigen (HMW-MMA, also referred to as NG2), an additional perivascular cells marker. Unlike endothelial cells, there is no specific marker for perivascular cells. Over the years, various marker proteins have been proposed, including myofilaments such as $\alpha$-SMA or desmin, and also PDGFR- $\beta$, and NG2 ${ }^{37-39}$. Of these, PDGFR- $\beta$ is considered a marker of immature perivascular cells, while the other markers are indicative for a mature phenotype. In tumors tissues, a heterogeneous population of perivascular cells has been found that is composed of distinct maturation stages and thus perivascular cell markers ${ }^{40}$.

In our in vivo model, we noted that the enhanced presence of tumor cell-associated perivascular cells in $\mathrm{VM}^{+}$tumors caused a slight trend towards a more immature vasculature phenotype. By competing with the endothelial sources of PDGF-B and/or by providing a perivascular cell-adhesive matrix, PDGF-B expressing tumor cells may cause reduced vessel coverage by perivascular cells resulting from their defective migration. Despite the endothelial mimicking by $\mathrm{VM}^{+}$tumor cells, vascular network formation by tumor cells cannot be inhibited by angiostatic drugs ${ }^{41}$. Our novel findings on the functional contribution of perivascular cells to the stability and formation of VM networks suggest that targeting of perivascular cells may prevent or reduce VM network formation. Over the years, oncology research focusing on perivascular cells has gained interest. Debate is continuing whether or not perivascular cells will be an interesting candidate to target tumor angiogenesis. It is speculated that the intimate 
interaction between endothelium and perivascular cells may offer resistance to endothelial cells. This may be due to the perivascular coverage of endothelial cells, thereby reducing the sensitivity of endothelium to targeting agents. Importantly, perivascular cells produce or stimulate the production of endothelial survival factors such as angiopoietin-1 and VEGF ${ }^{42,43}$. The secretion of PDGF-B from endothelial cells and tumor cells stimulated VEGF production by perivascular cells ${ }^{44}$. In prostate cancer, targeting of perivascular cells was shown to reduce neovasculatization ${ }^{45}$. The role of perivascular cells in endothelial resistance and/or survival suggests a potential role for these cells in a dual targeting strategy to increase the sensitivity of tumor vasculature to therapy. Indeed, the effectiveness of targeting both endothelial cells and perivascular cells has previously been demonstrated ${ }^{46,47}$. However, others have described the absence of increased vasculature sensitivity to angiogenesis inhibition in the absence of perivascular cells ${ }^{48}$.

Perivascular cells have recently been described as so-called "tumor gatekeeper cells" ${ }^{\prime 9}$. Tumor tissues with low perivascular cell coverage of their blood vessels were found to be more aggressive and had increased risk of tumor metastasis. It was proposed that antitumor drugs targeting or destroying these gatekeeper cells might increase the risk of tumor spreading due to increased leakiness of the tumor vasculature. Such event would facilitate the entrance of invading tumor cells into the blood stream, and would thus increase the risk of metastasis. Although reduced perivascular cell coverage in breast tumors in mice demonstrated a reduced tumor size, it also caused an increase in tumor cell metastasis to the lungs, thereby demonstrating that tumor growth is not necessarily a good parameter of treatment efficacy. Furthermore, perivascular cell depletion was reported to enhance tumor hypoxia and stimulate metastasis via c-Met signaling ${ }^{49}$. Possibly, this mechanism is exploited by $\mathrm{VM}^{+}$tumors. By producing PDGF-B vasculogenic tumor cells can compete with tumor endothelial cells for perivascular cell recruitment. In addition to the functional contribution of the perivascular cells to the stabilization and formation of vasculogenic networks, the reduced amount of vasculature coverage will result in vessel leakiness and may ultimately facilitate tumor cell intravasation. This would imply that the interaction of vasculogenic tumor cells with perivascular cells results in a sustained connection to blood flow through stable vasculogenic networks and provides tumor cells with a route for metastasis.

Together, our findings - linking vasculogenic mimicry to intratumoral perivascular cell invasion - provide novel insights for the debate on perivascular cell targeting. Treatment strategies targeting these cells may be beneficial by preventing or reducing VM network formation, thereby hampering tumor cell metastasis simultaneously. 


\section{Chapter 5}

\section{Supplemental figures}

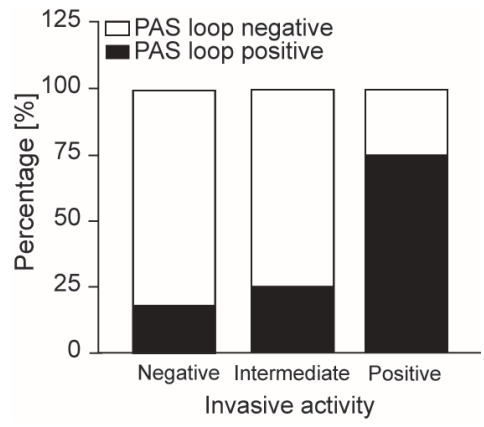

Figure S5.1 The presence of VM-characteristic PAS loops is related to tumor malignancy. Invasive activity was scored based on the number of mitotic figures per $\mathrm{mm}^{2}$ in the invasive component of the melanoma tissues. High numbers of mitotic figures are associated with a poor prognosis.
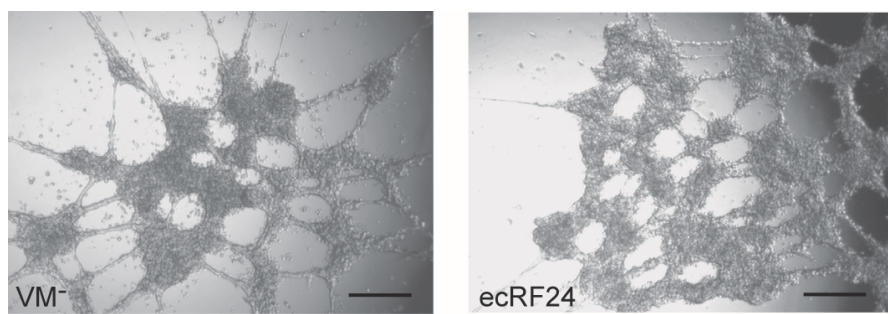

Figure S5.2 Vasculogenic networks are not structurally supported by $\mathrm{VM}^{-}$melanoma cells (VM') or endothelial cells (ecRF24). Scale bars represent $200 \mu \mathrm{m}$. 


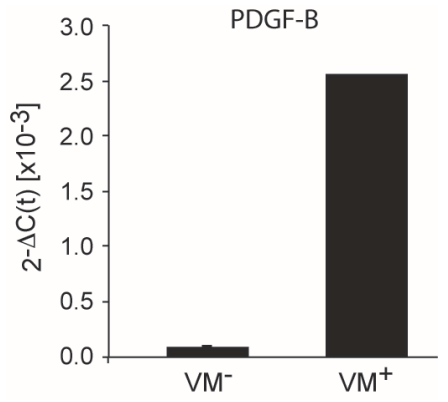

Figure S5.3 PDGF-B transcription in $\mathrm{VM}^{-}(\mathrm{A673})$ and VM${ }^{+}$(RD-ES) Ewing sarcoma cell lines. $(n=3)$

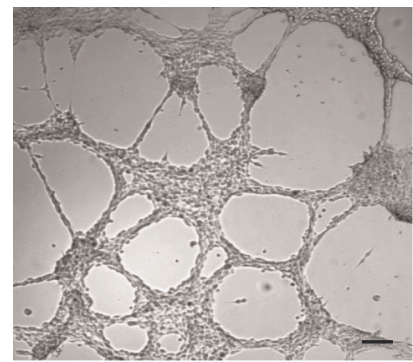

Figure S5.4 Vasculogenic network formation on Matrigel by B16F10 murine melanoma cells. Scale bars represent $100 \mu \mathrm{m}$. 


\section{References}

1. Maniotis AJ, Folberg R, Hess A, et al. Vascular channel formation by human melanoma cells in vivo and in vitro: vasculogenic mimicry. Am J Pathol, 1999; 155:739-52.

2. Hendrix MJ, Seftor EA, Hess AR, et al. Molecular plasticity of human melanoma cells. Oncogene, 2003; 22:3070-5.

3. Thies A, Mangold U, Moll I, et al. PAS-positive loops and networks as a prognostic indicator in cutaneous malignant melanoma. J Pathol, 2001; 195:537-42.

4. Warso MA, Maniotis AJ, Chen X, et al. Prognostic significance of periodic acid-Schiff-positive patterns in primary cutaneous melanoma. Clin Cancer Res, 2001; 7:473-7.

5. Seftor RE, Seftor EA, Koshikawa N, et al. Cooperative interactions of laminin 5 gamma2 chain, matrix metalloproteinase-2, and membrane type-1-matrix/metalloproteinase are required for mimicry of embryonic vasculogenesis by aggressive melanoma. Cancer research, 2001; 61:6322-7.

6. Hendrix MJ, Seftor EA, Meltzer PS, et al. Expression and functional significance of VE-cadherin in aggressive human melanoma cells: role in vasculogenic mimicry. Proceedings of the National Academy of Sciences of the United States of America, 2001; 98:8018-23.

7. Hess AR, Seftor EA, Gardner LM, et al. Molecular regulation of tumor cell vasculogenic mimicry by tyrosine phosphorylation: role of epithelial cell kinase (Eck/EphA2). Cancer research, 2001; 61:3250-5.

8. Carmeliet P. Mechanisms of angiogenesis and arteriogenesis. Nature medicine, 2000; 6:389-95.

9. von Tell D, Armulik A, Betsholtz C. Pericytes and vascular stability. Experimental cell research, 2006; 312:623-9.

10. Ribatti D, Nico B, Crivellato $E$. The role of pericytes in angiogenesis. The International journal of developmental biology, 2011; 55:261-8.

11. Armulik A, Abramsson A, Betsholtz C. Endothelial/pericyte interactions. Circ Res, 2005; 97:512-23.

12. Joyce NC, DeCamilli P, Lohmann SM, et al. cGMP-dependent protein kinase is present in high concentrations in contractile cells of the kidney vasculature. Journal of cyclic nucleotide and protein phosphorylation research, 1986; 11:191-8.

13. Kelley C, D'Amore $\mathrm{P}$, Hechtman $\mathrm{HB}$, et al. Microvascular pericyte contractility in vitro: comparison with other cells of the vascular wall. The Journal of cell biology, 1987; 104:483-90.

14. Hellberg C, Ostman A, Heldin CH. PDGF and vessel maturation. Recent results in cancer research. Fortschritte der Krebsforschung. Progres dans les recherches sur le cancer, 2010; 180:103-14.

15. Betsholtz C. Insight into the physiological functions of PDGF through genetic studies in mice. Cytokine \& growth factor reviews, 2004; 15:215-28.

16. Leveen P, Pekny M, Gebre-Medhin S, et al. Mice deficient for PDGF B show renal, cardiovascular, and hematological abnormalities. Genes \& development, 1994; 8:1875-87.

17. Lindblom P, Gerhardt H, Liebner S, et al. Endothelial PDGF-B retention is required for proper investment of pericytes in the microvessel wall. Genes \& development, 2003; 17:1835-40.

18. Bjarnegard M, Enge M, Norlin J, et al. Endothelium-specific ablation of PDGFB leads to pericyte loss and glomerular, cardiac and placental abnormalities. Development, 2004; 131:1847-57.

19. $\mathrm{Yu}$ J, Ustach C, Kim HR. Platelet-derived growth factor signaling and human cancer. Journal of biochemistry and molecular biology, 2003; 36:49-59.

20. Bittner $\mathrm{M}$, Meltzer $\mathrm{P}, \mathrm{Chen} \mathrm{Y}$, et al. Molecular classification of cutaneous malignant melanoma by gene expression profiling. Nature, 2000; 406:536-40.

21. Carmeliet P. Mechanisms of angiogenesis and arteriogenesis. Nat Med, 2000; 6:389-95.

22. Rubbens MP, Mol A, Boerboom RA, et al. Intermittent straining accelerates the development of tissue properties in engineered heart valve tissue. Tissue Eng Part A, 2009; 15:999-1008.

23. Furuhashi M, Sjoblom T, Abramsson A, et al. Platelet-derived growth factor production by B16 melanoma cells leads to increased pericyte abundance in tumors and an associated increase in tumor growth rate. Cancer research, 2004; 64:2725-33.

24. van der Schaft DW, Hillen F, Pauwels $P$, et al. Tumor cell plasticity in Ewing sarcoma, an alternative circulatory system stimulated by hypoxia. Cancer research, 2005; 65:11520-8.

25. Hillen $\mathrm{F}$, Baeten $\mathrm{Cl}$, van de Winkel $\mathrm{A}$, et al. Leukocyte infiltration and tumor cell plasticity are parameters of aggressiveness in primary cutaneous melanoma. Cancer immunology, immunotherapy: CII, 2008; 57:97-106. 
26. Vartanian AA, Stepanova EV, Gutorov SL, et al. Prognostic significance of periodic acid-Schiff-positive patterns in clear cell renal cell carcinoma. The Canadian journal of urology, 2009; 16:4726-32.

27. Rucker HK, Wynder HJ, Thomas WE. Cellular mechanisms of CNS pericytes. Brain research bulletin, 2000; 51:363-9.

28. Ribatti D, Nico B, Cimpean AM, et al. B16-F10 melanoma cells contribute to the new formation of blood vessels in the chick embryo chorioallantoic membrane through vasculogenic mimicry. Clinical and experimental medicine, 2012.

29. Stratman AN, Malotte KM, Mahan RD, et al. Pericyte recruitment during vasculogenic tube assembly stimulates endothelial basement membrane matrix formation. Blood, 2009; 114:5091-101.

30. Eble JA, Niland S. The extracellular matrix of blood vessels. Current pharmaceutical design, 2009; 15:1385-400.

31. Ozerdem U, Stallcup WB. Early contribution of pericytes to angiogenic sprouting and tube formation. Angiogenesis, 2003; 6:241-9.

32. Hellstrom $M$, Gerhardt $H$, Kalen $M$, et al. Lack of pericytes leads to endothelial hyperplasia and abnormal vascular morphogenesis. The Journal of cell biology, 2001; 153:543-53.

33. Bagley RG, Weber W, Rouleau C, et al. Pericytes and endothelial precursor cells: cellular interactions and contributions to malignancy. Cancer Res, 2005; 65:9741-50.

34. Gerhardt H, Betsholtz C. Endothelial-pericyte interactions in angiogenesis. Cell Tissue Res, 2003; 314:15-23.

35. Abramsson A, Berlin O, Papayan $\mathrm{H}$, et al. Analysis of mural cell recruitment to tumor vessels. Circulation, 2002; 105:112-7.

36. Hellstrom M, Kalen M, Lindahl P, et al. Role of PDGF-B and PDGFR-beta in recruitment of vascular smooth muscle cells and pericytes during embryonic blood vessel formation in the mouse. Development, 1999; 126:3047-55.

37. Andrae J, Gallini R, Betsholtz C. Role of platelet-derived growth factors in physiology and medicine. Genes \& development, 2008; 22:1276-312.

38. Bergers $\mathrm{G}$, Song $\mathrm{S}$. The role of pericytes in blood-vessel formation and maintenance. Neuro-oncology, 2005; 7:452-64.

39. Hamzah J, Jugold M, Kiessling $\mathrm{F}$, et al. Vascular normalization in Rgs5-deficient tumours promotes immune destruction. Nature, 2008; 453:410-4.

40. Song S, Ewald AJ, Stallcup W, et al. PDGFRbeta+ perivascular progenitor cells in tumours regulate pericyte differentiation and vascular survival. Nature cell biology, 2005; 7:870-9.

41. van der Schaft DW, Seftor RE, Seftor EA, et al. Effects of angiogenesis inhibitors on vascular network formation by human endothelial and melanoma cells. Journal of the National Cancer Institute, 2004; 96:1473-7.

42. Sundberg C, Kowanetz M, Brown LF, et al. Stable expression of angiopoietin-1 and other markers by cultured pericytes: phenotypic similarities to a subpopulation of cells in maturing vessels during later stages of angiogenesis in vivo. Laboratory investigation; a journal of technical methods and pathology, 2002; 82:387-401.

43. Franco $M$, Roswall $P$, Cortez $E$, et al. Pericytes promote endothelial cell survival through induction of autocrine VEGF-A signaling and Bcl-w expression. Blood, 2011; 118:2906-17.

44. Reinmuth N, Liu W, Jung YD, et al. Induction of VEGF in perivascular cells defines a potential paracrine mechanism for endothelial cell survival. FASEB journal: official publication of the Federation of American Societies for Experimental Biology, 2001; 15:1239-41.

45. Ozerdem U. Targeting of pericytes diminishes neovascularization and lymphangiogenesis in prostate cancer. Prostate, 2006; 66:294-304.

46. Lu C, Kamat AA, Lin YG, et al. Dual targeting of endothelial cells and pericytes in antivascular therapy for ovarian carcinoma. Clinical cancer research: an official journal of the American Association for Cancer Research, 2007; 13:4209-17.

47. Erber R, Thurnher A, Katsen AD, et al. Combined inhibition of VEGF and PDGF signaling enforces tumor vessel regression by interfering with pericyte-mediated endothelial cell survival mechanisms. Faseb J, 2004; 18:338-40.

48. Nisancioglu MH, Betsholtz $\mathrm{C}$, Genove $\mathrm{G}$. The absence of pericytes does not increase the sensitivity of tumor vasculature to vascular endothelial growth factor-A blockade. Cancer research, 2010; 70: 5109-15. 


\section{Chapter 5}

49. Cooke VG, LeBleu VS, Keskin D, et al. Pericyte depletion results in hypoxia-associated epithelial-tomesenchymal transition and metastasis mediated by met signaling pathway. Cancer cell, 2012; 21:6681. 


\section{Chapter \\ 6}

CD44 enhances tumor aggressiveness by promoting

tumor cell plasticity

Yvette WJ Paulis*, Daisy WJ van der Schaft*, Patricia MMB Soetekouw, Petra Al Hautvast, Patrick Pauwels, Vivianne CG Tjan-Heijnen, Arjan W Griffioen * equal contributions 


\section{Abstract}

Aggressive tumor cells can obtain the ability to transdifferentiate into cells with endothelial features and thus form vasculogenic networks. This phenomenon, called vasculogenic mimicry (VM), was found to be associated with increased malignancy and poor clinical outcome. To identify novel key molecules implicated in the process of vasculogenic mimicry, microarray analysis was performed to compare gene expression profiles of aggressive $\left(\mathrm{VM}^{+}\right)$and poorly aggressive (VM) Ewing sarcoma and breast carcinoma cells. This analysis led to the identification of the CD44/c-Met signaling cascade as heavily relevant for vasculogenic mimicry. CD44 was found the center of this cascade, and highly overexpressed in aggressive tumors. Increased expression of both CD44 standard and its splice variant CD44v6 was found. Functional analyses in Ewing sarcoma cells showed that overexpression of CD44 allowed enhanced adhesion to its extracellular matrix ligand hyaluronic acid. CD44 expression also facilitated the formation of vasculogenic structures in vitro, as CD44 knockdown experiments repressed migration and vascular network formation. From these results and the observation that CD44 expression is associated with vasculogenic structures and blood lakes in human Ewing sarcoma tissues, we conclude that CD44 increases aggressiveness in tumors through the process of vasculogenic mimicry. 


\section{Introduction}

Vasculogenic mimicry (VM) describes the process in which highly aggressive, plastic tumor cells gain characteristics normally restricted to endothelial cells. This transdifferentiation allows tumor cells to form matrix-rich vasculogenic tubular structures ${ }^{1}$. Through this means, tumor cells can contribute to blood circulation independent of regular angiogenesis. After the initial observation of VM in melanoma, evidence for its occurrence has been reported in other tumor types ${ }^{2-6}$ and research has focused on identifying the molecular mechanism underlying this phenomenon ${ }^{7}$. Further understanding of this process specifically revealed that in glioblastoma it is the stem-like glioblastoma cell subset that is responsible for the capacity to transdifferentiate to endothelial-like cells. It was demonstrated that these cells gain the ability to activate transcriptional programs assumed to be restricted to endothelial cells ${ }^{8,9}$.

Ewing sarcoma is a highly aggressive bone and soft tissue tumor that arises in children and young adults. In patients with localized disease, modern treatment modalities are able to achieve cure rates of approximately $70 \%$. However, the prognosis of patients with metastatic Ewing sarcoma at time of diagnosis still remains inferior, indicating the limitations of current treatments strategies ${ }^{10}$. Previously, we demonstrated the presence of VM in Ewing sarcoma ${ }^{11}$. This phenomenon is associated with increased tumor malignancy and may contribute to tumor progression.

CD44 is a transmembrane glycoprotein receptor originally identified to be involved in leukocyte adhesion and recirculation. At present, it is widely recognized as a pleiotropic molecule expressed by stem cells and involved in tumor metastasis ${ }^{12,13}$. It is a marker of epithelial-to-mesenchymal transition and described to be expressed on tumor endothelium. The main ligand for CD44 is hyaluronic acid. This extracellular matrix constituent functions as a microenvironmental cue to regulate cell behavior during processes like embryonic development, tissue remodeling, wound healing, inflammation, and tumor growth. In the latter process, hyaluronic acid is known to enhance malignancy by promoting cell invasiveness and epithelial-to-mesenchymal transition ${ }^{14,15}$. Following transcription, the CD44 message is subject to alternative splicing, thereby giving rise to several CD44 splice variants ${ }^{16}$. The expression of CD44 and its splice variants, mainly variant $6(\mathrm{CD} 44 \mathrm{v} 6)$, has been associated with malignant transformation ${ }^{17-20}$.

This study demonstrates by microarray analysis that CD44 expression is enhanced in aggressive (vasculogenic, $\mathrm{VM}^{+}$) tumor cells compared to poorly aggressive (nonvasculogenic, $\mathrm{VM}^{-}$) tumor cells of Ewing sarcoma and breast carcinoma origin. In Ewing sarcoma patient tissues, we found a positive correlation between CD44 expression and vasculogenic blood lake presence. The observation that tumor cells adopt mechanisms of angiogenic endothelial cells to increase their chances to survive is important and suggests that targeting of CD44 is a promising anticancer approach. 


\section{Materials and methods}

\section{Cell lines and 3-dimensional cell culture}

Ewing sarcoma cell lines EW7 and SIM.EW27 were previously characterized by Dr. O. Delattre (Pathologie Moléculaire des Cancers, Institut Curie, Paris Cedex). MDA-MB231 and MCF-7 breast carcinoma cell lines were obtained from the American Type Culture Collection (ATCC). Cells were maintained in RPMI-1640, supplemented with $10 \%$ fetal calf serum and $2 \mathrm{mM}$ L-glutamine. Cells were grown on standard culture dishes (Greiner Bio-One, Frickenhausen, Germany) except for the SIM.EW27, which were grown on gelatin-coated culture dishes.

Vasculogenic tube formation was tested using a 3-dimensional gel system. Wells from a 96-well plate were coated with $40 \mu \mathrm{l}$ Matrigel (BD Biosciences, Woerden, the Netherlands) at $37^{\circ} \mathrm{C}$ after which cells were plated at 20,000 cells per well and incubated for 16 hours to study vasculogenic network formation. At this time photographs were taken using a microscope (DMI3000B, Leica Microsystems B.V., Rijswijk, the Netherlands) equipped with an integrated camera. The images were quantified for the mean area value of randomly selected vascular network meshes using Image J 1.41. Network meshes were defined as a closed area surrounded by branching structures, i.e. avascular zones. For 3-dimensional collagen cultures, wells from a 24-well plate were coated with $25 \mu$ collagen type I (Vitrogen, Nutacon B.V., Leimuiden, the Netherlands). The collagen was dehydrated using $70 \%$ ethanol (5 minute incubation), which was followed by 3 washings with PBS. Subsequently 40,000 cells were plated in each well. Cells were allowed to grow confluent and the medium was replaced every day. Tubular patterns (when formed) were visible after 6 7 days at which time pictures were taken.

\section{Primary antibodies}

In this study, the following antibodies were used: anti-CD44 standard clone Hermes-3 (kindly provided by S. Jalkanen, Turku, Finland), CD44v3 clone VFF-327v3 (Bender Medsystems, Vienna, Austria), CD44v7 clone VFF-9, CD44v5 clone VFF-8, CD44v6 clone VFF-7 and VFF-18 (Bender Medsystems), CD44V10 clone VFF-14, anti-CD31 (DakoCytomation, Glostrup, Denmark) and anti-CD34 (Novocastra, Valkenswaard, the Netherlands). The conjugate antibodies were anti-mouse polyclonal antibodies conjugated with biotin as described in the methods for immunohistochemistry and flow cytometry.

\section{Microarray analysis}

Total RNA was isolated from the cell lines EW7, SIM.EW27, MDA-MB-231, and MCF-7 using the RNeasy RNA isolation kit (Qiagen, Venlo, the Netherlands). Possible genomic DNA contaminations were eliminated by on column RNase-free DNase treatment 
(Qiagen). RNA samples quantity and purity were determined using the Nanodrop ND1000 spectrophotometer (Nanodrop Technologies, Wilmington, USA) and RNA integrity was determined using the Bioanalyzer2100 (Agilent Technologies, Palo Alto, USA). RNA was amplified using the two-cycle cDNA synthesis kit (Affymetrix, Santa Clara, USA) in combination with the MEGAscript T7 in vitro transcription system (Ambion, Foster City, US). Biotin-labeled target complementary RNA was fractionated and hybridized to Human Genome U133A Plus 2.0 Arrays (Affymetrix). Each of these arrays contained $>54,000$ oligonucleotide probe sets corresponding to 38,500 characterized genes. Image data were analyzed using Affymetrix GeneChip ${ }^{\circledR}$ Operating Software (GCOS) version 1.4. For each transcript represented on the array, the expression algorithm computed the detection call (present, marginal, or absent), the detection $p$-value, and the average signal intensity value for each probe set. Transcripts differentially expressed (threshold of 2-fold) between aggressive $\left(\mathrm{VM}^{+}\right)$ and non-aggressive ( $\mathrm{VM}^{-}$) cell lines were used for further analysis. Gene identifiers and corresponding expression values of those transcripts were uploaded into Ingenuity Pathways Analysis (Ingenuity ${ }^{\circledR}$ Systems, www.ingenuity.com). These data were overlaid onto a global molecular network developed from information contained in Ingenuity's Knowledge Base. Networks were then algorithmically generated based on their connectivity.

\section{Quantitative real-time RT-PCR}

Total RNA was isolated using RNeasy (Qiagen), followed by RNase-free DNase treatment (Qiagen). RNA concentration was measured using the Nanodrop ND-1000 spectrophotometer (Nanodrop Technologies). cDNA was reverse transcribed using MMLV-RT (Bio-Rad, Veenendaal, the Netherlands) according to manufacturers' instructions. Quantitative real-time RT-PCR (qRT-PCR) was performed with primer sequences listed in Supplemental Table S6.1 with cyclophylin A and $\beta$-actin primers as reference genes (Eurogentec, Liege, Belgium). Reactions were run in an iCycler MylQ (Bio-Rad). qRT-PCR mixes contained 20 ng cDNA, 1xSYBR ${ }^{\circledR}$ Green PCR master mix (Eurogentec) spiked with $20 \mathrm{nM}$ fluorescein (Bio-Rad), and $400 \mathrm{nM}$ of each primer. Data were analyzed with the Sequence Detection System software (Applied Biosystems, Foster City, US).

\section{Flow cytometry}

After trypsinization, cells were fixed in $1 \%$ paraformaldehyde for 30 minutes at room temperature and incubated with primary antibodies directed to CD44s or CD44 variants appropriately diluted in PBS/0.1\% bovine serum albumin. Following 1 hour incubation on ice the cells were washed and subsequently incubated with biotinylated rabbit-anti-mouse IgG (DakoCytomation) followed by streptavidin-PE or streptavidinFITC (DakoCytomation). Cells were analyzed using the FACSCalibur Flow Cytometer (BD Biosciences). Data were analyzed using CellQuest ${ }^{\mathrm{TM}}$ software. 


\section{Adhesion assay}

Cells were harvested by trypsinization and counted. 10,000 cells were applied to a coated (5 mg/ml hyaluronic acid versus $3 \mathrm{mg} / \mathrm{ml}$ collagen) 96-wells plate and allowed to adhere for 1,2 , or 4 hours. The non-adhered cells were washed away and the adhered cells were counted per $0.25 \mathrm{~mm}^{2}$ field.

\section{Migration assay}

Cells were plated in $5 \mathrm{mg} / \mathrm{ml}$ hyaluronic acid-coated 96 -well plates at 40,000 cells per well and allowed to grow to confluence overnight. Wells were uniformly scratched using a guided 96-well pin tool (Peira, Turnhout, Belgium) to create wounds. Subsequently, wells were washed with PBS and fresh medium was added. Images were automatically captured on a Leica DMI3000 microscope (Leica, Rijswijk, the Netherlands) using Universal Grab 6.3 software (DCILabs, Keerbergen, Belgium). Scratch sizes were determined using Scratch Assay 6.2 (DCILabs), and wound closure was analyzed.

\section{Transfection}

EW7 cells were transiently transfected with siRNA targeting CD44, or non-silencing (scrambled, SCR) siRNA (Qiagen). In wells from a 24-well plate, $20 \mathrm{nM}$ siRNA was mixed with $1 \mu \mathrm{l}$ of HiPerFect Transfection Reagent (Qiagen). The mixture was allowed to complex for 15 minutes at room temperature. Afterwards, cells were plated at 35,000 cells per well and grown for 48 hours. Subsequently, cells were either fixed with $1 \%$ paraformaldehyde for flow cytometry analysis or used for Matrigel assay (see section Cell lines and 3-dimensional cell culture) or migration analysis (see section Migration assay).

\section{Immunohistochemistry}

A collection of 23 patient tissues was examined to study blood lakes and CD44 expression. These patient tissues were previously described in the study of van der Schaft et al. ${ }^{11}$, and selected based on tissue availability. Tumor tissues were obtained from the University of Leuven and the Leiden University Medical Center. Patients presented with Ewing sarcoma between 1987 and 2004. Most patients were included in the European Intergroup Cooperative Ewing's Sarcoma Study and Euro-EWING studies $^{21}$. Additionally sections from patients from the University of Gent were included. All patient materials were handled in a coded fashion according to the protocols as detailed by the Dutch association of Medical Scientific Associations.

For immunohistochemistry, paraffin sections were dried for 48 hours at $37^{\circ} \mathrm{C}$ prior to staining. Tissues sections were deparaffinized and rehydrated. Immersing the slides in $0.3 \% \mathrm{H}_{2} \mathrm{O}_{2}$ in methanol for 20 minutes blocked endogenous peroxidase activity. Heatinduced epitope treatment was performed by autoclave treatment. After washing with PBS, aspecific antibody binding was blocked by PBS containing $5 \%$ bovine serum 
albumin. Primary antibody binding was detected using biotinylated anti-mouse Ig antibodies (DakoCytomation) and visualized by streptavidin ABComplex/HRP (DakoCytomation). Afterwards, tissues were counterstained with hematoxylin (and eosin) and mounted with non-aqueous DePeX mounting medium (Serva Electrophoresis, Heidelberg, Germany). Histological sections were viewed at room temperature using a Olympus BX50 microscope equipped with a camera (Leica, DC300).

\section{Statistical analysis}

All data are expressed as mean values \pm standard error of the mean (SEM). Statistical analyses were performed using a Student's $t$ test (GraphPad Prism 5, GraphPad Software Inc., San Diego, CA). All values were tested two-sided and p-values $\leq 0.05$ were considered statistically significant.

\section{Results}

\section{CD44 expression is increased in aggressive vasculogenic tumor cells}

To study the gene expression profile associated with vasculogenic mimicry (VM), we used the aggressive EW7 Ewing sarcoma cell line, shown to form vascular-like structures in vitro and in vivo ${ }^{11}$, as well as the SIM.EW27 cell line, known to be less aggressive and not able to form tubes in vitro. We performed microarray analysis on these cells to assess their gene expression profiles. To investigate commonality of the findings in other tumor types, aggressive $\left(\mathrm{VM}^{+}\right)$and non-aggressive ( $\left.\mathrm{VM}^{-}\right)$breast carcinoma cell lines (MDA-MB-231 and MCF-7, respectively, see Supplemental Figure S6.1) were also analyzed. The microarray results indicated that 84 genes were differentially and commonly overexpressed by more than 10-fold in the aggressive cells of both Ewing sarcoma and breast carcinoma. Array data were validated by quantitative real-time RT-PCR (qRT-PCR) for a selection of 9 of the upregulated genes (Supplemental Figure S6.2).

Microarray data were further analyzed for gene ontology using the Database for Annotation, Visualization and Integrated Discovery (DAVID) Bioinformatics Resources 6.7 (http://david.abcc.ncifcrf.gov). Interestingly, we found a significant enrichment of genes implicated in vascular development in the aggressive cells versus the poorly aggressive cells of both Ewing sarcoma and breast carcinoma tumor types. In addition, functional clustering showed enhanced presence of genes implicated in cell-matrix interactions, coagulation cascades, and cellular migration and motility. Analysis of the most upregulated genes ( $\geq 50$-fold) in $\mathrm{VM}^{+}$Ewing sarcoma cells revealed the presence of many vascular-related genes such as neuropilin-1, tissue factor pathway inhibitor-2, integrins, CD44, transforming growth factor $\beta 1$, and thrombospondin 1 (Table 6.1). 
Table 6.1 Functional clustering of highly upregulated genes ( $\geq 50$-fold) in $\mathrm{VM}^{+}$(EW7) Ewing sarcoma cells compared VM- (SIM.EW27) Ewing sarcoma cells.

\begin{tabular}{|c|c|c|}
\hline Functional cluster $^{1}$ & Gene ontology (GO) & $\begin{array}{l}\text { Gene IDs identified in the functional } \\
\text { cluster }\end{array}$ \\
\hline Vascular development & $\begin{array}{l}\text { GO:0001568 blood vessel development } \\
\text { GO:0001944 vasculature development } \\
\text { GO:0048514 blood vessel morphogenesis } \\
\text { GO:0001525 angiogenesis } \\
\text { GO:0016477 cell migration } \\
\text { GO:0051674 localization of cell } \\
\text { GO:0048870 cell motility }\end{array}$ & 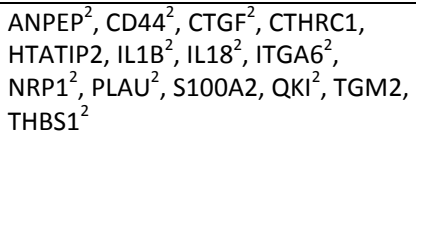 \\
\hline Coagulation & $\begin{array}{l}\text { GO:0042060 wound healing } \\
\text { GO:0050817 coagulation } \\
\text { GO:0007596 blood coagulation } \\
\text { GO:0007599 hemostasis } \\
\text { GO:0050878 regulation of body fluid levels }\end{array}$ & $\begin{array}{l}\mathrm{CD} 9, \mathrm{CD} 44^{2}, \mathrm{DCBLD} 2, \mathrm{~F} 2 \mathrm{RL} 2, \mathrm{IL}^{2} \mathrm{~B}^{2} \\
\mathrm{ITGA}^{2}, \mathrm{PLAU}^{2}, \mathrm{TFPI}^{2}\end{array}$ \\
\hline Cell-matrix interaction & $\begin{array}{l}\text { GO:0030155 regulation of adhesion } \\
\text { GO:0009611 response to wounding } \\
\text { GO:0006928 cell motion } \\
\text { GO:0050840 extracellular matrix binding } \\
\text { GO:0045785 positive regulation of cell } \\
\text { adhesion } \\
\text { GO:0005178 integrin binding } \\
\text { GO:0043236 laminin binding } \\
\text { GO:0007155 cell adhesion } \\
\text { GO:0022610 biological adhesion } \\
\text { GO:0007160 cell-matrix adhesion } \\
\text { GO:0005518 collagen binding } \\
\text { GO:0031589 cell-substrate adhesion } \\
\text { GO:0032403 protein complex binding } \\
\text { GO:0009986 cell surface }\end{array}$ & $\begin{array}{l}\text { ARHGDIB, CA2, CD9, CD } 44^{2}, \mathrm{CTGF}^{2}, \\
\text { DCBLD2, ITGA2 }{ }^{2}, \mathrm{ITGA}^{2}, \mathrm{IL}^{2} \mathrm{~B}^{2} \\
\text { IL18 }^{2}, \mathrm{NRP} 1^{2}, \text { PERP, PTPRR, SPP1, } \\
\text { TGFB1, TGM2, THBS1 }{ }^{2}\end{array}$ \\
\hline
\end{tabular}

${ }^{1}$ Functional clustering based on DAVID software analysis. ${ }^{2}$ Genes that have been well-described for their function in vascular development and/or VM. Gene IDs: ANPEP (alanyl (membrane) aminopeptidase); ARHGDIB (Rho GDP dissociation inhibitor (GDI) $\beta$ ); CA2 (carbonic anhydrase II); CTGF (connective tissue growth factor); CTHRC1 (collagen triple helix repeat containing 1); DCBLD2 (discoidin, CUB and LCCL domain containing 2); F2RL2 (coagulation factor II (thrombin) receptor-like 2); HTATIP2 (HIV-1 Tat interactive protein 2); ILB1 (interleukin 1 $\beta$ ); IL18 (interleukin 18); ITGA2 (integrin $\alpha 2$ ); ITGA6 (integrin $\alpha 6$ ); NRP1 (neuropilin 1); PLAU (plasminogen activator, urokinase); PERP (TP53 apoptosis effector); PTPRR (protein tyrosine phosphatase); S100A2 (S100 calcium binding protein A2); SPP1 (secreted phosphoprotein 1); QKI (quaking homolog, KH domain RNA binding); TGFB1 (transforming growth factor $\beta 1$ ); TFPI2 (tissue factor pathway inhibitor 2); TGM2 (transglutaminase 2); THBS1 (thrombospondin 1)

Further analysis of the microarray data using Ingenuity Pathways Analysis software (Ingenuity Systems, Redwood City, California, USA) identified the CD44/c-Met signaling pathway to be crucial in the process of VM (Figure 6.1a). 
a

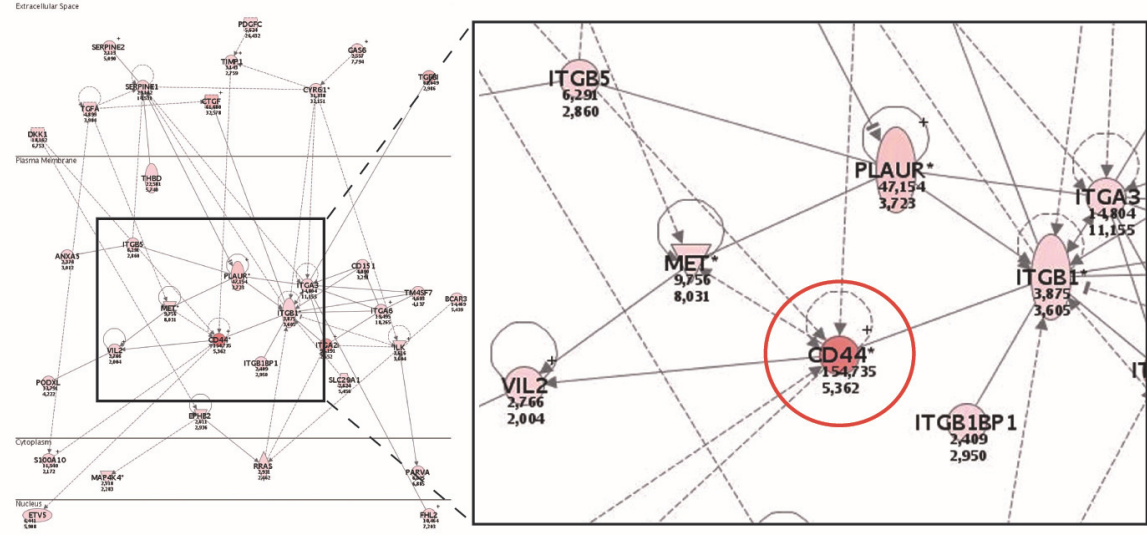

b
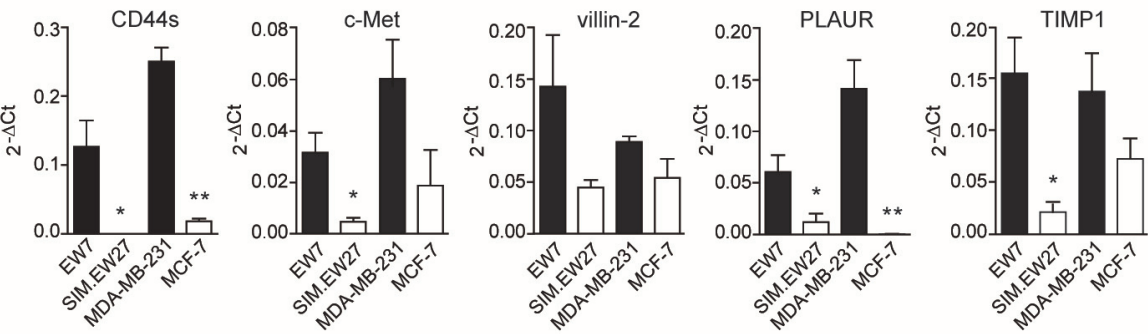

Figure 6.1 Vasculogenic tumor cells show enhanced expression of CD44/c-Met signaling components. (a) Ingenuity Pathways Analysis of microarray data showed enhanced expression of the CD44/c-Met signaling cascade. Red colors indicate enhanced expression in $\mathrm{VM}^{+}$tumor cells. Encircled is CD44. (b) Validation of the microarray data by qRT-PCR analysis of CD44s, c-Met, villin-2, PLAUR, and TIMP1 expression in Ewing sarcoma (EW7, SIM.EW27; $n=4$ ) and breast carcinoma (MDA-MB-231, MCF-7; $n=3$ ) cell lines. Black bars indicate $\mathrm{VM}^{+}$cell lines; white bars indicate $\mathrm{VM}^{-}$cell lines. Values represent the mean $\pm \mathrm{SEM}$. ${ }^{*} \mathrm{p} \leq 0.05$, $* * \mathrm{p} \leq 0.01$.

The analysis revealed that all 35 components of this signaling cascade were upregulated in the aggressive EW7 and MDA-MB-231 cells. Of these, CD44 was found to be the most differentially expressed gene. Five probe sets identifying (non-variant) CD44 standard (CD44s) on the array showed a robust overexpression in EW7 (on average 46.1-fold) and MDA-MB-231 (on average 4.8-fold), as compared to their nonaggressive counterparts (Table 6.2). Increased expression of CD44s and four additional selected members of the CD44/c-Met pathway were validated by qRT-PCR (Figure 6.1b). We also performed qRT-PCR analysis for the CD44 variants and found overexpression of variants 3, 5, 6 and 10 in vasculogenic cells (Figure 6.2a). Enhanced protein expression was validated in Ewing sarcoma cells for CD44s and CD44v6 using flow cytometric analysis (Figure 6.2b). CD44v10 showed a trend for enhanced expression in aggressive Ewing sarcoma cells, although not significantly. 
Chapter 6

Table 6.2 Ratio of CD44 expression between $\mathrm{VM}^{+}$tumor cells (EW7, MDA.MB.231) and VM tumor cells (SIM.EW27, MCF-7) based on probe set binding.

\begin{tabular}{|c|c|c|c|c|c|}
\hline Probe ID & $\begin{array}{l}\text { Gene } \\
\text { number }\end{array}$ & Gene & Gene name & $\begin{array}{c}\text { Ratio } \\
\text { EW7/ } \\
\text { SIM.EW27 }\end{array}$ & $\begin{array}{l}\text { Ratio } \\
\text { MDA.MB.231/ } \\
\text { MCF-7 }\end{array}$ \\
\hline 204489_s_at & Hs.169610.0 & CD44 & $\begin{array}{l}\text { Homo sapiens CD44 antigen (homing } \\
\text { function and Indian blood group } \\
\text { system) }\end{array}$ & $91,139^{1}$ & 3,966 \\
\hline 204490_s_at & Hs.169610.0 & CD44 & $\begin{array}{l}\text { Homo sapiens CD44 antigen (homing } \\
\text { function and Indian blood group } \\
\text { system) }\end{array}$ & $50,108^{1}$ & 4,791 \\
\hline 209835_x_at & Hs.169610.1 & CD44 & $\begin{array}{l}\text { Similar to CD44 antigen (homing } \\
\text { function and Indian blood group } \\
\text { system) }\end{array}$ & $24,049^{1}$ & 5,242 \\
\hline 210916_s_at & Hs.306278.0 & CD44 & Homo sapiens CD44 isoform RC (CD44) & $30,107^{1}$ & 5,197 \\
\hline 212014_x_at & Hs.169610.3 & CD44 & $\begin{array}{l}\text { CD44 antigen (homing function and } \\
\text { Indian blood group system) }\end{array}$ & $35,419^{1}$ & 4,542 \\
\hline
\end{tabular}

${ }^{1}$ present in EW7, absent in SIM.EW27.
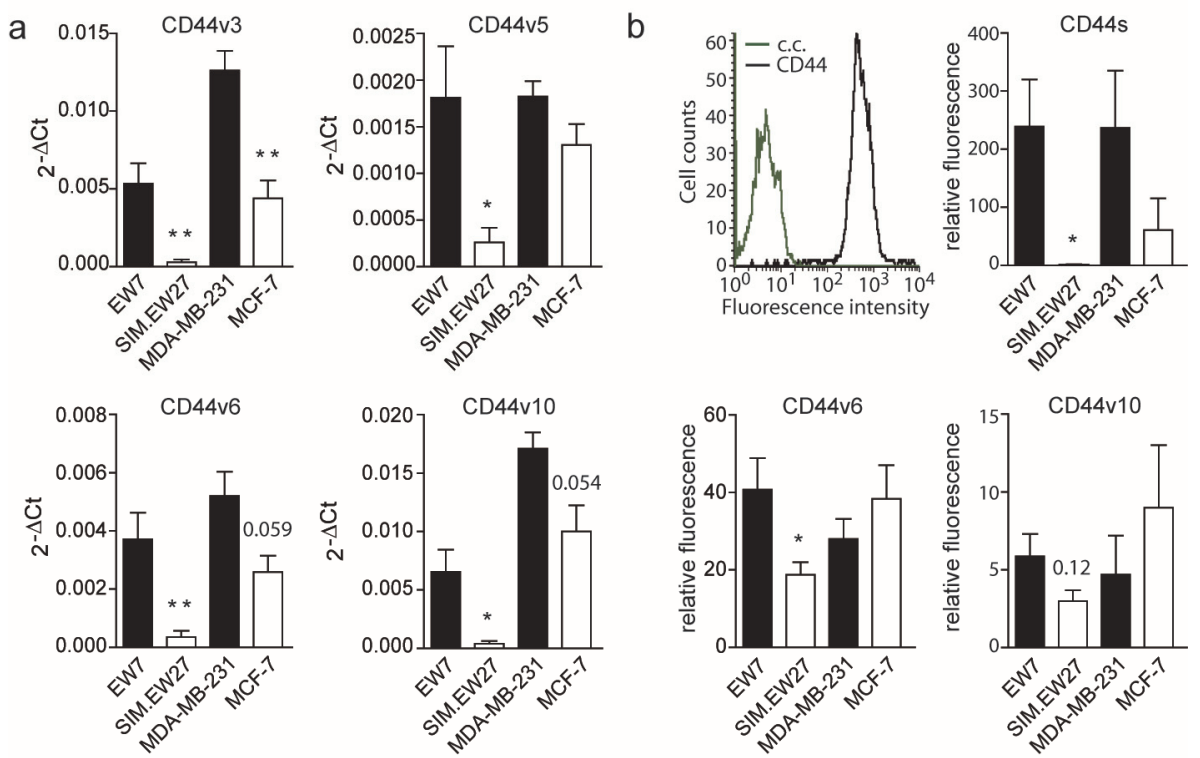

Figure 6.2 CD44 variant expression in Ewing sarcoma and breast carcinoma cell lines. (a) qRT-PCR analysis of CD44 variant expression in Ewing sarcoma (EW7, SIM.EW27; $n=5$ ) and breast carcinoma (MDA-MB-231, MCF-7; $n=3$ ) cell lines. (b) Flow cytometric analysis of CD44 variant expression ( $n=4)$. Upper left histogram represents the FACS plots for EW7 cells stained for CD44s, c.c. indicates conjugate control background staining. Black bars indicate $\mathrm{VM}^{+}$cell lines; white bars indicate $\mathrm{VM}^{-}$cell lines. Values represent the mean \pm SEM. $* \mathrm{p} \leq 0.05, * * \mathrm{p} \leq 0.01$. 


\section{CD44 provides aggressive Ewing sarcoma cells with adherence capacity}

Overexpression of CD44 in aggressive Ewing sarcoma and breast carcinoma cell lines urged us to investigate its functional relevance. Since we previously demonstrated that Ewing sarcoma displays the most overt presence of vasculogenic structures ${ }^{11}$, and that the relative overexpression of CD44 in aggressive cells was highest in this tumor type, we selected Ewing sarcoma for further investigation in this study. Cytospin preparations of vasculogenic EW7 Ewing sarcoma cells showed a clear membranous staining for CD44 (Figure 6.3a). This was also observed for EW7 cells grown on Matrigel, on which these cells arranged in vasculogenic networks (Figure 6.3b). CD44 is known to contribute to tumor malignancy by modulating the adhesion of tumor cells to the extracellular matrix ${ }^{22}$. However, for Ewing sarcoma this functional contribution has not been examined. Therefore, we next studied the differential adherence of EW7 cells to hyaluronic acid, the natural ligand of CD44, and compared it with adherence of the non-aggressive - low CD44 expressing - SIM.EW27 Ewing sarcoma cells. We found that EW7 cells adhered more efficiently to immobilized hyaluronic acid. Moreover, attachment kinetics of EW7 showed that binding to hyaluronic acid was faster than for poorly aggressive SIM.EW27 cells (Figure 6.3c). In contrast, the adhesion to collagen-coated plastic, which is known to depend on different adhesion molecules, did not differ between the cell lines (Figure 6.3d).
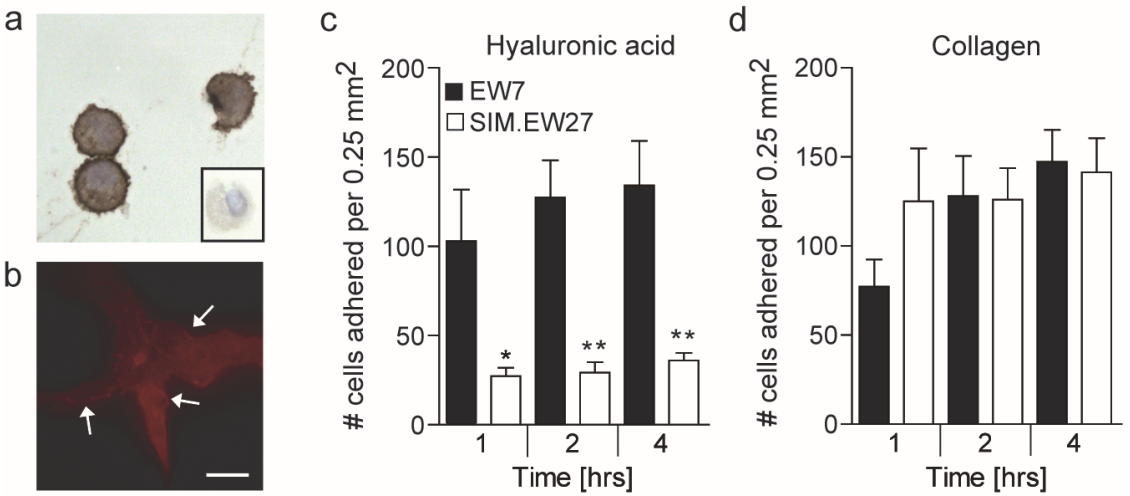

Figure 6.3 Aggressive Ewing sarcoma cells show membranous CD44 expression and gain increased adherence to the CD44 ligand hyaluronic acid. (a) Cytospin preparations of EW7 cells stained for CD44. Conjugate control is shown in the insert. (b) CD44 staining (red) on EW7 cells that are engaged in vasculogenic network formation on Matrigel. Arrows indicate membranous staining. Scale bar represents $100 \mu \mathrm{m}$. (c) Adhesion capacity of Ewing sarcoma cell lines to hyaluronic acid or (d) collagen after 1, 2, and 4 hours. Data in $c$ and $d$ are represented as mean $\pm \operatorname{SEM}(n=5)$. ${ }^{*} p \leq 0.05,{ }^{* *} p \leq 0.01$. 


\section{CD44 is required for vasculogenic network formation}

It was subsequently aimed to determine the influence of CD44 expression on VMcharacteristic network formation on a 3-dimensional matrix. Using siRNA knockdown, CD44 was suppressed by over $75 \%$ at the RNA level, while surface protein expression was reduced by approximately $40 \%$ in the EW7 cells (Figure 6.4a,b). At this knockdown rate, diminished CD44 expression resulted in a significantly reduced migration capacity of vasculogenic Ewing sarcoma cells on hyaluronic acid (Figure $6.4 c, d)$. Transferring the transfected cells to Matrigel revealed that patterned vasculogenic network formation by CD44 knockdown EW7 cells was suppressed as these networks were less refined compared to those formed by control cells (Figure $6.4 \mathrm{e})$. Vascular assembly was subsequently quantified based on the mean vascular mesh area. This indicates a closed area surrounded by vascular structures, i.e. an avascular zone, and is a descriptor of vascular development. The average mesh area of vascular networks formed by CD44 knockdown EW7 cells was significantly larger compared to the mesh area in vasculogenic structures formed by control cells (Figure 6.4f). This demonstrated the functional role of CD44 in the capacity of aggressive tumor cells to form vascular structures.
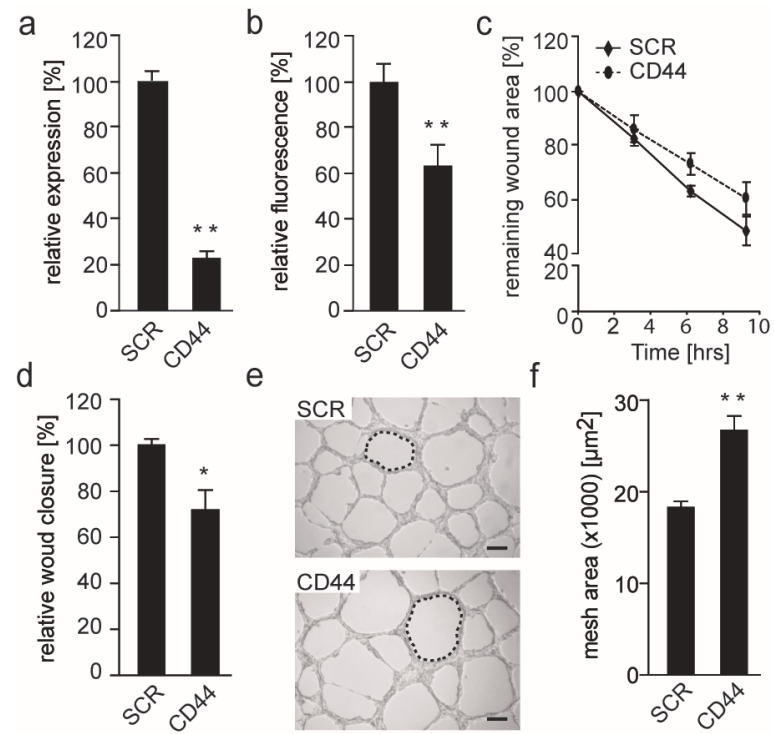

$\mathrm{f}$

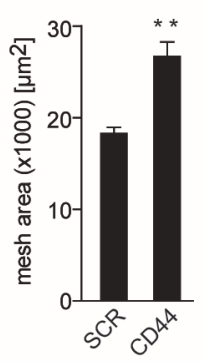

Figure 6.4 Reduced CD44 expression on EW7 cells decreases tumor cell migration and vasculogenic network formation. (a) qRT-PCR and (b) flow cytometic analysis of CD44 mRNA and protein expression, respectively, 48 hours after transfection of $\mathrm{VM}^{+}$EW7 Ewing sarcoma cells with non-silencing (SCR) or CD44 transcript targeting (CD44) siRNA. (c) Migration analysis of transfected EW7 cells on hyaluronic acid. Remaining wound area is displayed as the percentage compared to $t=0$. (d) Relative wound closure by transfected EW7 cells as compared to SCR after 6 hours. (e) Representative images of vasculogenic networks formed on Matrigel by SCR and CD44 targeted EW7 cells. Network meshes are indicated by a dotted line. Scale bars represent $200 \mu \mathrm{m}$. (f) Quantification of the average network mesh area in networks formed by SCR or CD44 transfected EW7 cells $(n=3)$. Data are presented as mean \pm SEM. ${ }^{*} p<0.05,{ }^{* *} p<0.01$. 


\section{CD44 is overexpressed in clinical Ewing sarcoma tissues}

To verify our in vitro findings, a unique set of human Ewing sarcoma tissues were used to stain for CD44. Interestingly, we found a significant correlation between the presence of blood lakes (Figure 6.5, upper panel), a characteristic of aggressiveness and an appearance of $\mathrm{VM}^{11}$, and expression of CD44. CD44 was found to be expressed in 14 out of 15 Ewing sarcoma tissues scored positive for the presence of blood lakes (93\% of cases, Table 6.3, p<0.002). As we previously described that the presence of blood lakes is negatively correlated to survival, CD44 expression can also be considered predicting short survival. CD44 expression was most clearly observed by cells at the periphery of the blood lake. Although CD44 is a marker of leukocytes, histological analysis at higher magnification demonstrated that CD44 was expressed by those tumor cells directly lining the blood lakes (Figure 6.5, lower panel), as was similarly described for vascular endothelial (VE)-cadherin, a well-described marker of $\mathrm{VM}^{11}$.
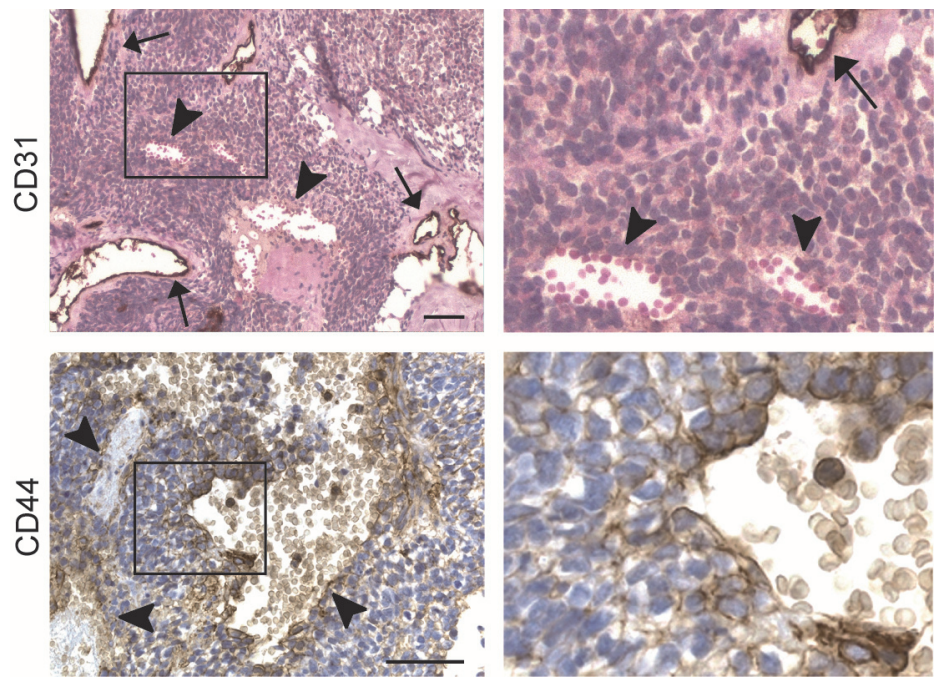

Figure 6.5 CD44 expression is related to presence of blood lakes in human Ewing sarcoma patient tissues. (Upper panel) Endothelial CD31 staining in Ewing sarcoma tissue section counterstained with hematoxylin and eosin. The magnification of the insert is displayed on the upper right. Arrows indicate regular blood vessels; arrowheads show VM-characteristic blood lakes. (Lower panel) CD44 staining on Ewing sarcoma cells enclosing blood lakes. Lower right image is an enlargement of the insert in the left image. Scale bars indicate $50 \mu \mathrm{m}$. 
Table 6.3 CD44 expression in human Ewing sarcoma tissues.

\begin{tabular}{lcc}
\hline Sample ID & Blood lakes & CD44 ${ }^{1}$ \\
\hline A15899 & + & ++ \\
690047 & + & - \\
1017783 & + & ++ \\
1115689 & + & + \\
1111044 & + & + \\
659137 & + & + \\
1070335 & + & + \\
668292 & ++ & ++ \\
697664 & + & + \\
04824 & + & + \\
09978 & + & + \\
4755 & + & + \\
$8677-3$ & + & + \\
$10265-1$ & + & + \\
$6511-2$ & + & + \\
654766 & - & - \\
103970715 & - & - \\
1115539 & - & - \\
696359 & - & + \\
NB2316 & - & - \\
105794 & - & - \\
$7167-1$ & - & + \\
$6476-2$ & - & + \\
\hline 1 CD & & + \\
present. & & +
\end{tabular}

\section{Discussion}

In the present report, we showed that CD44 expression is increased in aggressive, vasculogenic network forming tumor cells. Functional activity of CD44 in these cells, allowing adhesion to hyaluronic acid, suggests that this molecule is involved in enhanced aggressiveness through vasculogenic mimicry (VM). Indeed, knockdown of CD44 resulted in reduced tumor cell migration and suppressed network formation in vitro. In addition, CD44 expression was found to heavily correlate with the presence of blood lakes in tumor tissues of patients with Ewing sarcoma. In these clinical samples CD44 expression was associated with tumor cells directly lining the vasculogenic structures.

Transdifferentiation of plastic tumor cells into a vasculogenic phenotype allows their contribution to blood circulation ${ }^{1,11}$ and provides a tumor with a higher level of autonomy, further escape from host regulation, and therefore higher aggressiveness. This phenomenon is strongly associated with enhanced malignancy and shorter patient survival, independent of tumor type $\mathrm{e}^{2-6}$.

CD44 was originally identified as an adhesion molecule or homing receptor involved in leukocyte recirculation ${ }^{23}$. It is known in cancer cell biology that tumor cells are able to 
copy this recirculation mechanism in order to gain cellular motility and the capacity to metastasize ${ }^{16}$. Tumor cells are not the only cells that use this mechanism for enhanced motility. On endothelial cells, CD44 is known as a marker of tumor angiogenesis, and its adhesion function facilitates endothelial cell migration and sprouting ${ }^{24}$. It is therefore plausible that tumor cells that want to obtain endothelial cell characteristics induce the expression of CD44 to enable them to form vasculogenic structures. In agreement with this, we found that reduced expression of CD44 on vasculogenic tumor cells interfered with their vasculogenic network assembly. Although CD44 knockdown tumor cells remained their ability to form vascular structures, the area covered by vascular structures was significantly less. This demonstrated the functional contribution of CD44 during vascular network formation. As we achieved a maximal protein knockdown efficacy of $40 \%$, more effective targeting of this protein may severely hamper VM.

The role of CD44 during endothelial-related processes has been described in relation to c-Met signaling. CD44v6 was found to control endothelial cell sprouting and migration induced by the activation of $\mathrm{c}-\mathrm{Met}^{25}$, while CD44v10 was reported as a regulator of c-Met-mediated vascular integrity enhancement ${ }^{26}$. Interestingly, our microarray data suggested a critical involvement of the CD44/c-Met signaling cascade during VM. The c-Met oncogene encodes the tyrosine kinase receptor for hepatocyte growth factor (HGF), and in tumor cells the constitutive activation of c-Met is associated with enhanced growth, invasion, and survival ${ }^{27}$. Several reports have described the capacity of CD44 variants to promote or increase c-Met activation. Through binding to HGF, CD44v3 is able to concentrate the c-Met ligand at the cell surface. This results in the presentation of multimerized complexes and thus higher levels of c-Met activation ${ }^{28}$. In addition, CD44v6 can form a complex with both HGF and c-Met, which is required for HGF-induced c-Met activation ${ }^{29}$. Although the interaction of CD44 (variants) with c-Met has not been examined in this study, the above indicates that both molecules are important for proper endothelial function. Therefore, tumor cells that have adopted an endothelial phenotype may benefit from the expression of these proteins.

Interestingly, although vasculogenic tumor cells gain endothelial features, they do not gain sensitivity to angiogenesis inhibitors, as we have clearly demonstrated previously ${ }^{30}$. This finding may imply that $\mathrm{VM}$ is a resistance mechanism against angiostatic compounds ${ }^{31}$. These results profoundly indicate that a targeting strategy against VM is most urgently needed. The results of the current study suggest that CD44 would be an ideal target for therapy, as it would target multiple aspects of tumor biology. Firstly, CD44 inhibition would target the highly aggressive, and dedifferentiated, vasculogenic tumor cells. Secondly, targeting CD44 would attenuate tumor angiogenesis, thus decreasing blood and nutrient supply to the tumor cells. The combination of angiogenesis inhibition and CD44 targeting would prevent resistance, by means of VM, against the angiostatic compound. 
The third advantage of a CD44-based anticancer strategy would be the targeting of the tumor stem cell compartment. Besides VM, other tumor features like epithelialto-mesenchymal transition and stemness depend heavily on the capacity of tumor cells to gain a trans- or dedifferentiated phenotype. The presence of these features within a tumor is related to increased tumor malignancy, and this association is welldocumented for VM. Importantly, CD44, which we found to be overexpressed in vasculogenic tumor cells, has been well-described in relation to both epithelial-tomesenchymal transition and tumor-initiating stem cells. In transformed human mammary epithelial cells, induction of epithelial-to-mesenchymal transition generated cells with $\mathrm{CD} 44^{\text {high }} / \mathrm{CD} 24^{\text {low }}$ antigenic phenotype. This subset of cells is greatly enriched in the tumor-initiating cell (cancer-stem cell) population ${ }^{32}$. In addition, CD44 is a well-described tumor stemness marker. In breast and prostate carcinoma, CD44 is commonly used as a surface marker to identify cancer stem-like or progenitor cells, i.e. tumor cells with self-renewal potential ${ }^{33-35}$. Recently, it was demonstrated that glioblastoma stem-like cells are able to differentiate towards an endothelial lineage ${ }^{8}$. Interestingly, in addition to glioblastoma, a similar endothelial potential may be shared by CD44-expressing cells isolated from ovarian cancer ${ }^{36}$. The above demonstrates an important function for CD44 in retaining a trans- or dedifferentiated phenotype by aggressive tumor cells. Interestingly, the ability of plastic tumor cells to engage in VM is associated with their ability to express key pluripotent stem cell markers and activate embryonic signaling pathways ${ }^{8,9,37}$. This supports our data demonstrating the expression of CD44 on vasculogenic tumor cells, as these cells have aborted their original cell-specific lineage. Moreover, it suggests a function for CD44 as a gatekeeper of this newly adopted phenotype and a marker of increased tumor malignancy through tumor cell plasticity.

Although various studies have correlated the expression of CD44 to increased tumor malignancy, some studies did not find a positive association between CD44 expression or activation and tumor progression ${ }^{38-40}$. Another argument against a CD44-based targeting strategy is its expression in non-neoplastic cells of various tissue origin ${ }^{41}$, such as leukocytes. Therefore, serious side-effect may be expected. However, full ablation of immune cells is not expected as pluripotent hematopoietic stem cells do not express CD44. The current enrollment of patients in a clinical study with an antiCD44 antibody in cancer patients (https://clinicaltrials.gov; NCT01358903) suggests that side effects are either limited or manageable.

In conclusion, our results identified CD44 as a novel marker of vasculogenic tumor cells and show an important function for CD44 in the formation of vascular-like networks. Although its expression has previously been found to correlate to increased tumor malignancy and tumor stem cells, CD44 has not been associated with VM before. Our findings offer new opportunities for future treatment strategies, as targeting CD44 may not only affect VM, but may also inhibit tumor angiogenesis and target the cancer stem cell population. 


\section{Supplemental table and figures}

Table S6.1 Quantitative real-time PCR primer sequences.

\begin{tabular}{lll}
\hline Gene name & Forward primer $\left(5^{\prime}>3^{\prime}\right)$ & Reverse primer $\left(5^{\prime}>3^{\prime}\right)$ \\
\hline -actin & GCTGTGCTACGTCGCCCTG & GGAGGAGCTGGAAGCAGCC \\
Cyclophilin A & CTCGAATAAGTTGACTTGTGTTT & CTAGGCATGGGAGGGAACA \\
CD44s & GCAGTCAACAGTCGAAGAAGG & CCGTTGAGTCCACTTGGC \\
CD44v3 & AAATACCATCTCAGCAGGCT & TGGTGCTGGAGATAAAATCTT \\
CD44v5 & ATGTAGACAGAAATGGCACCA & TTGTAGAATGTGGGGTCTCTT \\
CD44v6 & AGTACAACGGAAGAAACAGCTA & TGTCCCTGTTGTCGAATGG \\
CD44v10 & ATAGGAATGATGTCACAGGTGG & TCCTTCGTGTGTGGGTAATG \\
PLAUR & CAGTGCCTGGATGTGA & AGGAAGTGGAAGGTGTCGTT \\
C-Met & GATGGCAAGAAAATTCACTGT & CTTCACTTCGCAGGCAGAT \\
Villin-2 & ACACTGCCAAGATTGCCC & GTCATCACCAGGTGCAGCT \\
TIMP1 & AGTGTCTGCGGATACTTCCA & CTAAGCTCAGCCTGTTCCAG \\
\hline
\end{tabular}

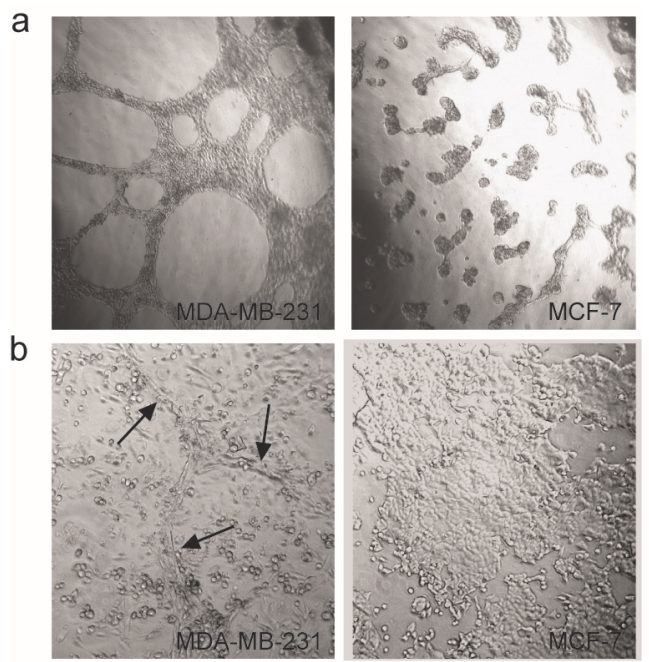

Figure S6.1 MDA-MB-231 breast carcinoma cells display vasculogenic propterties. (a) MDA-MB-231 cells, in contrast to MCF-7 cells, form vasculogenic structures when cultured in vitro on Matrigel or (b) on collagen matrix. Arrows indicate tubular patterns formed by tumor cells. 
Chapter 6
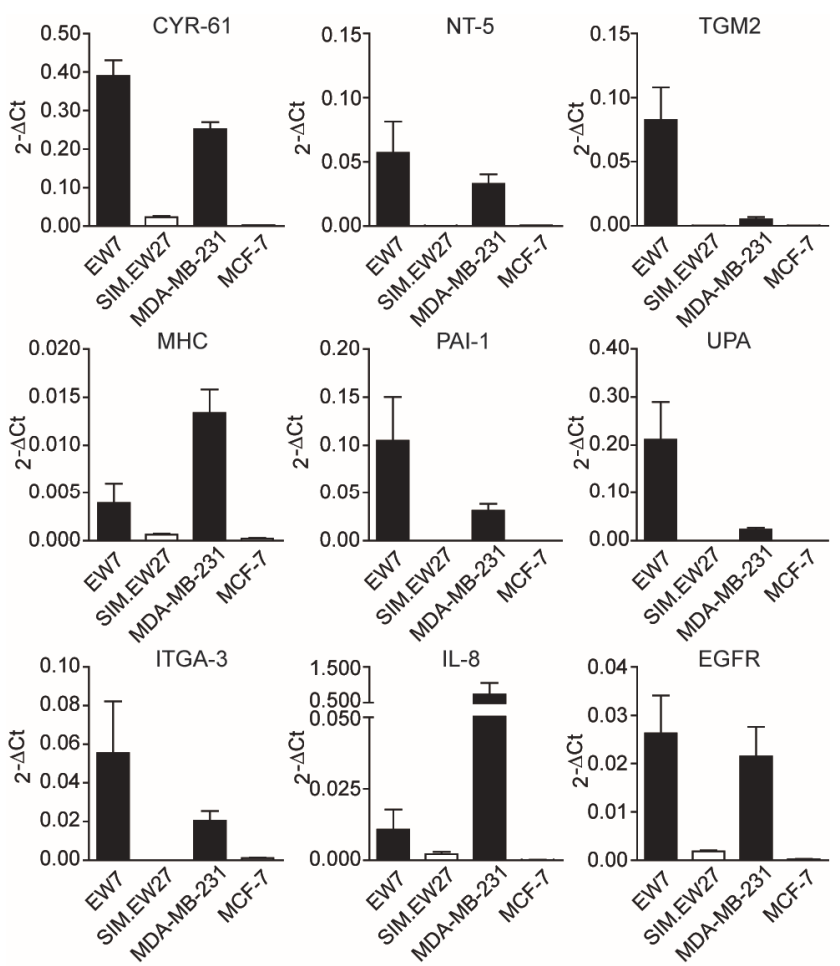

Figure S6.2 Validation of the microarray results. Expression analysis of a selection of genes identified by microarray analysis to be overexpressed by more than 10 -fold in both $\mathrm{VM}^{+}$Ewing sarcoma (EW7) and breast carcinoma (MDA-MB-231) cell lines as compared to the $\mathrm{VM}^{-}$Ewing sarcoma (SIM.EW27) and breast carcinoma (MCF-7) cell lines. 


\section{References}

1. Maniotis AJ, Folberg R, Hess A, et al. Vascular channel formation by human melanoma cells in vivo and in vitro: vasculogenic mimicry. Am J Pathol, 1999; 155:739-52.

2. Shirakawa $\mathrm{K}$, Wakasugi $\mathrm{H}$, Heike $\mathrm{Y}$, et al. Vasculogenic mimicry and pseudo-comedo formation in breast cancer. Int J Cancer, 2002; 99:821-8.

3. Sood AK, Fletcher MS, Zahn CM, et al. The clinical significance of tumor cell-lined vasculature in ovarian carcinoma: implications for anti-vasculogenic therapy. Cancer Biol Ther, 2002; 1:661-4.

4. Hendrix MJ, Seftor EA, Hess AR, et al. Vasculogenic mimicry and tumour-cell plasticity: lessons from melanoma. Nat Rev Cancer, 2003; 3:411-21.

5. Passalidou $E$, Trivella $M$, Singh $N$, et al. Vascular phenotype in angiogenic and non-angiogenic lung non-small cell carcinomas. British journal of cancer, 2002; 86:244-9.

6. Sharma N, Seftor RE, Seftor EA, et al. Prostatic tumor cell plasticity involves cooperative interactions of distinct phenotypic subpopulations: role in vasculogenic mimicry. The Prostate, 2002; 50:189-201.

7. Paulis YW, Soetekouw PM, Verheul HM, et al. Signalling pathways in vasculogenic mimicry. Biochim Biophys Acta, 2010; 1806:18-28.

8. Ricci-Vitiani L, Pallini R, Biffoni $M$, et al. Tumour vascularization via endothelial differentiation of glioblastoma stem-like cells. Nature, 2010; 468:824-8.

9. Wang R, Chadalavada K, Wilshire J, et al. Glioblastoma stem-like cells give rise to tumour endothelium. Nature, 2010; 468:829-33.

10. Jurgens H, Dirksen U. Ewing sarcoma treatment. Eur J Cancer, 2011; 47 Suppl 3:S366-7.

11. van der Schaft DW, Hillen F, Pauwels $P$, et al. Tumor cell plasticity in Ewing sarcoma, an alternative circulatory system stimulated by hypoxia. Cancer Res, 2005; 65:11520-8.

12. Ponta $\mathrm{H}$, Sherman L, Herrlich PA. CD44: from adhesion molecules to signalling regulators. Nat Rev Mol Cell Biol, 2003; 4:33-45.

13. Naor D, Sionov RV, Ish-Shalom D. CD44: structure, function, and association with the malignant process. Adv Cancer Res, 1997; 71:241-319.

14. Lesley J, Hyman R, Kincade PW. CD44 and its interaction with extracellular matrix. Adv Immunol, 1993; 54:271-335.

15. Toole BP. Hyaluronan: from extracellular glue to pericellular cue. Nat Rev Cancer, 2004; 4:528-39.

16. Gunthert $U$, Hofmann M, Rudy $W$, et al. A new variant of glycoprotein CD44 confers metastatic potential to rat carcinoma cells. Cell, 1991; 65:13-24.

17. Koopman G, Heider KH, Horst E, et al. Activated human lymphocytes and aggressive non-Hodgkin's lymphomas express a homologue of the rat metastasis-associated variant of CD44. J Exp Med, 1993; 177:897-904.

18. Kahara N, Ozaki T, Doi T, et al. CD44 expression in soft tissue sarcomas. Virchows Arch, 2000; 436:574-8.

19. Griffioen AW, Horst $\mathrm{E}$, Heider $\mathrm{KH}$, et al. Expression of CD44 splice variants during lymphocyte activation and tumor progression. Cell Adhes Commun, 1994; 2:195-200.

20. Harada N, Mizoi T, Kinouchi M, et al. Introduction of antisense CD44S CDNA down-regulates expression of overall CD44 isoforms and inhibits tumor growth and metastasis in highly metastatic colon carcinoma cells. Int J Cancer, 2001; 91:67-75.

21. Paulussen M, Ahrens S, Braun-Munzinger G, et al. [EICESS 92 (European Intergroup Cooperative Ewing's Sarcoma Study)-- preliminary results]. Klin Padiatr, 1999; 211:276-83.

22. Marhaba R, Zoller M. CD44 in cancer progression: adhesion, migration and growth regulation. Journal of molecular histology, 2004; 35:211-31.

23. de los Toyos J, Jalkanen S, Butcher EC. Flow cytometric analysis of the Hermes homing-associated antigen on human lymphocyte subsets. Blood, 1989; 74:751-60.

24. Griffioen AW, Coenen MJ, Damen CA, et al. CD44 is involved in tumor angiogenesis; an activation antigen on human endothelial cells. Blood, 1997; 90:1150-9.

25. Tremmel M, Matzke A, Albrecht I, et al. A CD44v6 peptide reveals a role of CD44 in VEGFR-2 signaling and angiogenesis. Blood, 2009; 114:5236-44.

26. Singleton PA, Salgia R, Moreno-Vinasco L, et al. CD44 regulates hepatocyte growth factor-mediated vascular integrity. Role of c-Met, Tiam1/Rac1, dynamin 2, and cortactin. J Biol Chem, 2007; 282:30643-57. 


\section{Chapter 6}

27. Corso S, Comoglio PM, Giordano S. Cancer therapy: can the challenge be MET? Trends Mol Med, 2005; 11:284-92.

28. van der Voort R, Taher TE, Wielenga VJ, et al. Heparan sulfate-modified CD44 promotes hepatocyte growth factor/scatter factor-induced signal transduction through the receptor tyrosine kinase c-Met. J Biol Chem, 1999; 274:6499-506.

29. Orian-Rousseau V, Chen L, Sleeman JP, et al. CD44 is required for two consecutive steps in HGF/c-Met signaling. Genes Dev, 2002; 16:3074-86.

30. van der Schaft DW, Seftor RE, Seftor EA, et al. Effects of angiogenesis inhibitors on vascular network formation by human endothelial and melanoma cells. J Natl Cancer Inst, 2004; 96:1473-7.

31. Carmeliet P, Jain RK. Molecular mechanisms and clinical applications of angiogenesis. Nature, 2011; 473:298-307.

32. Mani SA, Guo W, Liao MJ, et al. The epithelial-mesenchymal transition generates cells with properties of stem cells. Cell, 2008; 133:704-15.

33. Pham PV, Phan NL, Nguyen NT, et al. Differentiation of breast cancer stem cells by knockdown of CD44: promising differentiation therapy. Journal of translational medicine, 2011; 9:209.

34. Idowu MO, Kmieciak M, Dumur C, et al. CD44(+)/CD24(-/low) cancer stem/progenitor cells are more abundant in triple-negative invasive breast carcinoma phenotype and are associated with poor outcome. Human pathology, 2012; 43:364-73.

35. Hurt EM, Kawasaki BT, Klarmann GJ, et al. CD44+ CD24(-) prostate cells are early cancer progenitor/stem cells that provide a model for patients with poor prognosis. British journal of cancer, 2008; 98:756-65.

36. Alvero $\mathrm{AB}$, Chen $\mathrm{R}$, Fu HH, et al. Molecular phenotyping of human ovarian cancer stem cells unravels the mechanisms for repair and chemoresistance. Cell cycle, 2009; 8:158-66.

37. Hardy KM, Kirschmann DA, Seftor EA, et al. Regulation of the embryonic morphogen Nodal by Notch4 facilitates manifestation of the aggressive melanoma phenotype. Cancer research, 2010; 70:1034050.

38. Lyzak JS, Yaremko ML, Recant W, et al. Role of CD44 in nonpalpable T1a and T1b breast cancer. Hum Pathol, 1997; 28:772-8.

39. Ishida T. Immunohistochemical expression of the CD44 variant 6 in colorectal adenocarcinoma. Surg Today, 2000; 30:28-32.

40. Herrlich P, Morrison H, Sleeman J, et al. CD44 acts both as a growth- and invasiveness-promoting molecule and as a tumor-suppressing cofactor. Annals of the New York Academy of Sciences, 2000; 910:106-18; discussion 18-20.

41. Fox SB, Fawcett J, Jackson DG, et al. Normal human tissues, in addition to some tumors, express multiple different CD44 isoforms. Cancer research, 1994; 54:4539-46. 


\section{Chapter}

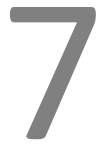

General discussion and future perspectives 
Living cells require an adequate blood flow for the delivery of oxygen and nutrients, and for the removal of waste products. As tumor cells are expected to depend on a similar mechanism, inhibition of novel vessel formation in tumors, i.e. antiangiogenesis therapy, is considered a promising treatment strategy resulting in reduced tumor growth and thus less malignant characteristics. However, over the last few years it has become clear that several tumors are able to survive harsh antiangiogenesis treatment conditions by intrinsic resistance mechanisms or inducing adaptive resistance. Therefore, tumor cells are able to grow and to metastasize despite of anti-angiogenesis therapy ${ }^{1-3}$. Vasculogenic mimicry - a feature of highly aggressive tumor cells, making them less dependent on host regulation - has been suggested as a possible mechanism of treatment resistance as its presence is known to be associated with shorter survival of patients.

For the work described in this thesis, we aimed to contribute to the research focusing on unraveling novel molecules and mechanisms implicated in the process of vasculogenic mimicry. Increasing the knowledge on this process may ultimately lead to effective targeting of vasculogenic networks formed by tumor cells. In chapter $\mathbf{3}$, we reviewed the current knowledge on the molecular events causing aggressive tumor cells to gain plasticity resulting in their ability to mimic endothelial cells.

As research continues on identifying novel molecules implicated in vasculogenic mimicry, it is becoming clear that - as for angiogenesis - vasculogenic mimicry is not depending on a single signaling event, but rather on a complex interaction between various pathways. Interestingly, molecules identified to be involved in vasculogenic mimicry are often related to embryonic vasculogenesis, suggesting that these plastic tumor cells reactivate embryonic signaling cascades. This supports the concept that many biological properties that are important during embryogenesis are also critical for tumor progression.

Despite of the similarities between endothelial cells and vasculogenic tumor cells, anti-angiogenesis therapies have not been able to inhibit this process ${ }^{4}$. Currently applied angiogenesis inhibitors mainly target the vascular endothelial growth factor (VEGF) signaling cascade. Whereas endothelial cells may show sensitivity to VEGF inhibition, tumor cells participating in vasculogenic mimicry do not depend on VEGF for their survival. Importantly, plastic tumor cells engaged in vasculogenic mimicry are insensitive to VEGF stimulation ${ }^{5}$. Therefore, it is unlikely that VEGF inhibition will be effective against vasculogenic mimicry. This suggests that anti-angiogenic compounds that do not target VEGF may be more effective in inhibiting vasculogenic networks formed by aggressive tumor cells.

Over the last few years, the development of tyrosine kinase inhibitors has taken a leap. The first developed tyrosine kinase inhibitors are known for their multi-targeted activity, as their interaction is not restricted to a specific kinase. Because these drugs target various signaling pathways, they are expected to have a broader efficacy 
compared to drugs that specifically target one pathway, such as bevacizumab (Avastin $^{\circledR}$, Genentech/Roche) ${ }^{6}$. Currently, sunitinib (SU11248, Sutent ${ }^{\circledR}$, Pfizer) and sorafenib (BAY43-9006, Nexavar ${ }^{\circledR}$, Bayer) are clinically applied as angiostatic drugs, mainly due to their inhibitory effect of VEGF receptor signaling. In our aim to examine the possible inhibitory effects of currently approved, non-VEGF-targeting, treatment strategies on vasculogenic tube formation by tumor cells, we analyzed vasculogenic Ewing sarcoma cells for increased expression of previously identified targets (chapter 4). This analysis showed increased expression of c-Kit, the tyrosine kinase receptor for the ligand stem cell factor (SCF), in vasculogenic Ewing sarcoma cells compared to non-vasculogenic Ewing sarcoma cells. Imatinib (STI571, Gleevec ${ }^{\circledR}$, Novartis Pharmaceuticals) is a tyrosine kinase inhibitor that has been FDA-approved to target tumor cells that are characterized by the presence of mutated transmembrane receptor c-Kit in gastrointestinal stromal tumors (GIST) ${ }^{7,8}$ or Bcr-Abl tyrosine kinase variants in chronic myeloid leukemia $(\mathrm{CML})^{8-10}$. Although imatinib was applied initially to target tumor cells, recent studies have shown the effectiveness of this compound on tumor vascularization. In both GIST and CML, the antitumor effect of imatinib was associated with a decreased microvessel density ${ }^{11,12}$. Imatinib is most likely not affecting the function of tumor vessels via VEGF inhibition, but by reducing the activity of the platelet-derived growth factor receptor (PDGFR). Perivascular cells, i.e. vascular smooth muscle cells and pericytes, express this receptor. By secretion of platelet-derived growth factor-B (PDGF-B), endothelial cells generate a chemoattractive signal for perivascular cells to migrate towards them and provide structural support. By hampering the signaling from endothelial cells to perivascular cells, imatinib is thought to be involved in tumor angiogenesis through reduced perivascular cell coverage of the tumor vessels ${ }^{13,14}$. This results in reduced vascular integrity and therefore increased chance for vessel collapse. Due to these effects, the delivery of oxygen to tumor cell will be less effective. Interestingly, we found that imatinib also affected the ability of vasculogenic tumor cells to mimic endothelial cells. Although the mechanism remains to be elucidated, exposure of vasculogenic tumor cells to this drug resulted in downregulation of VE-cadherin expression and EphA2 phosphorylation. In addition, we observed reduced expression of matrix metalloproteinase-2 (MMP-2), which is important for tumor cell movement through extracellular matrix. Combined, these results negatively affected the ability of vasculogenic tumor cells to assemble in a vasculogenic network as observed on Matrigel and collagen matrix. These data demonstrated the ability of a novel angiogenesis inhibitor, with a multi-targeted approach, to inhibit vasculogenic mimicry. Therefore, imatinib treatment may affect tumor vascularization not only by its effect on vessel stabilization, but also by preventing the induction of vasculogenic network assembly.

Imatinib inhibits tumor angiogenesis by reducing the perivascular cell coverage of tumor blood vessels. By these means, tumor vessels become instable and leaky, which 
results in inefficient blood flow. The interaction of endothelial cells with perivascular cells is beneficial for endothelial cells in multiple ways. By wrapping the endothelial tube, perivascular cells contribute to vessel stabilization ${ }^{15}$, persistence of flow ${ }^{16}$, endothelial survival ${ }^{17}$, and prevent tumor cell intravasation, i.e. metastasis. In chapter 5 , we described that the presence of $\alpha$-smooth muscle actin positive ( $\alpha$ $\mathrm{SMA}^{+}$) perivascular cells within matrix networks correlated to the vasculogenic potential of tumor cells. Perivascular cells do not only play an important role in blood vessel stabilization, but also during vasculogenic mimicry. To stimulate perivascular invasion towards immature vasculogenic networks, vasculogenic tumor cells were shown to copy the endothelial mechanism of PDGF-B/PDGFR- $\beta$ signaling. Similar to endothelial cells, the interaction of vasculogenic tumor cells with perivascular cells resulted in vascular network stabilization and matrix deposition. This suggests that the targeting of perivascular cells or PDGF-B signaling may have a beneficial effect by reducing the amount of vasculogenic mimicry networks. We previously described that imatinib abolished the activation of PDGFR- $\beta$ on perivascular cells. By these means, this drug is able to inhibit tumor angiogenesis. As we identified perivascular cells as important contributors during vasculogenic mimicry network assembly, imatinib treatment may not only affect angiogenesis by reducing the stabilization of tumor vessel, but also vasculogenic mimicry due to reduced stability of vasculogenic networks. In agreement with this, in vitro experiments showed that imatinib was able to inhibit perivascular cell invasion. In addition to the above, imatinib also showed to be effective against vasculogenic mimicry in the absence of perivascular cells as imatinib reduced the trans-endothelial differentiation capacity of plastic tumor cells (chapter 4). This also affected the ability of the tumor cells to form vasculogenic structures. Together with the results from chapter 5, these data provide reasonable evidence that imatinib may be highly effective against vasculogenic mimicry. First, it may affect the stability of vasculogenic networks by hampering perivascular cell attraction via PDGFR- $\beta$ inactivation. Secondly, it reduces the capacity of plastic tumor cells to engage in trans-endothelial differentiation and vascular network formation. Analysis of tumor tissues from patients treated with this tyrosine kinase inhibitor may indicate whether or not this hypothesis is valid. Nevertheless, it indicates that we should extend our targeting strategies beyond tumor cells and endothelial cells. Although initial research aimed to develop compounds to target tumor cells, endothelial cells gained interest later on due to their assumed genetic stability compared to tumor cells. This would reduce the risk for adaptive resistance. However, as for tumor cells, tumor endothelial cells have been able to alter their genetic characteristics $^{18,19}$. Currently, the role of perivascular cells in tumor biology is gaining focus and their functional contribution is highly analyzed and debated. As perivascular cells promote endothelial survival, targeting of perivascular cells is assumed to increase the sensitivity of endothelial cells for angiogenesis inhibitory compounds. The studies examining this dual (endothelial cells and perivascular cells) targeting strategy have been inconclusive so far. Although several studies have described the 
high effectiveness of dual targeting on reducing tumor vascularization ${ }^{20,21}$, others have reported lack of additional response by this dual targeting approach compared to endothelial cell targeting alone ${ }^{22}$. In addition, it has been speculated that perivascular cells are 'tumor gatekeeper cells' as their close association with the vasculature prevents tumor cell intravasation and therefore tumor cell metastasis. Targeting of perivascular cells may thus promote vessel leakiness, which would facilitate tumor cell intravasation and increase the risk for metastasis ${ }^{23}$. By attracting perivascular cells to vasculogenic networks, vasculogenic tumor cells may promote this latter mechanism. This would enable tumor cell metastasis, while maintaining the tumor cell-lined vascularization system. Future research has to determine whether or not perivascular cells will provide an optimal target to prevent tumor progression

Anti-angiogenesis therapies are based on the assumption that tumor cells require oxygen and nutrients to survive. Angiostatic compounds reduce the capacity of tumor cells to induce an angiogenic cascade, thereby diminishing tumor vascularization. This creates hypoxic tumor areas. It has been suggested that vasculogenic mimicry is induced as a resistance mechanism when tumor angiogenesis is inhibited. However, it remains speculative whether the mechanism for tumor cell transdifferentiation towards an endothelial phenotype is an intrinsic feature or induced in response to a hostile, hypoxic, microenvironment, i.e. adaptive resistance. Recent data have shown that vasculogenic mimicry can be induced in response to bevacizumab treatment ${ }^{24}$. In ovarian cancer, anti-angiogenesis treatment by this drug initially induced a reduction in tumor growth. However, it also resulted in accelerated metastasis, together with a marked hypoxia and vasculogenic mimicry network formation ${ }^{2}$. Based on the numerous studies showing a close association between hypoxia and vasculogenic mimicry(-associated genes), it is conceivable that therapeutic use of anti-angiogenesis agents may promote tumor plasticity and metastatic progression by reducing oxygen tension. Hypoxia is known to affect tumor progression and metastasis. Oxygen depletion induces a more invasive phenotype in tumor cells, causing increased invasion and metastasis dissemination ${ }^{25,26}$. In Ewing sarcoma tissues, it has been demonstrated that the cells lining the vasculogenic mimicry-characteristic blood lakes are maintained in a hypoxic microenvironment. In various tumor types, hypoxia plays a major role in the transdifferentiation of tumor cells towards an endothelial phenotype $^{27-31}$ and the expression of hypoxia-inducible factor-1 $\alpha$ (HIF-1 $\alpha$ ) was shown to stimulate the formation of vasculogenic mimicry networks ${ }^{32}$. In breast carcinoma, the presence of hypoxia induced tumor cell dedifferentiation ${ }^{33,34}$. Consistent with this, the hypoxic tumor cells surrounding vasculogenic structures display the most prominent expression of genes related to an endothelial phenotype ${ }^{29,35}$. Together, this knowledge suggests that a hypoxic microenvironment may be important for the initiation of an adaptive tumor cell response inducing tumor cell transdifferentiation. This would enable the formation of a vascularization network independent of host regulation. 
In addition to studies supporting that vasculogenic mimicry is induced in response to hypoxia, i.e. adaptive resistance, vasculogenic mimicry may also result from intrinsic resistance by tumor cells that have already adopted a high degree of plasticity. Other tumor features like stemness depend heavily on the capacity of tumor cells to gain and maintain a trans- or dedifferentiated phenotype. The presence of these plasticityassociated features within a tumor is related to increased tumor malignancy, and this association is well-documented for vasculogenic mimicry ${ }^{36}$.

Stem cells are defined as undifferentiated cells that are capable of self-renewing and differentiation into a wide variety of mature progeny. The clonogenic and heterogenic nature of tumor masses suggests that a rare population of cells, which act like normal stem cells, are responsible for tumor growth and metastasis. This subset of tumor cells is called cancer stem cells (CSCs) and they are believed to have the ability to selfrenew and to give rise to heterogeneous differentiated cell types ${ }^{37,38}$. The presence of cancer stem cells is related to a poor prognosis and increased malignancy ${ }^{39}$ as they harbor enhanced invasive properties ${ }^{40}$, and increased resistance to therapy ${ }^{41}$. The main question in cancer stem cell research remains: do cancer stem cells arise from oncogenic mutations in existing stem/progenitor cells or from an acquisition of oncogenic lesions in terminally differentiated cells resulting in dedifferentiation to a primitive stem cell-like state? It is expected that both scenarios are likely to exist based on the context.

In chapter 6, we described that vasculogenic mimicry positive tumor cell express CD44, a well-described marker of tumor stemness ${ }^{42-44}$. In Ewing sarcoma patient tissues, CD44 was predominantly expressed by those tumor cells directly lining the vasculogenic mimicry-characteristic blood lakes. Hypoxia regulates pathways involved in the maintenance of the (cancer) stem cells and thus forms an ideal niche for dedifferentiated, stem cell-like, cells. Consistent with this, the tumor cells lining vasculogenic networks are maintained in hypoxic microenvironment. Furthermore, the ability of plastic tumor cells to engage in vasculogenic mimicry has previously been associated to their ability to express key pluripotent stem cell markers and activate embryonic signaling pathways ${ }^{45,46}$.

It is hypothesized that cancer stem cells contribute to tumor neovascularization. It was recently established that in glioblastoma, a variable number of endothelial cells carried the same genetic alterations as the tumor cells. This suggested that these endothelial cells were of neoplastic origin. It was established that so-called glioblastoma stem-like cells were able to differentiate towards an endothelial lineage and that the tumor cell-derived endothelial cells were essential for tumor survival ${ }^{47}$. Interestingly, this report noted that in addition to glioblastoma, a similar endothelial potential may be shared by CD44-expressing cells isolated from ovarian cancer ${ }^{48}$. 
Together with our data showing CD44 expression by vasculogenic mimicry positive tumor cells, this suggests that tumor cells classified as vasculogenic mimicry positive may in fact be endothelial-like tumor cells derived from differentiating cancer stem cells. Consistent with this, in vitro studies in chapter 6 demonstrated the functional contribution of CD44 to the assembly of vasculogenic networks by vasculogenic tumor cells. These data provide novel insights into the mechanism of vasculogenic mimicry as a mode of intrinsic resistance.

As our knowledge of vasculogenic mimicry is increasing, it becomes clear how complicated this process actually is. The recent report on cancer stem cell differentiation towards endothelial-like cells, combined with our data - demonstrating increased expression of the stem cell marker CD44 in vasculogenic tumor cells and the close association of vasculogenic networks with hypoxic tumor regions - strongly suggest that cancer stem cells are of critical importance in the formation of tumor cell-lined vascular networks. In order to prevent vasculogenic mimicry research has to focus on how vasculogenic tumor cells arise and what factors stimulate tumor cells to adopt endothelial features. This knowledge will help to develop better therapeutic strategies that can either prevent vasculogenic mimicry or efficiently target the vascular networks formed.

\section{Future perspectives}

It is currently thought that anti-angiogenesis drug therapies will not provide the results that were expected years ago. The lack of effectiveness of angiogenesis inhibitors may be explained by the low efficacy of inhibition. In such a case, tumor angiogenesis will continue even in the presence of an anti-angiogenesis drug. However, reports have shown that in tissue sections of patients treated with angiostatic compounds a significant reduction of the microvessel density was displayed. This indicates that these compounds are indeed interfering with the blood supply toward the tumor. Assuming that angiostatic drugs are efficiently inhibiting the process of tumor angiogenesis, the lack of an adequate tumor response, resulting in the absence of clinical benefit, may indicate either (i) the independency of a tumor towards reduced blood supply, or (ii) the induction of resistance mechanisms. The first explanation would imply that the original hypothesis, claiming that tumors cells rely heavily on a constant growth of novel blood vessels for their growth, is invalid. This suggests that the inhibition of tumor angiogenesis would not provide the expected tumor response, simply because tumor cells are not depending on angiogenesis for their progression. The second rational for the low efficacy of angiogenesis inhibitors, i.e. the induction of resistance mechanisms, may be due to the present concept of single pathway targeting drug treatments. Currently applied treatment strategies are mainly aiming to target the VEGF signaling cascade. Due to genetic heterogeneity and 
continuous selection of tumor cells with favorable mutations, tumors have an evolutionary drive resulting in counteracting new targeting strategies thereby inducing resistance. Therefore, it seems likely that angiogenesis inhibition may be more effective when combined with other forms of cancer therapy to eradicate resistance mechanisms. Multimodal targeting strategies are expected to be more effective in the clinic compared to single targeting agents. In addition to multimodal targeting, so-called 'dirty' treatment strategies by broad targeting tyrosine kinase inhibitors may have unexpected effects as their mode of action is not restricted to a single molecule.

After the initial discovery of vasculogenic mimicry in 1999, the existence of this process has been subject of debate. Since then, increasing data reports have contributed to the acceptance of this mechanism. However, vasculogenic mimicry is still not routinely examined in most mouse studies or clinical trials testing novel (angiostatic) drugs. Most studies examine the effects of their compound on tumor cell vascularization by counting the microvessel density. Furthermore, the effects of novel drugs are analyzed based on proliferation, apoptosis, and tumor growth. However, the validity of these parameters is currently being challenged. For tumor growth, it has been demonstrated that a reduced tumor volume may be associated with increased tumor metastasis ${ }^{23,24}$. In addition, it is clear now that tumor angiogenesis is no longer the sole mechanism for tumor vascularization ${ }^{49}$, and that tumor cells have a range of mechanisms present to overcome angiogenesis inhibition. Importantly, it is known that treatment resistance mechanisms are associated with increased malignancy and poor patient prognosis. For vasculogenic mimicry, the presence of matrix networks is indicative for increased risk for tumor progression. Possibly, the presence of vasculogenic channels lined by tumor cells in tissue sections may also imply that angiostatic treatment will not be effective. The existence of this correlation has to be examined in future studies. Furthermore, if vasculogenic mimicry were to be indicative for treatment response, this would allow for better patient screening. By these means, treatment may be personalized based on individual tumor characteristics. This would minimize the administration of drugs that are likely to be ineffective, thereby preventing unnecessary side effects. In addition, patient screening will increase the cost-effectiveness of treatment strategies. Therefore, it should become a standard procedure to include histological analyses for alternative vascularization routes like vasculogenic mimicry. By hematoxylin and eosin, and periodic acid-Schiff (PAS) staining, the presence of vasculogenic mimicry matrix-rich patterned networks can easily be assessed in tissue sections. In future, novel imaging techniques may eliminate the need for histological analysis on tissue biopsies. By developing antibodies specific for vasculogenic mimicry conjugated with a radioactive label, vasculogenic mimicry can be visualized within a tumor after injection of such conjugated antibodies by means of PET/CT scanning. By including analyses for vasculogenic mimicry as a standard for patient samples, better prognoses can be 
made and patients with an increased risk for tumor progression or reduced treatment response can be selected.

Recently, it was shown that vasculogenic mimicry may be induced in response to antiangiogenesis therapy ${ }^{24}$. This implies that screening of tumor tissues prior to treatment alone is insufficient. Although vasculogenic mimicry may not be detected before the initiation of treatment, tumor cell plasticity resulting in vasculogenic mimicry may be induced in response to angiogenesis inhibition. This may either be as a mechanism to induce the persistence of blood flow, or as a mechanism to induce tumor cell metastasis. Research techniques enable the isolation of tumor cells from a specific region of a tissue section. By these means, tumor cells from a vasculogenic mimicry positive tumor area after treatment can be compared to tumor cells that did not display any vasculogenic potential in that same tumor area prior to the start of treatment. Genetic profiling of these cells may provide novel insights into the signaling cascades that initiate and maintain the vasculogenic potential of aggressive tumor cells.

Although the onset of vasculogenic mimicry remains to be determined, we favor the view that targeting of vasculogenic mimicry is an inevitable approach to follow. Therefore, the aim of this thesis was to find ways to inhibit or eradicate vasculogenic tumor cells. We have identified two novel potential targets to inhibit vasculogenic mimicry. First, we showed that perivascular cells are of high importance throughout the process of vasculogenic mimicry. By targeting these cells, the tumor vasculature may become more prone to angiogenesis inhibitors, while vasculogenic networks formed by tumor cells lose their stability. Results from this thesis have demonstrated that the tyrosine kinase inhibitor imatinib may be a good candidate for the targeting of vasculogenic mimicry. This drug inhibits perivascular cell invasion (chapter 5), but also targets the plasticity of vasculogenic tumor cells itself (chapter 4). By affecting two distinct cell populations, the chance for resistance is expected to decrease. Second, by genomic screening we found CD44 as a rather specific marker of the tumor cell population that is engaged in the process of vasculogenic mimicry. Chapter 6 described this research and demonstrated that this process can be inhibited by small interfering RNA knockdown of CD44. Interestingly, clinical phase I trials have been started to test the effects of a novel CD44 targeting antibody (Roche). First of all, it would be extremely interesting to analyze the tumor tissues from these studies, and see whether CD44-specific therapies will affect vasculogenic mimicry. There is, however, a major threat in the development of anti-vasculogenic mimicry therapies. Due to the rareness of this process (ranging from 5-25\% depending on the tumor type) and the very limited expression in a vasculogenic mimicry positive tumor, it is to be expected that if drugs would influence this process, results based on overall survival may be minimal or even absent. As the overall goal in cancer research is to target tumor growth and progression, studies aim to obtain results based on parameters like tumor volume, microvessel density and overall survival. Although 
drugs targeting specific subsets of tumor cells may not achieve significant results based on these measures, in a combination therapy they could have an enormous synergistic activity. It is therefore of critical importance that tissues will be investigated for the effect of a novel compound on vasculogenic mimicry, before abandoning the drug. Although this may be a significant risk of anti-vasculogenic mimicry drugs, for CD44 this does not seems to be an issue, as the effect of CD44 targeting can be through many mechanisms, including targeting of angiogenic tumor endothelial cells and cancer stem cells.

Together, the work presented in this thesis supports the concept of a multi-targeting approach to effectively target tumor angiogenesis and prevent or inhibit resistance through vasculogenic mimicry. This multi-targeting can be accomplished by 'dirty' targeting drugs like imatinib, or by affecting different subsets of (tumor) cells at the same time. By these means, resistance will be minimized. 


\section{References}

1. Hori K, Li HC, Saito S, et al. Increased growth and incidence of lymph node metastases due to the angiogenesis inhibitor AGM-1470. British journal of cancer, 1997; 75:1730-4.

2. Ebos JM, Lee CR, Cruz-Munoz W, et al. Accelerated metastasis after short-term treatment with a potent inhibitor of tumor angiogenesis. Cancer cell, 2009; 15:232-9.

3. Paez-Ribes M, Allen E, Hudock J, et al. Antiangiogenic therapy elicits malignant progression of tumors to increased local invasion and distant metastasis. Cancer cell, 2009; 15:220-31.

4. van der Schaft DW, Seftor RE, Seftor EA, et al. Effects of angiogenesis inhibitors on vascular network formation by human endothelial and melanoma cells. Journal of the National Cancer Institute, 2004; 96:1473-7.

5. Maniotis AJ, Folberg R, Hess A, et al. Vascular channel formation by human melanoma cells in vivo and in vitro: vasculogenic mimicry. The American journal of pathology, 1999; 155:739-52.

6. Gotink KJ, Verheul HM. Anti-angiogenic tyrosine kinase inhibitors: what is their mechanism of action? Angiogenesis, 2010; 13:1-14.

7. Tuveson DA, Willis NA, Jacks T, et al. STI571 inactivation of the gastrointestinal stromal tumor c-KIT oncoprotein: biological and clinical implications. Oncogene, 2001; 20:5054-8.

8. Radford IR. Imatinib. Novartis. Current opinion in investigational drugs, 2002; 3:492-9

9. Mauro MJ, Druker BJ. STI571: targeting BCR-ABL as therapy for CML. The oncologist, 2001; 6:233-8.

10. Kantarjian HM, Cortes J. New strategies in chronic myeloid leukemia. International journal of hematology, 2006; 83:289-93.

11. Kim R, Emi M, Arihiro K, et al. Chemosensitization by STI571 targeting the platelet-derived growth factor/platelet-derived growth factor receptor-signaling pathway in the tumor progression and angiogenesis of gastric carcinoma. Cancer, 2005; 103:1800-9.

12. Kvasnicka HM, Thiele J, Staib P, et al. Reversal of bone marrow angiogenesis in chronic myeloid leukemia following imatinib mesylate (STI571) therapy. Blood, 2004; 103:3549-51.

13. Rocha A, Azevedo I, Soares R. Anti-angiogenic effects of imatinib target smooth muscle cells but not endothelial cells. Angiogenesis, 2007; 10:279-86.

14. Pirraco A, Coelho P, Rocha A, et al. Imatinib targets PDGF signaling in melanoma and host smooth muscle neighboring cells. Journal of cellular biochemistry, 2010; 111:433-41.

15. von Tell D, Armulik A, Betsholtz C. Pericytes and vascular stability. Experimental cell research, 2006; 312:623-9.

16. Kutcher ME, Kolyada AY, Surks HK, et al. Pericyte Rho GTPase mediates both pericyte contractile phenotype and capillary endothelial growth state. The American journal of pathology, 2007; 171: 693-701.

17. Hellstrom $M$, Gerhardt $H$, Kalen $M$, et al. Lack of pericytes leads to endothelial hyperplasia and abnormal vascular morphogenesis. The Journal of cell biology, 2001; 153:543-53.

18. Hida K, Hida Y, Amin DN, et al. Tumor-associated endothelial cells with cytogenetic abnormalities. Cancer research, 2004; 64:8249-55.

19. Streubel B, Chott A, Huber D, et al. Lymphoma-specific genetic aberrations in microvascular endothelial cells in B-cell lymphomas. The New England journal of medicine, 2004; 351:250-9.

20. Lu C, Kamat AA, Lin YG, et al. Dual targeting of endothelial cells and pericytes in antivascular therapy for ovarian carcinoma. Clin Cancer Res, 2007; 13:4209-17.

21. Erber R, Thurnher A, Katsen AD, et al. Combined inhibition of VEGF and PDGF signaling enforces tumor vessel regression by interfering with pericyte-mediated endothelial cell survival mechanisms. Faseb J, 2004; 18:338-40.

22. Nisancioglu MH, Betsholtz C, Genove G. The absence of pericytes does not increase the sensitivity of tumor vasculature to vascular endothelial growth factor-A blockade. Cancer research, 2010; 70: 5109-15.

23. Cooke VG, LeBleu VS, Keskin D, et al. Pericyte depletion results in hypoxia-associated epithelial-tomesenchymal transition and metastasis mediated by met signaling pathway. Cancer cell, 2012; 21: 66-81.

24. $\mathrm{Xu} \mathrm{Y,} \mathrm{Li} \mathrm{Q}, \mathrm{Li} \mathrm{XY}$, et al. Short-term anti-vascular endothelial growth factor treatment elicits vasculogenic mimicry formation of tumors to accelerate metastasis. Journal of experimental \& clinical cancer research : CR, 2012; 31:16. 
25. Du R, Lu KV, Petritsch C, et al. HIF1alpha induces the recruitment of bone marrow-derived vascular modulatory cells to regulate tumor angiogenesis and invasion. Cancer cell, 2008; 13:206-20.

26. Pennacchietti S, Michieli P, Galluzzo M, et al. Hypoxia promotes invasive growth by transcriptional activation of the met protooncogene. Cancer cell, 2003; 3:347-61.

27. Yao LQ, Feng YJ, Ding JX, et al. Characteristics and differentiated mechanism of vascular endothelial cells-like derived from epithelial ovarian cancer cells induced by hypoxia. International journal of oncology, 2007; 30:1069-75.

28. Hendrix MJ, Seftor RE, Seftor EA, et al. Transendothelial function of human metastatic melanoma cells: role of the microenvironment in cell-fate determination. Cancer research, 2002; 62:665-8.

29. van der Schaft DW, Hillen F, Pauwels $P$, et al. Tumor cell plasticity in Ewing sarcoma, an alternative circulatory system stimulated by hypoxia. Cancer research, 2005; 65:11520-8.

30. Ma JL, Han SX, Zhu Q, et al. Role of Twist in vasculogenic mimicry formation in hypoxic hepatocellular carcinoma cells in vitro. Biochemical and biophysical research communications, 2011; 408:686-91.

31. Zhang S, Li M, Zhang D, et al. Hypoxia influences linearly patterned programmed cell necrosis and tumor blood supply patterns formation in melanoma. Laboratory investigation; a journal of technical methods and pathology, 2009; 89:575-86.

32. Sun $B$, Zhang D, Zhang $S$, et al. Hypoxia influences vasculogenic mimicry channel formation and tumor invasion-related protein expression in melanoma. Cancer letters, 2007; 249:188-97.

33. Helczynska K, Kronblad A, Jogi A, et al. Hypoxia promotes a dedifferentiated phenotype in ductal breast carcinoma in situ. Cancer research, 2003; 63:1441-4.

34. Kirschmann DA, Seftor EA, Hardy KM, et al. Molecular pathways: vasculogenic mimicry in tumor cells: diagnostic and therapeutic implications. Clinical cancer research : an official journal of the American Association for Cancer Research, 2012; 18:2726-32.

35. Ruf W, Seftor EA, Petrovan RJ, et al. Differential role of tissue factor pathway inhibitors 1 and 2 in melanoma vasculogenic mimicry. Cancer research, 2003; 63:5381-9.

36. Hillen $\mathrm{F}$, Baeten $\mathrm{Cl}$, van de Winkel $\mathrm{A}$, et al. Leukocyte infiltration and tumor cell plasticity are parameters of aggressiveness in primary cutaneous melanoma. Cancer immunology, immunotherapy : CII, 2008; 57:97-106.

37. Reya T, Morrison SJ, Clarke MF, et al. Stem cells, cancer, and cancer stem cells. Nature, 2001; 414:105-11.

38. Guo W, Lasky JL, 3rd, Wu H. Cancer stem cells. Pediatric research, 2006; 59:59R-64R.

39. Liu R, Wang X, Chen GY, et al. The prognostic role of a gene signature from tumorigenic breast-cancer cells. The New England journal of medicine, 2007; 356:217-26.

40. Sheridan $\mathrm{C}$, Kishimoto $\mathrm{H}$, Fuchs RK, et al. CD44+/CD24- breast cancer cells exhibit enhanced invasive properties: an early step necessary for metastasis. Breast cancer research : BCR, 2006; 8:R59.

41. Li X, Lewis MT, Huang J, et al. Intrinsic resistance of tumorigenic breast cancer cells to chemotherapy. Journal of the National Cancer Institute, 2008; 100:672-9.

42. Pham PV, Phan NL, Nguyen NT, et al. Differentiation of breast cancer stem cells by knockdown of CD44: promising differentiation therapy. Journal of translational medicine, 2011; 9:209.

43. Idowu MO, Kmieciak M, Dumur C, et al. CD44(+)/CD24(-/low) cancer stem/progenitor cells are more abundant in triple-negative invasive breast carcinoma phenotype and are associated with poor outcome. Human pathology, 2012; 43:364-73.

44. Hurt EM, Kawasaki BT, Klarmann GJ, et al. CD44+ CD24(-) prostate cells are early cancer progenitor/stem cells that provide a model for patients with poor prognosis. British journal of cancer, 2008; 98:756-65.

45. Wang R, Chadalavada K, Wilshire J, et al. Glioblastoma stem-like cells give rise to tumour endothelium. Nature, 2010; 468:829-33.

46. Hardy KM, Kirschmann DA, Seftor EA, et al. Regulation of the embryonic morphogen Nodal by Notch4 facilitates manifestation of the aggressive melanoma phenotype. Cancer research, 2010; 70: 10340-50.

47. Ricci-Vitiani L, Pallini R, Biffoni M, et al. Tumour vascularization via endothelial differentiation of glioblastoma stem-like cells. Nature, 2010; 468:824-8.

48. Alvero $\mathrm{AB}$, Chen $\mathrm{R}, \mathrm{Fu} \mathrm{HH}$, et al. Molecular phenotyping of human ovarian cancer stem cells unravels the mechanisms for repair and chemoresistance. Cell cycle, 2009; 8:158-66. 
49. Hillen F, Griffioen AW. Tumour vascularization: sprouting angiogenesis and beyond. Cancer metastasis reviews, 2007; 26:489-502. 
Summary 
Tumor angiogenesis, the growth of new blood vessels out of pre-existing ones, is an important process initiated by tumor cells to overcome oxygen and nutrient deficiency. Without the presence of blood vessels, tumors would not be able to grow and metastasize. Therefore, it was hypothesized years ago that blockage of the angiogenic cascade would halt the outgrowth of novel blood vessels and thereby prevent tumor growth and progression. Unfortunately, clinically applied angiogenesis inhibitors have shown only limited results so far, as the lifespan of patients cannot be prolonged for more than a few months. Even worse, anti-angiogenesis compounds appear to select for more malignant tumor cells that hold the capacity to survive the hostile microenvironment.

The ability of tumor cells to survive and progress despite angiostatic treatment suggests that tumor cells are able to evade the effects of angiogenesis inhibition. By initiating alternative routes for tumor vascularization, tumor cells eliminate their need for novel blood vessel formation. In a process called vasculogenic mimicry, highly aggressive tumor cells gain the capacity to transdifferentiate and adopt an endothelial-like phenotype. These plastic tumor cells form vasculogenic tubular networks that contain blood cells. By their ability to mimic endothelial cells, vasculogenic tumor cells are proposed to acquire a secondary vascularization mechanism and thereby become independent of tumor angiogenesis. In addition, vasculogenic mimicry has been suggested to provide a route for metastasis due to its (in)direct connection to the circulation. Apart from its speculated function, the presence of vasculogenic mimicry-characteristic structures within a tumor is correlated to a poor patients' survival. In this thesis, the role of vasculogenic mimicry in tumor biology was further investigated.

Following the initial report on vasculogenic mimicry, research on this topic has focused on identifying novel molecules implicated in vasculogenic network formation by aggressive tumor cells. As more and more (signaling) molecules involved in vasculogenic tube formation are being identified, it is becoming clear how complicated this biological phenomenon is. In chapter $\mathbf{3}$, we reviewed the current knowledge on vasculogenic mimicry. Critical signaling proteins were described in relation to each other and combined in a proposed signaling cascade. Furthermore, the relation between vasculogenic mimicry and the embryonic signaling molecules Notch, Nodal and Wingless was described. Also, vasculogenic mimicry was discussed in relation to ongoing fields of cancer research. Due to their shared characteristics, vasculogenic mimicry is proposed to be related to the presence of cancer stem cells. As for vasculogenic tumor cells, cancer stem cells display a high degree of cellular plasticity and the tumor microenvironment appears to be of critical importance to maintain both biological processes. Finally, the clinical significance of vasculogenic mimicry was described in this chapter. 
Despite the similarity of vasculogenic tumor cells to endothelial cells, angiostatic drugs have not been able to target vasculogenic mimicry. In chapter 4 , we described the ability of the tyrosine kinase inhibitor imatinib, which has recently been shown to target tumor vasculature, to reduce the vasculogenic potential of aggressive tumor cells. Microarray analysis showed that vasculogenic Ewing sarcoma cells showed increased expression of c-Kit tyrosine kinase, one of the tyrosine kinases targeted by imatinib. Exposure of aggressive tumor cells to this compound diminished the expression of genes associated with their vasculogenic potential, like vascular endothelial (VE)-cadherin and matrix metalloproteinase (MMP)-2. In addition, imatinib treatment reduced the phosphorylation of EphA2 protein. In 3-dimensional cultures on Matrigel and collagen pre-exposure of vasculogenic tumor cells to imatinib resulted in a reduced vascular network formation. The results demonstrated in this chapter indicate that broad 'dirty' targeting compounds may target multiple processes involved in tumor progression.

Perivascular cells play an important role during vascular assembly as they stabilize and maturate newly formed vessels. Currently, the role of perivascular cells during tumor biology is examined in relation to treatment response and metastasis. In chapter $\mathbf{5}$, we demonstrated that vasculogenic tumor cells resemble endothelial cells based on their interaction with perivascular cells. Immunohistochemical analysis of a series of human cutaneous melanoma tissues revealed the presence of $\alpha$-smooth muscle actin positive $\left(\alpha-\mathrm{SMA}^{+}\right)$cells within vasculogenic mimicry-characteristic matrix networks. In vitro characterization of the interaction between vasculogenic melanoma cells and perivascular cells demonstrated the functional contribution of perivascular cells to vasculogenic network stabilization. This stabilizing effect may be due to the deposition of extracellular matrix. Interestingly, the extracellular matrix formed in co-cultures of vasculogenic melanoma cells and perivascular cells was organized in a similar honeycomb-like structure as observed in vivo. The interaction between perivascular cells and vasculogenic tumor cells also enhanced tumor cell sprouting. The chemo attractive factor for perivascular cells, platelet-derived growth factor (PDGF)-B, was expressed by vasculogenic tumor cells both in vivo and in vitro. Consistent with our in vitro observation, we demonstrated that in vivo growth of our vasculogenic melanoma cell line was associated with the presence of tumor cell-associated $\alpha-\mathrm{SMA}^{+}$ cells. In addition, the expression of PDGF-B by vasculogenic tumor cells resulted in an increased number of perivascular cells that were not attached to regular $\left(\mathrm{CD} 31^{+}\right)$ tumor blood vessels. Summarizing, the results from this chapter show that vasculogenic tumor cells copy the endothelial mechanism for perivascular cell interaction as observed during blood vessel maturation and functionally benefit from the association with these supporting cells.

The ability of tumor cells to transdifferentiate and acquire an endothelial phenotype is associated with the differentiation plasticity of aggressive tumor cells. By microarray 
analysis, we aimed to find novel targetable molecules that may ultimately lead to specific targeting of vasculogenic tumor cells. In chapter 6, we described that vasculogenic mimicry positive Ewing sarcoma cells have an increased expression of CD44 (variants) compared to non-vasculogenic Ewing sarcoma cells. CD44 expression was correlated to an increased adhesion to the extracellular matrix component hyaluronic acid. Knockdown studies demonstrated that the expression of CD44 was correlated to the vasculogenic potential of plastic tumor cells. Interestingly, CD44 is a well-described marker of activated endothelium and of cancer stem cells, i.e. aggressive tumor cells with a highly dedifferentiated phenotype. In Ewing sarcoma tissue sections, tumor cells expressing CD44 were found to be closely associated with vasculogenic mimicry-characteristic blood lakes. Results presented in this chapter demonstrate that vasculogenic tumor cells share characteristics with both endothelial cells and cancer stem cells. The similarities with this latter cell type may indicate the close relation between the presence of vasculogenic tumor cells and cancer stem cells.

Finally, in chapter 7 we discussed the main findings of the research presented in this thesis and the future perspectives for their clinical translation.

In this thesis, we investigated the role of vasculogenic mimicry in tumor biology. By the identification of novel key molecules and the analysis of the interaction between these vasculogenic tumor cells and perivascular cells, we have identified mechanisms that provide novel insights into this process. This knowledge may contribute to the development of treatment strategies that circumvent treatment-induced resistance through vasculogenic mimicry. Ultimately, this will lead to the development of clinically more effective treatment strategies against cancer. 
Samenvatting 
Tumorangiogenese, de groei van nieuwe bloedvaten uit bestaande vaten, is een belangrijk proces dat geïnitieerd wordt door tumorcellen om te kunnen overleven wanneer er een tekort is aan zuurstof en voedingsstoffen. Zonder bloedvaten zouden tumoren niet kunnen blijven groeien en metastaseren. Om die reden werd jaren geleden gesuggereerd dat het blokkeren van de angiogene respons de groei van nieuwe bloedvaten zou verhinderen, en daarmee tumorgroei en -progressie zou kunnen voorkomen. Helaas hebben angiogeneseremmers in de kliniek tot dusver nog niet de gewenste resultaten getoond. Behandeling van patiënten met deze remmers kan de levensverwachting slechts met enkele maanden verlengen. Een nadelig resultaat is bovendien dat angiogeneseremmers mogelijk selecteren voor zeer maligne tumorcellen die in staat zijn te overleven in een vijandelijke micro-omgeving.

Het gegeven dat tumorcellen in staat zijn te overleven en zelfs kwaadaardiger kunnen worden ondanks anti-angiogenese behandeling suggereert dat tumorcellen uiteindelijk ongevoelig worden voor deze behandelingsmethode. Door het initiëren van alternatieve methoden voor vascularisatie zorgen tumorcellen dat zij de noodzaak voor tumorangiogenese omzeilen. In een proces genaamd 'vasculogenic mimicry' kunnen zeer agressieve tumorcellen transdifferentiëren en een endotheelcelachtig fenotype aannemen. Deze plastische tumorcellen vormen buisachtige netwerken waarin bloedcellen aanwezig zijn. Doordat tumorcellen in staat zijn endotheelcellen te imiteren, wordt mogelijk een secundair vascularisatie mechanisme geïnitieerd waardoor tumorcellen onafhankelijk worden van tumorangiogenese. Naast de bijdrage van deze tumorcellen aan de vascularisatie wordt ook gespeculeerd dat de gevormde buisstructuren tumorcel metastasering bevorderen gezien hun connectie met de circulatie. Ondanks de speculatieve functie van vasculogenic mimicry is het evident dat de aanwezigheid van deze vasculaire netwerken binnen een tumor geassocieerd is met een slechte prognose voor de patiënt. In dit proefschrift is de rol van vasculogenic mimicry in de tumorbiologie verder onderzocht.

Ons onderzoek heeft zich primair gericht op het identificeren van nieuwe moleculen die betrokken zijn bij de vorming van vasculaire netwerken door vasculogene tumorcellen. De toenemende identificatie van (signaal)moleculen die betrokken zijn bij vasculaire buisvorming maakt ons duidelijk hoe gecompliceerd dit biologische fenomeen daadwerkelijk is. In hoofdstuk $\mathbf{3}$ is de huidige kennis over vasculogenic mimicry besproken. De belangrijkste signaalmoleculen zijn beschreven in relatie tot elkaar en samengevoegd in een beoogde signaalcascade. Daarnaast is het verband tussen vasculogenic mimicry en de embryonale signaalmoleculen Notch, Nodal en Wingless beschreven. Verder is vasculogenic mimicry besproken in relatie tot andere belangrijke velden van kankeronderzoek. Vanwege de gelijkenis in karakteristieken is vasculogenic mimicry mogelijk gerelateerd aan de aanwezigheid van kankerstamcellen. Net als vasculogene tumorcellen vertonen kankerstamcellen een hoge mate van cellulaire plasticiteit en de tumor micro-omgeving blijkt van grote 
invloed te zijn op beide processen. Tenslotte is de klinische relevantie van vasculogenic mimicry in dit hoofdstuk besproken.

Ondanks de overeenkomst tussen vasculogene tumorcellen en endotheelcellen lijken angiostatische middelen over het algemeen niet in staat te zijn om vasculogenic mimicry te remmen. In hoofdstuk 4 hebben wij beschreven dat de tyrosine kinase remmer imatinib, waarvan recentelijk is aangetoond dat deze anti-angiogenese effecten heeft, ook vasculogenic mimicry door agressieve tumorcellen kan beïnvloeden. Microarray analyse heeft aangetoond dat vasculogene Ewing sarcoomcellen verhoogde expressie vertonen van c-Kit tyrosine kinase. Deze tyrosine kinase is een van de enzymen die geremd wordt door imatinib. Blootstelling van agressieve tumorcellen aan imatinib verminderde de expressie van genen die geassocieerd zijn met de vasculogene potentie van agressieve tumorcellen, zoals vascular endothelial (VE)-cadherin en matrix metalloproteinase (MMP)-2. Daarnaast veroorzaakte imatinib een verminderde fosforylering van het EphA2 eiwit. In een 3dimensionele kweek op Matrigel of collageen zorgde behandeling met imatinib voor een verminderde netwerkformatie door vasculogene tumorcellen. De resultaten uit dit hoofdstuk tonen aan dat 'dirty targeting drugs' mogelijk meerdere processen beïnvloeden die betrokken zijn bij tumorprogressie.

Perivasculaire cellen zijn van groot belang voor de stabilisatie en maturatie van nieuwe bloedvaten. Tegenwoordig worden perivasculaire cellen onderzocht in relatie tot de tumorrespons op behandeling en de mogelijkheid van tumorcellen om te kunnen metastaseren. In hoofdstuk $\mathbf{5}$ hebben wij aangetoond dat vasculogene tumorcellen endotheelcellen ook nabootsen met betrekking tot hun interactie met perivasculaire cellen. Immunohistochemische analyse van een serie humane huidmelanomen heeft aangetoond dat $\alpha$-smooth muscle actin positieve $\left(\alpha-\mathrm{SMA}^{+}\right)$ cellen aanwezig zijn binnen de vasculogenic mimicry-karakteristieke matrix netwerken. In vitro analyse van de interactie tussen vasculogene melanoomcellen en perivasculaire cellen toonde aan dat dit laatstgenoemde celtype bijdraagt aan de stabilisatie van vasculaire netwerken die gevormd zijn door tumorcellen. Dit stabiliserende effect is mogelijk het gevolg van extracellulaire matrix vorming. Belangrijk is dat de extracellulaire matrix in co-kweken van vasculogene melanoomcellen en perivasculaire cellen georganiseerd was in eenzelfde honingraatachtige structuur als in vivo wordt waargenomen. Naast de stabilisatie van vasculaire netwerken zorgde de interactie van perivasculaire cellen en vasculogene tumorcellen ook voor een toename in tumorcel 'sprouting' (vorming van uitstulpingen). Platelet-derived growth factor (PDGF)-B, het eiwit dat zorgt voor de aantrekking van perivasculaire cellen, werd door vasculogene tumorcellen zowel in vivo als in vitro tot expressie gebracht. In overeenstemming met onze in vitro resultaten hebben wij aangetoond dat in vivo groei van onze vasculogene melanoomcellijn gerelateerd was met de aanwezigheid van tumorcel-geassocieerde 
$\alpha-\mathrm{SMA}^{+}$cellen. Daarnaast zorgde de expressie van PDGF-B door vasculogene tumorcellen voor een toename van het aantal perivasculaire cellen die niet gekoppeld waren aan reguliere $\left(\mathrm{CD}_{3} 1^{+}\right)$tumorbloedvaten. Samen laten de resultaten van dit hoofdstuk zien dat vasculogene tumorcellen de mechanismen die endotheelcellen gebruiken voor het aantrekken van perivasculaire cellen kunnen kopiëren. Daarbij blijkt dat vasculogene tumorcellen functioneel voordeel halen uit hun interactie met deze stabiliserende perivasculaire cellen.

Het vermogen van tumorcellen om te transdifferentiëren en een endotheelcel fenotype aan te nemen is geassocieerd met de hoge differentiatie plasticiteit van agressieve tumorcellen. Met behulp van microarray analyse hebben wij beoogd om nieuwe moleculen te identificeren die kunnen bijdragen aan de doelgerichte bestrijding van vasculogene tumorcellen. In hoofdstuk 6 hebben wij laten zien dat vasculogene Ewing sarcoomcellen een verhoogde expressie vertonen van CD44 (varianten) ten opzichte van niet-vasculogene Ewing sarcoomcellen. De expressie van CD44 resulteerde in een verhoogde adhesie van tumorcellen aan het extracellulaire matrixcomponent hyaluronzuur. Knockdown studies toonden aan dat de expressie van CD44 bijdraagt aan het vasculogene potentiaal van plastische tumorcellen. Belangrijk is dat CD44 een veel beschreven marker is van geactiveerde endotheelcellen en van kankerstamcellen, oftewel agressieve tumorcellen met een zeer gededifferentieerd fenotype. In Ewing sarcoomweefsels werd CD44 expressie voornamelijk geobserveerd in tumorcellen die het lumen van vasculogenic mimicrykarakteristieke bloedmeren bekleden. De resultaten uit dit hoofdstuk tonen aan dat vasculogene tumorcellen overeenkomsten vertonen met zowel endotheelcellen als kankerstamcellen. Dit laatste suggereert een verband tussen de aanwezigheid van vasculogene tumorcellen en kankerstamcellen.

Tenslotte zijn in hoofdstuk 7 de belangrijkste resultaten van ons onderzoek besproken en zijn de toekomstperspectieven voor hun klinische toepasbaarheid bediscussieerd.

In dit proefschrift is de rol van vasculogenic mimicry in de tumorbiologie onderzocht. Door de identificatie van nieuwe moleculen en de analyse van de interactie tussen vasculogene tumorcellen en perivasculaire cellen hebben wij mechanismen geïdentificeerd die ons nieuwe inzichten bieden in dit complexe proces. Deze kennis zal mogelijk bijdragen aan de ontwikkeling van nieuwe behandelmethoden die resistentie via vasculogenic mimicry kunnen omzeilen. Dergelijke strategieën kunnen leiden tot de ontwikkeling van behandelingen met verbeterde klinische effectiviteit tegen kanker. 
Dankwoord 
Eindelijk, het is zover! Mijn promotieonderzoek zit er op en het dankwoord kan geschreven worden. Het waren een aantal heftige jaren, waarin ik veel heb geleerd en natuurlijk zijn er heel wat mensen die ik daarvoor moet bedanken.

Professor Tjan-Heijnen, beste Vivianne. Bedankt voor de mogelijkheid om mijn promotieonderzoek binnen jouw afdeling uit te voeren. Door mijn verhuizing naar het VU medisch centrum zijn de contact momenten in Maastricht minder frequent geworden. Tijdens de meetings met jou en Patricia was het echter altijd weer goed om te evalueren hoe mijn onderzoek in de kliniek zou kunnen bijdragen, iets wat tijdens het werken in het laboratorium toch wel eens uit het oog verloren wordt. Ik wil je bedanken voor alle inzet voor mijn projecten en alle hulp, zeker ook tijdens de laatste loodjes.

Professor Griffioen, beste Arjan. Toen ik een half jaar na de start van mijn project te horen kreeg dat je toch definitief zou vertrekken naar Amsterdam was dat even zwaar. Ik heb echter geen spijt gehad van mijn keuze om mee te gaan, want ik heb veel geleerd op het nieuwe lab. Je hebt me gedurende deze vier jaar weten te boeien met al jouw (wetenschappelijke) kennis en vooral ook met jouw ongekende namengeheugen. Bij deze wil ik je bedanken voor de afgelopen vier jaar van onderzoek en de mogelijkheden die ik heb gekregen om mijn onderzoek zelf in te richten.

Beste Patricia, bedankt voor je enthousiasme tijdens onze meetings en alle hulp tijdens de schrijf- en afrondingsfase. Ook jouw klinische bijdrage aan het project is zeker van pas gekomen. Ondanks mijn niet zo frequente aanwezigheid heb ik me altijd welkom gevoeld binnen de Medische Oncologiegroep.

Alle leden van de beoordelingscommissie, bestaande uit prof. dr. A. zur Hausen, prof. dr. E. Boven en prof. dr. M. Vooijs, wil ik bedanken voor de tijd en aandacht die zij besteed hebben aan mijn proefschrift.

Edith, Mat en Petra, ik wil jullie alle drie bedanken voor jullie hulp tijdens mijn eerste jaar in Maastricht. Petra, zonder jouw inzet om mij op gang te helpen met alle angiogenese assays waren de eerste maanden een stuk minder productief verlopen. Ik heb een erg gezellige tijd met jullie gehad en vond het jammer om weg te gaan.

Gelukkig hebben mijn nieuwe roomies en collega's in Amsterdam ervoor gezorgd dat ik ook een hele leuke tijd daar heb gehad. Laura, ondertussen ben je al weer een tijdje weg, maar bedankt voor de gezellige tijd als mijn eerste kamergenootje in het CCA. Richard, na drie jaar heb jij het uiteindelijk het langst met mij uitgehouden op dezelfde kamer. Het was erg handig om jouw kennis in de buurt te hebben. Ik zal niet snel vergeten hoe goed jij je kunt focussen op zaken en je dan compleet afsluit. Zelfs roepen vanaf het bureau naast je heeft dan geen zin meer! Bedankt voor drie leuke jaren. Saskia, je was een gezellige aanvulling op onze kamer en ik heb veel met je 
gelachen, maar helaas hield je het na 1,5 jaar bij ons weer voor gezien. Heerlijk dat je dan toch weer bij een Limburger terecht komt in het $A M C$, het zit je ook niet mee. Kitty, bijna 2,5 jaar hebben we samen op de kamer gezeten. Bedankt voor de super gezellige tijd en het aanhoren van mijn geklaag als er weer eens iets niet ging zoals ik het zou willen. Ik wist niet wat ik hoorde toen je zei dat je mee wilde gaan naar Guusje, maar als Hollander heb je je prima gedragen daar ;). Geniet van alle rust nu je niet meer hoeft te reageren op mijn Limburgse taal wanneer ik mijn "beurs" weer eens moest pakken. Een heel hoofdstuk als dankwoord aan jou is het toch niet geworden, maar hopelijk is dit ook voldoende. Ik wens jou en Slave alle geluk toe met jullie kereltje! Esther, nog een klein jaartje zijn wij kamergenootjes geweest. Als ik tegen het einde nog geen dipje had dan was het vanzelf wel gekomen door jouw succes. Ik wens je nog veel succes in Oxford en daarna weer in Amsterdam met jouw promotieonderzoek, maar ik denk dat dit geen probleem gaat worden.

Roy, regelmatig hadden we na een werkbespreking nog een brainstormsessie over mijn project, waar dan nieuwe ideeën uit kwamen rollen die meestal helaas niet realiseerbaar waren of niet de gewenste resultaten gaven. Bedankt voor al deze input en natuurlijk ook voor de gezelligheid op het CCA, onder andere door het opzetten van het cCAFE samen met Iris. Veel succes met het afronden van jouw promotie, en ook veel geluk met jullie kleine meid! Iris, hoewel je ruim een jaar na mij begonnen bent als AIO, voelt het toch alsof we gelijk op zijn gegaan. Je bent (als student) samen met mij in Maastricht begonnen en even na mij in Amsterdam gestart aan je eigen project. Bedankt voor alle gezelligheid en het luisterende oor als dat nodig was. Ons dialect heeft wel wat mensen raar doen opkijken en het heeft even geduurd voordat Nederlands praten tegen jou minder vreemd werd. Maar aangezien ik in Maastricht promoveer, vind ik dat er wel een klein woordje dialect in dit boekje mag komen: Ich wins dich väöl sukses mit ut aafronje van dien promosie! Ich zeen de oetneudiging haopelijk sjnel komme! Kristy, jij ook bedankt voor alle gezelligheid de afgelopen jaren, zeker in de celkweek hebben we als buren heel wat afgekletst. Voor jou zit het er nu ook bijna op, veel succes met het schrijven en de laatste loodjes. Koen, Maarten, Mariette en Maria, de geneeskundige AIO's onder ons. Ik wens jullie allemaal nog veel succes met jullie onderzoek en wil jullie bedanken voor de gezellige tijd.

Maaike, Tse en Jennifer, bedankt voor al jullie hulp en gezelligheid op het lab, maar ook voor de ontspannende momenten daarbuiten. Ed, zonder de chocolade-boost die ik geregeld op mijn bureau vond had ik het vast niet gered! Bedankt voor de leuke tijd en de geruststelling dat ik niet de enige ben die de humor van Tell Sell inziet. Rajshri, bedankt voor de gezellige tijd in de laatste maanden van fulltime kleuringen. Samen hebben we kunnen lachen om kleuringen die om onverklaarbare reden mis gingen, coupes die op het einde van een lange dag kleuren van het glaasje afgeveegd werden, en ga zo maar door. 
Victor, bedankt voor alle kritische inbreng en tips tijdens de werkbesprekingen en je feedback op mijn manuscripten. Jouw frisse kijk op het project heeft zeker bijgedragen aan dit onderzoek. Verder bedankt voor alle Illustrator-hulp en de gezelligheid op het lab en in de pauzes, waar ik me kostelijk vermaakt heb met jouw anekdotes. Judy, hoewel jij zegt dat het minder is geworden, klopt het verhaal toch nog steeds: jij vliegt door de gangen en over het lab! Ondanks je drukke schema was je altijd bereid om mij nieuwe technieken uit te leggen of te helpen met data analyses. Super bedankt voor alle hulp en gezelligheid. Laurens, Linda en Ruben, ik wens jullie allemaal veel succes met jullie onderzoek.

Henk D, jij bent in de afgelopen jaren vaak mijn redder in nood geweest. Zodra er weer eens een apparaat niet naar behoren functioneerde, kwam ik in paniek naar jou toe waarna jij het probleem kwam oplossen. Mijn dank daarvoor is groot. Ik hoop dat je het wat rustiger hebt nu mijn computerproblemen er niet meer zijn. Henk $V$ en Henk $B$, bedankt voor al jullie inbreng tijdens de meetings en de interesse in het project. Saskia, Simone, Leonie, Kamaar, letje, Nienke, Kees en alle anderen die ik vergeet te noemen maar er wel altijd bij waren, bedankt voor jullie gezelligheid in de pauzes, bij de woensdag-lekkersdag, en alle andere momenten.

Daisy, bedankt voor de prettige samenwerking in de afgelopen jaren. Hoewel je al een behoorlijke tijd weg bent bij het Angiogenese Laboratorium heb ik toch nog regelmatig terug kunnen vallen op jouw mimicry-expertise. Bedankt daarvoor en veel succes met jouw eigen onderzoek.

Caroline, Marjolein, Felix en Bart, samen zijn we ondertussen een hele tijd geleden aan de bachelor-/masteropleiding begonnen in Maastricht en nu zijn we allemaal bezig met de afronding van onze promoties. Caroline en Marjolein, hoewel we tijdens ons afstuderen nog regelmatig pastameetings hadden, is vanwege de afstand het afspreken tijdens ons promoveren lastig geweest. De weekendjes shoppen en bijkletsen waren echter een welkome ontspanning, waar ik erg van heb genoten en nog lang van hoop te zullen genieten. Lein, fijn dat jij de spits voor ons hebt afgebeten, en Lien, heel veel succes met het afronden van het boekje. Felix, bedankt voor de gezellige 'dates' met jou en Anouk met de daarbij horende etentjes en spelletjes. Voor jou is het ook nog even doorbijten, maar de finish komt in zicht. Ook bedankt voor jouw wijze woorden "effe dimmen hè" die we veelvuldig gehoord en gebruikt hebben de afgelopen jaren ;). Bart en Anneleen, gelukkig hebben we jullie de afgelopen tijd weer wat vaker gezien ondanks de grote afstand naar België. Veel geluk in jullie nieuwe huisje en ik hoop dat jullie boekjes er ook snel zullen komen. Hopelijk komen Kas en ik uiteindelijk weer wat dichterbij te wonen, zodat het afspreken met jullie allemaal weer wat makkelijker gaat. 
Leo, Gerda, Eveline en Rosalie, eindelijk is het dan zover dat ik kan zeggen dat het klaar is op de vraag hoe het met mijn onderzoek gaat. Alhoewel, klaar is iets natuurlijk nooit in het onderzoek. Samen met jullie hebben Kas en ik Leiden tussen ons werk door verkend. Bedankt voor de gezellige uitstapjes.

Leonie, als grote zus ben je vaak mijn voorbeeld geweest, maar je hebt het niet altijd kunnen waarderen wanneer ik weer eens dezelfde keuzes maakte als jij. Gelukkig is dat met het promoveren niet zo geweest en de afgelopen jaren hebben wij regelmatig problemen en oplossingen uitgewisseld. Bedankt voor de gezellige avondjes bijkletsen en, om me bij jou aan te sluiten, de afleiding tijdens carnaval. De volgende keer dat je in Leiden komt shoppen, moeten we toch maar eens halverwege de straat gaan starten, want veel verder dan de eerste helft ben je nog niet gekomen in al die tijd;). Jeroen, ik kan me onze familie al niet meer zonder jou voorstellen. Feestjes zouden maar een saaie boel zijn zonder jouw aanwezigheid (om over de foto's nog maar te zwijgen..). Nadat ik Leonie de afgelopen jaren heb kunnen bellen voor promotieproblemen, kan ik nu profiteren van jouw kennis en kunde op onderwijsgebied. Ik wil jullie beiden bedanken voor alle steun en gezelligheid en niet alleen in de afgelopen paar jaren.

Papa en mama, het is fijn om te weten dat jullie altijd voor mij klaar zullen staan. Jullie hebben mij altijd gesteund en gestimuleerd, en mij de mogelijkheden gegeven om te komen tot waar ik nu ben. Ik vond het jammer om verder weg te moeten gaan wonen, maar de weekenden dat we weer in het zuiden waren heb ik des te meer genoten. Bedankt voor al jullie support, op meerdere vlakken en jullie eigen mentaliteit in het leven waar ik veel van heb geleerd. Het klinkt misschien cliché, maar ik kan me geen betere ouders wensen. Nu Leonie en ik (bijna) helemaal student af zijn kunnen jullie de potjes allemaal op gaan maken, geniet ervan!

Kas, jij bent er de afgelopen jaren dag in dag uit voor mij geweest en hebt dus mijn promotiegrillen tot vervelens toe moeten doorstaan. Het is niet overdreven als ik zeg dat dit boekje er zonder jou niet zou zijn geweest, want alleen was ik niet naar Amsterdam vertrokken. Samen zijn we in het diepe gesprongen door naar Leiden te verhuizen en ik vind dat we er daar met zijn tweeën iets moois van gemaakt hebben. $\mathrm{Nu}$ gaan voor jou de laatste loodjes van het promoveren beginnen en ik kan alleen maar hopen dat ik jou net zo goed kan steunen als jij mij. Lieve Kas, bedankt voor alle humor, steun en liefde, en jouw talent om mij op te beuren. Ik ben benieuwd waar de komende jaren ons heen zullen brengen! 
Curriculum Vitae 
Yvette Paulis was born on April 17th 1985 in Roermond (the Netherlands). She graduated from secondary education (Gymnasium) at BC Broekhin in Roermond in 2003. She continued her education at the University of Maastricht, where she studied Clinical Molecular Life Sciences. During her Master studies she performed an internship on the epigenetic regulation by Polycomb group proteins during hypoxia at the department of Molecular Genetics (University of Maastricht) in the laboratory of dr. J.W. Voncken (2007). Her Master project was performed at the Maastricht Radiation Oncology (Maastro) department under the supervision of dr. M. Koritzinsky, and focused on the importance of hypoxia-induced Mxi-1 expression for tumor cell survival (2008). She obtained her Master of Science degree Cum Laude in 2008. From 2008 to 2012 she worked on her PhD research, focusing on tumor cell plasticity through vasculogenic mimicry, at the department of Medical Oncology (Angiogenesis Laboratory) under the supervision of prof. dr. V.C.G. Tjan-Heijnen and prof. dr. A.W. Griffioen. Initially, this laboratory was located at Maastricht University Medical Center in Maastricht and from June 2009 onwards in the VU University Medical Center in Amsterdam. In August 2012, she enrolled in an educational program at the University of Leiden to obtain her Master of Education degree. 
